NBER WORKING PAPER SERIES

\title{
THE EXTENSIVE MARGIN OF EXPORTING PRODUCTS: A FIRM-LEVEL ANALYSIS
}

\author{
Costas Arkolakis \\ Sharat Ganapati \\ Marc-Andreas Muendler \\ Working Paper 16641 \\ http://www.nber.org/papers/w16641
}

\author{
NATIONAL BUREAU OF ECONOMIC RESEARCH \\ 1050 Massachusetts Avenue \\ Cambridge, MA 02138 \\ December 2010
}

We thank the editor Virgiliu Midrigan and two anonymous referees. We are grateful to Hiau Looi Kee and Marcelo Olarreaga for sharing augmented UNCTAD TRAINS data on non-tariff measures and detailed explanations. We benefitted from helpful comments and discussions by David Atkin, Andrew Bernard, Lorenzo Caliendo, Thomas Chaney, Arnaud Costinot, Don Davis, Gilles Duranton, Jon Eaton, Elhanan Helpman, Gordon Hanson, Sam Kortum, Giovanni Maggi, Kalina Manova, Marc Melitz, Peter Neary, Jim Rauch, Veronica Rappaport, Steve Redding, Kim Ruhl, Peter Schott, Daniel Trefler and Jon Vogel as well as several seminar and conference participants. Oana Hirakawa, Olga Timoshenko and Bingyu Zhang provided excellent research assistance. Muendler and Arkolakis acknowledge NSF support (SES-0550699 and SES-0921673) and support from the Yale University High Performance Computing Center with gratitude. An Online Supplement is available at econ.ucsd.edu/muendler/papers/abs/braxpmkt. The views expressed herein are those of the authors and do not necessarily reflect the views of the National Bureau of Economic Research.

NBER working papers are circulated for discussion and comment purposes. They have not been peerreviewed or been subject to the review by the NBER Board of Directors that accompanies official NBER publications.

(C) 2010 by Costas Arkolakis, Sharat Ganapati, and Marc-Andreas Muendler. All rights reserved. Short sections of text, not to exceed two paragraphs, may be quoted without explicit permission provided that full credit, including $(\odot)$ notice, is given to the source. 
The Extensive Margin of Exporting Products: A Firm-level Analysis

Costas Arkolakis, Sharat Ganapati, and Marc-Andreas Muendler

NBER Working Paper No. 16641

December 2010, Revised July 2020

JEL No. F12,F14,L11

\section{$\underline{\text { ABSTRACT }}$}

To quantify trade frictions, we examine multi-product exporters. We build a flexible general equilibrium model and estimate market entry costs using Brazilian firm-product-destination data under rich demand and market-access cost shocks. Our estimates show that additional products farther from a firm's core competency come at higher production costs, but there are substantive economies of scope in market-access costs. Market-access costs differ across destinations, falling more rapidly in scope at nearby regions and at destinations with fewer non-tariff barriers. We evaluate a counterfactual scenario that harmonizes market-access costs across destinations and find global welfare gains similar to eliminating all current tariffs.

\section{Costas Arkolakis \\ Department of Economics}

Yale University, 28 Hillhouse Avenue

P.O. Box 208268

New Haven, CT 06520-8268

and NBER

costas.arkolakis@yale.edu

Sharat Ganapati

Georgetown University

Edward B. Bunn, S.J. Intercultural Center

37 th and O Streets, NW

Washington, DC 20057

and CESifo

sganapati@gmail.com
Marc-Andreas Muendler

Department of Economics, 0508

University of California, San Diego

9500 Gilman Drive

La Jolla, CA 92093-0508

and NBER

muendler@ucsd.edu 
Trade frictions shape the pattern of trade, the transmission of macroeconomic conditions, and their aggregate consequences in international trade and open-economy macroeconomics. Research tends to characterize trade frictions with iceberg transport costs and ad-valorem tariffs, especially when considering aggregate trade data (e.g. Arkolakis, Costinot and Rodríguez-Clare 2012). Drawing on firm and firm-destination data, researchers have recently opened up the black box of market access costs, which deter firms from export market entry (Das, Roberts and Tybout 2007, Moxnes 2010, Eaton, Kortum and Kramarz 2011, Allen 2014, Chaney 2014). This literature typically measures the importance of fixed or sunk costs beyond variable trade costs, focusing on firm entry into exporting and abstracting from policy. We use firm-productdestination data to uncover the precise nature of these market access costs, focusing on both the firms' export market entry and their new product entry. To produce market-access cost estimates of policy relevance, we tie cost components to non-tariff policy instruments.

We build a framework of multi-product exporters that generalizes earlier models and offers a flexible setup to rigorously measure the relevance of market-access costs for exporter-product presence in foreign markets. We base our framework on novel regularities, using detailed information on the entry and sales of Brazilian exporters and their individual products by foreign destination. We structurally estimate the framework and relate market access cost estimates to observed policy-driven non-tariff measures (NTMs) as well as geography and product-related barriers, which have proven elusive objects for rigorous quantification to date. NTMs are arguably as important for trade openness as are tariffs, they are prominent in trade negotiations, and they are instruments in trade conflicts. ${ }^{1}$ Based on our estimates we evaluate a counterfactual scenario that harmonizes market-access costs across export destinations to their observed global minima and find welfare gains similar to eliminating all current tariffs.

Our framework extends the monopolistic competition model of Melitz (2003) by embedding a multi-product setup into a conventional constant elasticity of substitution (CES) demand system. We model within-firm product heterogeneity with two key mechanisms. First, we assume

\footnotetext{
${ }^{1}$ Niu et al. (2018, Table 6) estimate for a sample of 97 countries that in 1997 the ad-valorem equivalent of NTMs used to weakly exceed import tariffs in about 56 percent of HS- 6 product lines but by 2015 NTMs surpassed tariffs in 73 percent of HS-6 products. For comprehensive policy reports on non-tariff measures see OECD (2005), UNCTAD (2010), WTO (2012). Recent trade agreements between the EU and other countries, including CETA with Canada or the EU-Mercosur Association Agreement, prominently address non-tariff barriers such as customs procedures, technical regulations, and standards. While the most recent trade accord between the United States, Mexico and Canada (USMCA) does not alter conventional non-tariff measures, it introduces labor standards as a novel type of NTM. The three prior U.S. agreements from 2012 with Panama, Colombia and South Korea placed particular importance on the reduction of conventional non-tariff barriers. China frequently uses non-tariff measures such as safety and environmental standards, at present for example to restrict agricultural exports from Canada and coal from Australia. While tariffs are a prominent instrument in recent U.S. trade disputes, the United States is also using crucial non-tariff measures in its disputes with China, such as the so-called Entity List that imposes export licensing requirements on specific foreign businesses and persons.
} 
as in Eckel and Neary (2010, henceforth EN) that a firm faces declining efficiency in supplying additional products that are farther from its core competency. Second, we introduce local product appeal shocks, extending firm-destination heterogeneity as in Eaton, Kortum and Kramarz (2011) to the product-destination level. Product appeal shocks allow us to nest a version of the Bernard, Redding and Schott (2011, henceforth BRS) model that attributes within-firm product heterogeneity to local demand shocks. In our framework, the firm faces two extensive margins and one intensive margin: it elects its presence at export destinations at one extensive margin, it chooses its exporter scope (the number of products) in each destination at another extensive margin, and sets the prices for each individual product in each destination at the intensive margin. ${ }^{2}$

We consider three types of costs. First, there are product-specific production costs at the firm level similar to EN (core competency). Second, there are variable trade costs (shipping costs in the form of iceberg trade costs and ad-valorem tariffs), which vary with sales but do not depend on the exporter's scope. Both production costs and variable trade costs deter trade at all margins. Third, to capture the specificities of non-tariff barriers for market access, we consider a flexible schedule of fixed exporting costs by firm, product, and destination market, generalizing the firm-destination level exporting costs in Chaney (2008). This market-access cost schedule can vary by firm-product and accommodates the possible cases of economies and diseconomies of scope. ${ }^{3}$ The market-access cost schedule affects only the two extensive margins: a firm's entry into a destination with the first product and its exporter scope there. The first exported item to a particular destination may face higher entry costs than a subsequent item. Examples of such barriers include the financial cost and time required for both paperwork and border compliance, sanitary and phytosanitary as well as other technical regulations that can affect approval of a first export product differently from subsequent products, and price or quantity control measures with differential importance.

To quantify this theory, we document individual product sales and exporter scope using firmproduct-destination data from Brazil, a typical exporter country close to the median in exports per capita in 2000. We then characterize the nature of market-access costs at the microeconomic level, so we can subsequently conduct adequate aggregate simulations. We elicit three main facts. First, within firms and destinations, we look at sales by product. Wide-scope exporters sell large amounts of their top-selling products. Moreover, they sell considerably smaller

\footnotetext{
${ }^{2}$ Our product-level approach thus differs from firm-level research, including Arkolakis (2010), in that we give substance to market-access costs and directly estimate these costs from product entry and product sales. The parametrization of our estimation model fully nests the Arkolakis (2010) market penetration costs.

${ }^{3}$ Seminal references on economies of scope are Panzar and Willig (1977) and (1981). Formally, there are economies of scope for sales $x$ and $y$ of two products if the cost function satisfies $C(x+y)<C(x)+C(y)$, that is if the cost function is subadditive.
} 
amounts of their lowest-selling products than do narrow-scope exporters. Second, within destinations and across firms, we look at exporter scope: there are a few dominant exporters with wide scope but many narrow-scope firms. The median exporter only ships one or two products per destination. Moreover, the average exporter scope is larger at geographically closer destinations, indicating variation in incremental market-access costs. Third, within destinations and across firms, firm average product sales and exporter scope exhibit a strong positive covariation in distant destinations, but no clear relationship in close-by destinations. When it comes to observed policy measures, more NTMs at a destination strengthen the positive association between average product sales and exporter scope similar to a destination's remoteness, and more NTMs at a destination depress product sales and exporter scope in a similar manner as does a destination's remoteness.

In our model these facts have a number of theoretical implications. For a wide-scope firm to profitably sell minor amounts of its lowest-selling products, incremental market-access costs must be low at wide scope. The finding is at odds with models of multi-product firms where market-access costs are constant for additional products and underlies our flexible market-access cost schedule that allows for potential economies of scope. For example, market-access costs are constant in BRS, EN and Mayer, Melitz and Ottaviano (2014). Our model's combination of scope-dependent production costs and market-access costs delivers variation in average exporter scope on the one hand and generates the correlation of average product sales and exporter scope across destinations on the other hand, consistent with our second and third facts. Given common production costs regardless of a product's export destination, the destination-dependent correlation between average product sales and exporter scope implies that market-access costs vary in systematic ways across destinations and affect country-level trade flows.

For our quantification we adopt a simulated method of moments (SMM) estimator in order to handle the three stochastic elements of the model. These elements-Pareto distributed firm-level productivity, a stochastic firm-level market-access cost component, and local product appeal shocks-are needed to match the empirical regularities in the Brazilian exporting transaction data. ${ }^{4}$ We also document, for practical purposes, that results from ordinary least squares under only one stochastic element (firm-level productivity) provide a useful approximation to the full SMM estimation. In the main estimation, we target our first two facts, which the estimated model closely matches. We also illustrate the success of this estimation by showing that the estimated model fits the third fact (on the destination-specific correlation of average product sales and exporter scope), which we deliberately do not target in estimation. A decomposition

\footnotetext{
${ }^{4}$ In Appendix F we vary the productivity distribution, using a log-normal specification instead of Pareto. While we lose analytic tractability in the model, the quantitative results under the SMM estimation remain similar.
} 
of the variance in product sales shows that product- and firm-level heterogeneity accounts for two-fifths of the variation in product sales, while idiosyncratic product appeal shocks abroad account for the other three-fifths. This finding highlights both the relevance of our extended multi-product framework and the important interplay of a firm's core competency with local demand conditions abroad.

The estimation shows that additional products farther from a firm's core competency incur higher unit production costs, but the estimation also uncovers economies of scope in incremental market-access costs that fall for additional products at destination-specific rates. We relate the varying market-access cost schedules to country characteristics, including the prevalence of NTMs at a destination, and find that NTMs are a salient predictor of incremental market-access costs. Given this importance of NTMs for market-access cost schedules, we simulate a reduction in market-access costs for additional products and the effect on global trade. To capture only components of market-access costs that appear amenable to policy, we hypothetically reduce market-access costs worldwide to the schedules observed in nearby destinations with low incremental market-access costs. This counterfactual standardization of incremental market-access costs generates welfare gains similar to eliminating today's remaining observable tariffs.

An influential macroeconomic literature connects firms to economy-wide outcomes and studies how firm shocks translate into consequences for the real exchange rate, the trade balance, and other variables (e.g. Gopinath and Itskhoki 2010, Amiti, Itskhoki and Konings 2014, Di Giovanni, Levchenko and Mejean 2014, Almunia et al. 2018). Our paper offers a specific quantification of the market-specific costs that firms face when they respond to shocks with varying export-market participation. Trade frictions such as market-access costs determine to what extent goods and services can be traded and therefore crucially delineate real exchange rate levels and changes. ${ }^{5}$

To measure trade restrictiveness in the aggregate, Kee, Nicita and Olarreaga (2009) and Niu et al. (2018) propose index numbers in partial equilibrium and relate them to NTMs. ${ }^{6}$ We adopt a general-equilibrium framework and allow for rich micro-foundations for the incidence of

\footnotetext{
${ }^{5}$ Trade frictions have been proposed as a potential common cause behind major puzzles in international macroeconomics (Obstfeld and Rogoff 2001). Fitzgerald (2012) and Eaton, Kortum and Neiman (2016) provide supporting evidence for the relevance of variable trade costs in international financial anomalies. Others argue that those puzzles are better explained with financial frictions (Van Wincoop, Eric and Warnock 2010, Coeurdacier and Rey 2013).

${ }^{6}$ Earlier indexes of trade restrictiveness ask how harmful protection is to a country itself (for surveys see Feenstra 1995, Anderson and Neary 2005). An index of a country's trade restrictiveness is akin to a single hypothetical advalorem tariff that would be equivalent either in terms of welfare (Anderson and Neary 1996) or import volumes (Anderson and Neary 2003) to the country's overall set of protectionist measures. Baldwin, Evenett and Low (2009) and Egger et al. (2015) examine the potential impact of new non-tariff commitments in preferential trade agreements.
} 
market-access costs on firm and product entry. However, our complementary approach foregoes NTM survey information by source country and tariff line. Examples of incremental marketaccess costs among NTMs are product-level health regulations, safety standards, certifications, and licenses. ${ }^{7}$

Most variation in trade flows comes from the extensive margin of exporter entry into foreign markets (Eaton, Kortum and Kramarz 2004, Bernard et al. 2009). Researchers have studied the origins of exporter success in firm capabilities (Bernard et al. 2003, Melitz 2003) and more recently in the formation of networks and exporter-to-importer links (Chaney 2014, Bernard, Moxnes and Ulltveit-Moe 2018, Eaton et al. 2016), in particular under the impediment of advalorem tariffs and iceberg transport costs (e.g. Cherkashin et al. 2015). Our paper broadens the perspective to other forms of trade frictions, including variable trade costs and fixed marketaccess costs while accounting for market penetration costs, and retrains the focus from the aggregate to the microeconomic level of individual exporter products.

Research into multi-product firms has expanded markedly in recent years (see, for example, BRS, EN, Thomas (2011), Amador and Opromolla (2013), Álvarez, Faruq and López (2013), Mayer, Melitz and Ottaviano (2014), and Eckel et al. (2016), among others). ${ }^{8}$ That body of research stresses the significance of multi-product firms either from an empirical perspective or from a theoretical one. Our work aims to make contact of these two large parts of the literature by bringing together theory and data. We use facts about multi-product firms to understand the costs and benefits of expanding product lines. In turn, we use the general-equilibrium structure of our model to asses the global implications of policies related to removing product expansion costs. ${ }^{9}$

Aggregate consequences differ substantively under varying market entry cost assumptions. Arkolakis, Costinot and Rodríguez-Clare (2012) show for a wide family of models, which includes ours, that conditional on identical observed trade flows these models predict identical ex-post welfare gains irrespective of firm turnover and product-market reallocation. Their find-

\footnotetext{
${ }^{7}$ Some NTMs are arguably market-access costs that an exporter incurs prior to the shipment of the first unit of a product and not again (UNCTAD 2010), while other NTMs such as customs procedures may also act like shipping costs in that they lengthen storage time and the duration of export financing. As the empirical literature on NTMs starts to make available more precise NTM variables, they can be embedded into our framework's shipping cost and market-access cost functions. For now, our market-access cost estimates do not discern individual NTMs from other lasting trade barriers at the border, such as language. Our counterfactual simulations, however, are designed to capture policy relevant market entry and behind-the-border costs.

${ }^{8}$ Nocke and Yeaple (2014) and Dhingra (2013) study multi-product exporters but do not generate a within-firm sales distribution, which lies at the heart of our analysis.

${ }^{9}$ Timoshenko (2015) empirically analyzes multi-product firm dynamics. Qiu and Zhou (2013) document the importance of variety-specific introduction fees, which we call incremental market-access costs. Morales, Sheu and Zahler (2019) structurally study the path-dependent sequential entry of multi-product firms into additional export markets.
} 
ings also imply, however, that models in that family differ markedly in their implications for trade flows and welfare with respect to ex-ante changes in market-access costs. The predictions as to how trade policy affects global trade crucially vary with the nature of market entry costs. Our framework provides a market-specific micro-foundation for such market-access costs, and we use it to compute the impact of the elimination of policy-related entry costs on trade flows and welfare.

The paper has six sections. In Section I we describe the model and its firm-level predictions. Section II presents the data and observed empirical patterns. Section III introduces the SMM estimator to identify the model's parameters. Section IV closes the model and describes aggregate outcomes in general equilibrium. Counterfactuals involving variations in market-access costs follow in Section V. We conclude with Section VI.

\section{Model}

Our model rests on two sources of heterogeneity on the firm side: a firm's productivity and a firm's array of destination-specific entry costs for its first product. Heterogeneity in productivity at the firm level generates the familiar dispersion in total sales, and in our model also the dispersion in exporter scope (the number of products sold). The heterogeneity in entry cost for the first product at the firm-destination level helps us break the rigidity of deterministic destination rankings and accommodate the substantive empirical variation across firm presence patterns in estimation. Moreover, heterogeneity in market access cost allows us to nest Arkolakis (2010) market penetration costs.

We introduce a third source of heterogeneity on the consumer side: a stochastic demand component at the firm-destination-product level. This added variation allows us to nest a version of the BRS model as a special case and permits potentially rich variation in a given firm-product's sales rank across destinations. Beyond the conceptual benefit of nesting predecessor models, the three sources of heterogeneity moderate concerns of misspecification in our simulated method of moments estimation, while parameters of the shock distributions can be disciplined with our data.

The remaining parameters for a firm's product access and local pricing decisions are deterministic. Most important for our generalization of earlier multi-product exporter models, we introduce a flexible market-access cost function that may exhibit economies or diseconomies of scope. To generate overall diseconomies of scope (which are necessary for optimal scope to be finite), and to nest a version of the EN model and Mayer, Melitz and Ottaviano (2014), we let a firm face higher marginal production costs for additional products farther away from its core 
competency. ${ }^{10}$

\section{I.A Setup}

There are $N$ countries. The source country of an export shipment is denoted with $s$ and the destination market with $d$. There is a measure of $L_{d}$ consumers at destination $d$. Consumers have symmetric preferences with a constant elasticity of substitution $\sigma$ over a continuum of varieties. In this multi-product setting, a "variety" offered by a firm $\omega$ from source country $s$ to destination $d$ is the product composite

$$
X_{s d}(\omega) \equiv\left(\sum_{g=1}^{G_{s d}(\omega)} \xi_{s d g}(\omega)^{\frac{1}{\sigma}} x_{s d g}(\omega)^{\frac{\sigma-1}{\sigma}}\right)^{\frac{\sigma}{\sigma-1}}
$$

where $G_{s d}(\omega)$ is the exporter scope (the number of products) that firm $\omega$ sells in country $d, g$ is the running index of a firm's product at destination $d, \xi_{s d g}(\omega)$ is an i.i.d. shock to firm $\omega$ 's $g$-th product's appeal (with mean $\mathbb{E}\left[\xi_{s d g}(\omega)\right]=1$, positive support and known realization at the time of consumer choice), and $x_{s d g}(\omega)$ is the quantity of product $g$ that consumers consume. In marketing terminology, the product composite is often called a firm's product line or product mix. We assume that every product line is uniquely offered by a single firm, but a firm may ship different product lines to different destinations.

\section{I.B Consumers}

A consumer's utility at destination $d$ is

$$
\left(\sum_{k=1}^{N} \int_{\omega \in \boldsymbol{\Omega}_{k d}} X_{k d}(\omega)^{\frac{\sigma-1}{\sigma}} \mathrm{d} \omega\right)^{\frac{\sigma}{\sigma-1}} \text { for } \sigma>1,
$$

where $\Omega_{k d}$ is the set of firms that ship from source country $k$ to destination $d$. For simplicity we assume that the elasticity of substitution across a firm's products is the same as the elasticity of substitution between varieties of different firms. ${ }^{11}$ It is straightforward to generalize the model

\footnotetext{
${ }^{10}$ Marginal production costs are constant for a given product in that they do not vary with production volume. For an appropriately defined market-access cost schedule that depends on the choice of consumers reached through marketing, we also nest the Arkolakis (2010) model within our (stochastic) market entry components (see the Online Supplement S2).

${ }^{11}$ Allanson and Montagna (2005) adopt a similar nested CES form to study the product life-cycle and market structure, and Atkeson and Burstein (2008) use a similar nested CES form in a heterogeneous-firms model of trade but do not consider multi-product firms.
} 
to consumer preferences with two nests, where the inner nest holds a firm's product line with an elasticity of substitution that differs from the elasticity of substitution between product lines in the outer nest. If the firm's products in the inner nest were closer substitutes to each other than product lines are substitutable across firms, then a firm's additional products would cannibalize the sales of its infra-marginal products. We present this nested CES utility in Appendix C and show why the presence of a cannibalization effect does not alter the estimation relationships for the parameters that we wish to identify (detailed derivations are in the Online Supplement).

The representative consumer earns a wage $w_{d}$ from inelastically supplying labor to producers in country $d$ and receives a per-capita dividend distribution $\pi_{d}$ equal to her share $1 / L_{d}$ in total profits of national firms. We denote total income with $Y_{d}=\left(w_{d}+\pi_{d}\right) L_{d}$. The consumer observes the product appeal shocks $\xi_{s d g}(\omega)$ prior to her consumption choice so that the firstorder conditions of utility maximization imply a product demand

$$
x_{s d g}(\omega)=\left(\frac{p_{s d g}(\omega)}{P_{d}}\right)^{-\sigma} \xi_{s d g}(\omega) \frac{T_{d}}{P_{d}}
$$

where $p_{s d g}$ is the price of product $g$ in destination $d$ and we denote by $T_{d}$ the total expenditure of consumers in country $d$. In the calibration, we will allow for the possibility that total consumption expenditure $T_{d}$ is different from country output $Y_{d}$ (allowing for trade imbalances), so we use different notation for the two terms. We define the corresponding ideal price index $P_{d}$ as

$$
P_{d} \equiv\left[\sum_{k=1}^{N} \int_{\omega \in \boldsymbol{\Omega}_{k d}} \sum_{g=1}^{G_{k d}(\omega)} \xi_{k d g}(\omega) p_{k d g}(\omega)^{-(\sigma-1)} \mathrm{d} \omega\right]^{-\frac{1}{\sigma-1}}
$$

\section{I.C Firms}

Following Chaney (2008), we assume that there is a continuum of potential producers of measure $J_{s}$ in each source country $s$.

Firms face three types of costs: variable shipping costs (iceberg trade costs), variable production costs (which are constant for a given product but higher for products farther away from a firm's core competency), and fixed market-access costs (which depend on a firm's local exporter scope but do not vary with sales). Each firm draws a productivity parameter $\phi(\omega)$ and an array of destination specific market-access cost shocks $c_{d}(\omega) \in(0, \infty)$.

The firm chooses how many products to ship to a given destination and what price to charge for each product at a destination. Following the firms' choices, consumers learn the product specific taste shocks $\xi_{s d g}(\omega)$ for each firm-product $g$ at its potential destination $d$. Then production and sales are realized. We will suppress the $\omega$ notation whenever there is no risk of confusion. 


\section{I.C.1 Variable transport and product-specific production costs}

When exported, products incur standard iceberg trade costs so that $\tau_{s d}>1$ units must be shipped from $s$ for one unit to arrive at destination $d$, but $\tau_{s s}=1$ for domestic sales. This iceberg trade cost is common to all firms and firm-products shipping from $s$ to $d$.

A firm produces each product $g$ with a linear production technology, employing sourcecountry labor given a firm-product specific efficiency $\phi_{g}$. For convenience, we order each firm's products in terms of their efficiency, from most efficient to least efficient: $\phi_{1} \geq \phi_{2} \geq \ldots \geq \phi_{G_{s d}}$. We characterize the efficiency of the $g$-th product of a firm $\phi$ as

$$
\phi_{g} \equiv \phi / h(g) \quad \text { with } \quad h(1)=1 \text { and } h^{\prime}(g)>0
$$

for $g=1,2, \ldots, G_{s d}$. The function $h(g)$ is common to all firms. Under the efficiency ordering of products we call the firm's core product $g=1$.

\section{I.C.2 Fixed market-access costs}

The firm faces an array of product-destination specific incremental market-access $\operatorname{costs} c_{d} f_{s d}(g)$. A firm that adopts an exporter scope of $G_{s d}$ therefore incurs a total market-access cost of

$$
F_{s d}\left(G_{s d}, c_{d}\right)=c_{d} \sum_{g=1}^{G_{s d}} f_{s d}(g)
$$

at destination $d$, where its idiosyncratic market-access cost is $c_{d}$. The firm's market-access cost is zero at zero scope and strictly positive otherwise:

$$
f_{s d}(0)=0 \quad \text { and } \quad f_{s d}(g)>0 \quad \text { for all } g=1,2, \ldots, G_{s d}
$$

where $f_{s d}(g)$ is a continuous function in $[1,+\infty) .{ }^{12}$ Similar to Eaton, Kortum and Kramarz (2011), we assume that the access cost shock $c_{d}$ is i.i.d. across firms and destinations.

The incremental market-access cost $c_{d} f_{s d}(g)$ can include fixed production costs (e.g. for $\left.0<f_{s s}(g)<f_{s d}(g)\right)$. The incremental market-access costs $c_{d} f_{s d}(g)$ may increase or decrease with exporter scope in a given destination market $d$. But the firm's total market-access costs $F_{s d}\left(G_{s d}, c_{d}\right)$ at the destination necessarily increase with exporter scope $G_{s d}$ because $f_{s d}(g)>0$ for $g \geq 1 .{ }^{13}$ We assume that the incremental market-access costs $c_{d} f_{s d}(g)$ require labor from the

\footnotetext{
${ }^{12}$ Brambilla (2009) adopts a similar specification. We explore its implications in a firm-product model.

${ }^{13}$ This specification accommodates a potentially separate firm-level access cost (sometimes referred to as a onetime beachhead cost), which can be subsumed in the first product's market-access cost. The only requirement is that our later assumptions on the shape of the market-access cost schedule are satisfied. In continuous product space with nested CES utility, in contrast, market-access costs must be non-zero at zero scope because a firm would
} 
destination country $d$ so that $F_{s d}\left(G_{s d}, c_{d}\right)$ is homogeneous of degree one in $w_{d}$. Combined with the varying firm-product efficiencies $\phi_{g}$, this market-access cost structure allows us to endogenize the exporter scope choice at each destination. Whereas the incremental marketaccess cost is meant to capture the barriers to access that may differ for different exporters depending on the number of products sold, the idiosyncratic access cost shock implies that there is no strict hierarchy of destinations across exporters. Some exporters may sell to less popular destinations but not to the most popular ones.

In summary, there are two scope-dependent cost components: the marginal cost schedule $h(g)$ and the incremental market-access cost $f_{s d}(g)$. Suppose for a moment that the incremental market-access cost is constant in destination $d$ and independent of $g$ with $f_{s d}(g)=f_{s d}$. Then a firm in our model faces diseconomies of scope in destination $d$ because the marginal-cost schedule $h(g)$ strictly increases with the product index $g$. But, if incremental market-access costs $f_{s d}(g)$ decrease sufficiently strongly with $g$, our functional form allows for overall economies of scope in destination market $d$.

Before we proceed to firm optimization, we introduce a parameterized example for these functions that will later allow us to quantitatively match the patterns observed in the Brazilian data. For quantification, we will specify

$$
\begin{aligned}
& f_{s d}(g)=f_{s d} \cdot g^{\delta_{s d}} \quad \text { for } \delta_{s d} \in(-\infty,+\infty) \quad \text { and } \\
& h(g)=g^{\alpha} \quad \text { for } \alpha \in[0,+\infty) .
\end{aligned}
$$

The choice of these two functions is guided by the log-linear relationships that we will use in Section II. Introducing the example at this stage helps us provide intuition for the role that the parameters $\delta_{s d}$ and $\alpha$ will play in later estimation. The parameter $\delta_{s d}$ is the scope elasticity of market-access cost. The product $\alpha(\sigma-1)$ is the scope elasticity of product efficiency and its estimated value will determine how fast sales drop for additional products farther away from the firm's core competency. We define $\tilde{\alpha} \equiv \alpha(\sigma-1)$ for short. We allow $\delta_{s d}$ to vary by destination, but take the production-related $\alpha$ as constant across destinations.

We show in the Online Supplement that the market-access cost specification (6) is readily reformulated to accommodate the market penetration costs in Arkolakis (2010) for a firm's product composite, where $f_{s d}$ may depend on the optimal share of consumers reached. Market penetration costs do not affect our final estimation model because the relevant marketing cost parameters get subsumed in the (stochastic) market-access cost component $c_{d} f_{s d}(1)$.

otherwise export to all destinations worldwide (Bernard, Redding and Schott 2011, Arkolakis and Muendler 2011). 


\section{I.C.3 Firm optimization}

Firms with the same productivity $\phi$ and the same access cost shock for a given destination $c_{d}$ make identical product entry decisions in equilibrium. It is therefore convenient to name firms selling to a given destination $d$ by their characteristics $\left(\phi, c_{d}\right)$.

Conditional on destination market access, the firm chooses individual product prices given consumer demand under monopolistic competition. The resulting first-order conditions from the profit maximizing equation produce identical markups over marginal cost $\tilde{\sigma} \equiv \sigma /(\sigma-1)>1$ for $\sigma>1 .^{14}$

A type $\left(\phi, c_{d}\right)$ firm chooses an exporter scope $G_{s d}\left(\phi, c_{d}\right)$. Plugging the optimal pricing decision into the firm's profit function and summing over the firm's products, we obtain firm-level profits at a destination $d$ for a firm $\left(\phi, c_{d}\right)$ selling $G_{s d}$ products,

$$
\pi_{s d}\left(\phi, c_{d}\right)=\max _{G_{s d}} D_{s d} H\left(G_{s d}, \boldsymbol{\xi}\right)^{-(\sigma-1)} \phi^{\sigma-1}-c_{d} \sum_{g=1}^{G_{s d}} f_{s d}(g)
$$

with the revenue shifter

$$
D_{s d} \equiv\left(\frac{P_{d}}{\tilde{\sigma} \tau_{s d} w_{s}}\right)^{\sigma-1} \frac{T_{d}}{\sigma}
$$

\footnotetext{
${ }^{14}$ After a firm observes each product $g$ 's appeal shock at a destination $\xi_{s d g}(\omega)$, its total profit from selling an optimal number of products $G_{s d}$ to destination market $d$ is

$$
\pi_{s d}\left(\phi, c_{d}\right)=\max _{G_{s d}} \sum_{g=1}^{G_{s d}}\left[\max _{\left\{p_{s d g}\right\}_{g=1}^{G_{s d}}}\left(p_{s d g}-\tau_{s d} \frac{w_{s}}{\phi / h(g)}\right)\left(\frac{p_{s d g}}{P_{d}}\right)^{-\sigma} \xi_{s d g} \frac{T_{d}}{P_{d}}\right]-F_{s d}\left(G_{s d}, c_{d}\right) .
$$

Suppose the firm sets every individual price $p_{s d g}$ after it observes the appeal shocks. Its first-order conditions with respect to every individual price $p_{s d g}$ imply an optimal product price

$$
p_{s d g}(\phi)=\tilde{\sigma} \tau_{s d} w_{s} h(g) / \phi
$$

with an identical markup over marginal cost $\tilde{\sigma} \equiv \sigma /(\sigma-1)>1$. Importantly, the optimal product price does not depend on the appeal shock realization because the shock enters profits multiplicatively; it is therefore not relevant for the firm's choice problem whether prices are set before or after the firm observes the product appeal shocks. We adopt the convention that a firm commits to its price prior to the realization of product appeal shocks, and then ships the demanded quantities given price. The price commitment is credible because price choice remains optimal ex post. Firms may face a loss in the market if the demand shock realization implies that sales fail to cover the market entry costs. Under the common assumption that households receive profits and cover losses in a representative portfolio of the continuum of domestic firms, they do not suffer an overall loss in equilibrium by the law of large numbers.
} 
and the firm-level efficiency index

$$
H\left(G_{s d}, \boldsymbol{\xi}\right) \equiv\left(\sum_{g=1}^{G_{s d}} \xi_{s d g} h(g)^{-(\sigma-1)}\right)^{-\frac{1}{\sigma-1}}
$$

The index $H(\cdot)$ measures the harmonic mean efficiency of a firm's product line offered at a destination $d$, with the products' local appeal shocks as weights (collected in the vector $\boldsymbol{\xi}$ ). ${ }^{15}$ The firm-level efficiency index $H(\cdot)$ decreases with exporter scope $G_{s d}$ at the destination because firms have to add less efficient products, farther from their core competency, when they widen their scope.

For profit maximization with respect to exporter scope to be well defined, we make the following assumption.

Assumption 1 (Strictly increasing combined incremental scope costs). Combined incremental scope costs $z_{s d}\left(G, c_{d}\right) \equiv c_{d} f_{s d}(G) h(G)^{\sigma-1}$ strictly increase in exporter scope $G$.

Under our parameterization (6), Assumption 1 requires that the sum $\delta_{s d}+\tilde{\alpha}$ is larger than zero since $z_{s d}\left(G, c_{d}\right)=c_{d} f_{s d}(1) G^{\delta_{s d}+\tilde{\alpha}}$, where $\tilde{\alpha} \equiv \alpha(\sigma-1)$. The sum $\delta_{s d}+\tilde{\alpha}$ is the elasticity of combined incremental scope costs with respect to scope, or the scope cost elasticity for brevity.

Given the firm's pricing decision and this assumption, the firm's optimal scope choice is the largest $G \in\{0,1, \ldots\}$ such that operating profits from the last adopted product $G$ equal (or exceed) its incremental market-access costs:

$$
\pi_{s d}^{g=1}(\phi)=D_{s d} \phi^{\sigma-1} \geq c_{d} f_{s d}(G) h(G)^{\sigma-1} \equiv z_{s d}\left(G, c_{d}\right)
$$

where $\pi_{s d}^{g=1}(\phi)$ is the operating profit of the core product.

Figure 1 illustrates the choice of optimal exporter scope under Assumption 1. A firm widens its exporter scope at a destination as long as its combined incremental scope costs $z_{s d}(g)$ remain below the core product's operating profit $\bar{\pi}_{s d}^{g=1}(\phi)$. A necessary condition for a well defined optimum is that combined incremental scope costs strictly increase in scope beyond $\pi^{g=1}(\phi)$ at some scope. Assumption 1 adopts a stronger sufficient condition, similar to a global secondorder condition, so that a firm faces overall diseconomies of scope at any scope. One of the components of combined scope costs—either $h(\cdot)$ or $f(\cdot)$ — may still exhibit economies of scope. The essence of our quantification approach is to study the slope of the combined incremental scope cost schedule and the contribution of its components at the micro level, so we can conduct a precise welfare analysis of non-tariff market-access costs in the aggregate.

\footnotetext{
${ }^{15}$ The shocks $\xi_{s d g}$ and $\boldsymbol{\xi}$ could be written as $\xi_{s d g}(\omega)$ and $\boldsymbol{\xi}(\omega)$ to emphasize that they are firm specific.
} 
Figure 1: Optimal Exporter Scope at a Destination

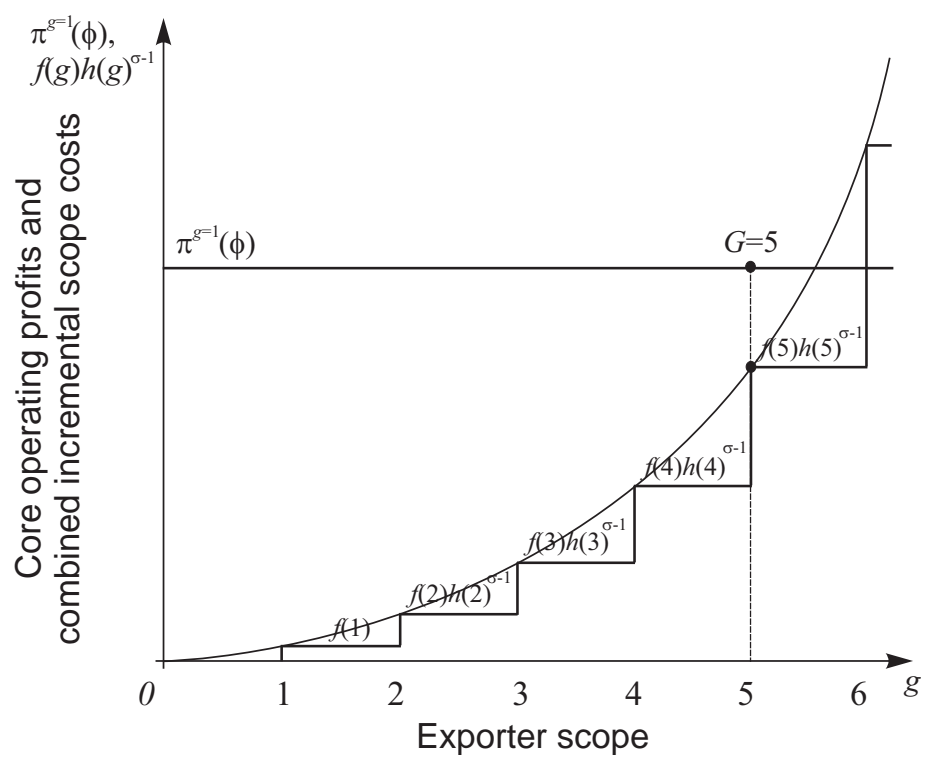

Note: Operating profits for the core product at a destination $d$ are $\pi^{g=1}(\phi)$ and depend on a firm's productivity $\phi$. Combined incremental scope costs $z\left(G, c_{d}\right) \equiv c_{d} f(G) h(G)^{\sigma-1}$ strictly increase in $G$ by Assumption 1, where $f(0)=0$ and $h(1)=1$, and are scaled by a firm's idiosyncratic market-access cost component $c_{d}$.

For a firm to enter a destination, the optimal scope condition (9) must be satisfied at least for the core product (with $h(1)=1$ ). Reformulating (9) accordingly, we can define the productivity threshold $\phi_{s d}^{*}\left(c_{d}\right)$ such that a firm from $s$ with $\phi \geq \phi_{s d}^{*}$ exports to $d$ at least the core product:

$$
\phi_{s d}^{*}\left(c_{d}\right)^{\sigma-1} \equiv c_{d} f_{s d}(1) / D_{s d}
$$

Similarly, we can define the productivity threshold $\phi_{s d}^{*, G}\left(c_{d}\right)$ such that a firm from $s$ with $\phi \geq$ $\phi_{s d}^{*, G}\left(c_{d}\right)$ sells at least $G$ products at destination $d$ :

$$
\phi_{s d}^{*, G}\left(c_{d}\right)^{\sigma-1} \equiv \frac{z_{s d}\left(G, c_{d}\right)}{c_{d} f_{s d}(1)} \phi_{s d}^{*}\left(c_{d}\right)^{\sigma-1}=\frac{z_{s d}\left(G, c_{d}\right)}{D_{s d}}
$$

where we adopt the notational simplification $\phi_{s d}^{*}\left(c_{d}\right) \equiv \phi_{s d}^{*, 1}\left(c_{d}\right)$. If Assumption 1 holds then $\phi_{s d}^{*}\left(c_{d}\right)<\phi_{s d}^{*, 2}\left(c_{d}\right)<\phi_{s d}^{*, 3}\left(c_{d}\right)<\ldots$ so that more productive firms introduce more products in a given destination. As a result, $G_{s d}\left(\phi, c_{d}\right)$ is a step-function that weakly increases in $\phi$ for any given $c_{d}$.

The firm's optimal price choice for each product precedes the realization of the appeal shock $\xi_{s d g}$. Once the vector $\boldsymbol{\xi}$ of appeal shocks for a firm $\omega$ is realized, the firm supplies the marketclearing quantity of each product under the product's constant marginal cost. Using consumer demand (2) and the above definitions, we can express each individual product's sales by a firm 
of type $\left(\phi, c_{d}\right)$ in equilibrium as

$$
y_{s d g}\left(\phi, c_{d}, \xi_{s d g}\right)=\sigma z_{s d}\left(G_{s d}\left(\phi, c_{d}\right), c_{d}\right)\left(\frac{\phi}{\phi_{s d}^{*, G}\left(c_{d}\right)}\right)^{\sigma-1} h(g)^{-(\sigma-1)} \xi_{s d g} .
$$

Summing over $g$, the firm's total sales at a destination become

$$
t_{s d}\left(\phi, c_{d}, \boldsymbol{\xi}\right)=\sigma c_{d} f_{s d}(1)\left(\frac{\phi}{\phi_{s d}^{*}\left(c_{d}\right)}\right)^{\sigma-1} H\left(G_{s d}\left(\phi, c_{d}\right), \boldsymbol{\xi}\right)^{-(\sigma-1)}
$$

for the firm-level efficiency index $H(\cdot)$ defined in (8).

Proposition 1 If Assumption 1 holds, then for all $s, d \in\{1, \ldots, N\}$

- exporter scope $G_{s d}\left(\phi, c_{d}\right)$ is positive and weakly increases in $\phi$ for $\phi \geq \phi_{s d}^{*}\left(c_{d}\right)$, and

- total firm exports $t_{s d}\left(\phi, c_{d}, \boldsymbol{\xi}\right)$ are positive and strictly increase in $\phi$ for $\phi \geq \phi_{s d}^{*}\left(c_{d}\right)$.

Proof. The first statement follows immediately from the discussion above. The second statement follows because $H\left(G_{s d}\left(\phi, c_{d}\right), \boldsymbol{\xi}\right)$ strictly increases in $G_{s d}\left(\phi, c_{d}\right)$ a.s., given the positive support of $\xi_{s d g}$, but $G_{s d}\left(\phi, c_{d}\right)$ weakly increases in $\phi$, so $H\left(G_{s d}\left(\phi, c_{d}\right), \boldsymbol{\xi}\right)$ weakly increases in $\phi$. By (13), $t_{s d}\left(\phi, c_{d}, \boldsymbol{\xi}\right)$ also monotonically depends on $\phi$ itself, so $t_{s d}\left(\phi, c_{d}\right)$ strictly increases in $\phi$.

\section{I.D Structural equations}

To take the firm's choices of destinations, products, and export production to the data we use the functional forms (6) together with a firm's productivity, market access, and product appeal shocks. We assume that a firm's productivity $\phi$ is drawn from a general distribution $A(\cdot)$, its market-access costs $c_{d}$ are drawn from distribution $B(\cdot)$, and product appeal shocks are drawn from distribution $C(\cdot)$. These distributions are unknown to the econometrician; we will specify plausible families for estimation in Section III.

The optimal exporter scope for firms with $\phi \geq \phi_{s d}^{*}\left(c_{d}\right)$ is given by (9) and can be written as

$$
G_{s d}\left(\phi, c_{d}\right)=\text { integer }\left\{\left[\phi / \phi_{s d}^{*}\left(c_{d}\right)\right]^{\frac{\sigma-1}{\delta_{s d}+\tilde{\alpha}}}\right\}
$$

under the definition $\tilde{\alpha} \equiv \alpha(\sigma-1)$. Using this relationship and equation (12) we can express optimal sales of the $g$-th product in destination $d$ for a firm $\left(\phi, c_{d}\right)$ as a function of the total number of products that the firm sells in $d$ :

$$
y_{s d g}\left(\phi, c_{d}, \xi_{s d g}\right)=\sigma c_{d} f_{s d}(1) G_{s d}\left(\phi, c_{d}\right)^{\delta_{s d}+\tilde{\alpha}} g^{-\tilde{\alpha}}\left(\phi / \phi_{s d}^{*, G}\left(c_{d}\right)\right)^{\sigma-1} \xi_{s d g}
$$


Summing over a firm's products $g$, we find its total sales $t_{s d}\left(\phi, c_{d}, \boldsymbol{\xi}\right)=\sum_{g} y_{s d g}\left(\phi, c_{d}, \xi_{s d g}\right)$ and, dividing total sales by exporter scope, we obtain average product sales per firm, or average exporter scale. Given (15), exporter scale takes the form

$$
a_{s d}\left(\phi, c_{d}, \boldsymbol{\xi}\right) \equiv \frac{t_{s d}\left(\phi, c_{d}, \boldsymbol{\xi}\right)}{G_{s d}\left(\phi, c_{d}\right)}=\sigma c_{d} f_{s d}(1) G_{s d}\left(\phi, c_{d}\right)^{\delta_{s d}+\tilde{\alpha}-1}\left(\frac{\phi}{\phi_{s d}^{*, G}\left(c_{d}\right)}\right)^{\sigma-1} \sum_{g=1}^{G_{s d}\left(\phi, c_{d}\right)} \xi_{s d g} g^{-\tilde{\alpha}}
$$

for the firm-level efficiency index $H\left(G_{s d}, \boldsymbol{\xi}\right)^{-(\sigma-1)}=\sum_{g=1}^{G_{s d}} \xi_{s d g} g^{-\tilde{\alpha}}$.

Given these firm relationships, we now describe the data and empirical analogues to these equations. We defer the discussion of existence and closed form general-equilibrium results to Section IV.

\section{Data and Regularities}

Our Brazilian exporter data originate from the export declarations for the year 2000. From these customs records we construct a three-dimensional panel of exporters, their destination countries, and their export products at the Harmonized System (HS) 6-digit level, with sales aggregated for the year 2000. In terms of exports per capita Brazil is close to the median country in $2000 .^{16}$ We have two empirical objectives: to systematically investigate regularities about multi-product firms, and to disentangle potentially policy-driven non-tariff measures.

We start by reporting a set of novel regularities about multi-product firms as well as aspects of known facts (Eaton, Kortum and Kramarz 2004, Bernard, Redding and Schott 2011, Arkolakis and Muendler 2013). We arrive at the stylized facts guided by two principles. First, it is not possible to generate the regularities with mere random shocks (balls thrown at bins as in Armenter and Koren (2014)). Second, the regularities must characterize the extensive margin of product entry (exporter scope) or the remaining intensive margin of average product sales (average exporter scale), or both, at varying levels of aggregation. We pay particular attention to differences between nearby and far-away destinations to discipline market-access costs. We think of the new regularities as a body of facts that any theory of multi-product firms with heterogeneous productivity should match.

In addition, we also aim to disentangle policy-driven non-tariff measures (NTMs) from other components of market-access barriers. For this purpose, we draw on the NTM data underlying

\footnotetext{
${ }^{16} \mathrm{By}$ WTF and WDI data for all industries and countries, Brazil ranks at the 48th percentile (top 100th country out of 192) in terms of exports per capita in 2000. Brazil's total exports in 2000 are at the 88th percentile worldwide (top 27th country out of 205). When it comes to established facts, Brazil's exporters exhibit the typical regularities (see e.g. Arkolakis and Muendler 2013).
} 
the Kee, Nicita and Olarreaga (2009) estimates of NTM ad-valorem equivalents.

\section{II.A Data sources and preparations}

Products in the original SECEX (Secretaria de Comercio Exterior) exports data for 2000 are reported using 8-digit codes (under the Mercosur nomenclature), of which the first six digits coincide with the 6-digit Harmonized System (HS) codes. We aggregate the data to the HS 6-digit product and firm level so that the resulting dataset is comparable to data for other countries. ${ }^{17}$

We restrict our sample to manufacturing firms and their exports of manufactured products, removing intermediaries and their commercial resales of manufactures. The restriction makes our findings closely comparable to BRS and Eaton, Kortum and Kramarz (2011). Using a firm's self-declared sector from an annual firm employment census $(R A I S)$, we find that 93 percent of Brazil's manufactured product exports are shipped by manufacturing firms themselves, and 7 percent by wholesale trading companies. Our resulting manufacturing firm sample has 10,215 exporters selling 3,717 manufactured products at the 6-digit HS level to 170 foreign destinations, and a total of 162,570 exporter-destination-product observations. Appendix B describes the Brazilian data with additional detail.

For the year 2000, UNCTAD's TRAINS (Trade Analysis and Information System) data offer the arguably most comprehensive coverage of NTMs. Kee, Nicita and Olarreaga (2009) augment these data in two ways. First, for the comparably protective textiles, apparel, and footwear industries in the EU, they bring in NTM information from the EU Standards Database as prepared by Shepherd (2007). Second, beginning in 1992 they update TRAINS information globally using the individual records from the WTO's Trade Policy Reviews and add accordingly identified NTMs. ${ }^{18}$ There is a large number of NTM types. We follow Kee, Nicita and Olarreaga (2009) and Niu et al. (2018) and consider four core NTMs: price control measures designed to affect the prices of imported goods including so-called para-tariff measures to raise the import price (TRAINS two-digit codes 61-63), quantity restrictions intended to limit trade through licences and import prohibitions other than technical measures (codes 31-33), anti-competitive measures granting exclusive or special preference to one or more limited groups of economic operators in trade (code 70), and technical measures including sanitary and phytosanitary measures to pre-

\footnotetext{
${ }^{17}$ Our findings are similar at the Mercosur nomenclature 8-digit level (see Online Supplement).

${ }^{18}$ UNCTAD has meanwhile improved coverage of NTMs and reports additional detail of NTMs using a new classification by UNCTAD's MAST (Multi-Agency Support Team), still at the HS 6-digit product level (for an implementation see Niu et al. 2018). For the year 2000, however, we opt for the augmented coverage that Kee, Nicita and Olarreaga (2009) provide. The comprehensive Global Trade Alert data by Evenett (2009) include NTMs but only since 2009. Bown (2011) constructs and documents complementary data on temporary trade safeguards and antidumping measures, while our emphasis is on longer-term NTMs and their relationship to the extensive margin of exporting products.
} 
vent the spread of disease as well as standards on technical specifications or quality requirements to protect human and animal health and the environment (code 81).

We construct an NTM variable that remains deliberately close to the raw data at the level of the HS 6-digit product $j$ and destination country $d$ : We first assign NTM information available only at the more aggregate HS 2- or 4-digit levels to the HS 6-digit level, following Kee, Nicita and Olarreaga (2009). For lower-level HS 8-digit codes we consider the maximal count of NTMs within the 6-digit HS code. (For a conversion of HS 1992/H0 and HS 2002/H2 codes to HS 1996/H1 we use WITS product concordances from the World Bank.) Second, we use information for the year 2000 to assess whether there is a core NTM or not. When information on an HS 6-digit product and country is missing, we use information from 2001. For the remaining missing products and countries, we use the year 1999, so our NTM coverage reflects the best available information in the period 1999-2001. Third, similar to Kee, Nicita and Olarreaga (2009), we construct a single indicator variable $N T M_{j d}$ that takes the value 1 when country $d$ imposes at least one of the four core NTMs in an HS 6-digit product, and zero otherwise. We do not estimate the ad-valorem equivalent of the $N T M_{j d}$ variable (as do Kee, Nicita and Olarreaga 2009, Niu et al. 2018) and instead use its observed value.

NTMs and conventional tariffs may be related, as substitutes or complements, in trade policy. To control for tariffs empirically, we collect average tariff rates for Brazilian exporters by export destination and product category from the WTO's Integrated Database. In contrast to the multilateral NTM data, these tariff rates are available at the bilateral level and therefore more precisely measured than the $N T M_{j d}$ variable. We define the region Latin America and the Caribbean (LAC) as does the World Bank (including the North American country Mexico and Central America).

\section{II.B Regularities}

To characterize firms, we decompose a firm $\omega$ 's total exports $t_{d}(\omega)$ to destination $d$ into the number of products $G_{d}(\omega)$ sold at $d$ (the exporter scope in $d$ ) and average product sales per firm $a_{d}(\omega) \equiv t_{d}(\omega) / G_{d}(\omega)$ in $d$ (the average exporter scale in $d$ ). We elicit three major stylized facts from the data at three levels of aggregation, ranging from the individual product level within firms to the exporter scope and exporter scale distributions across firms.

\section{Fact 1 Within firms and destinations,}

1. wide-scope exporters sell large amounts of their top-selling products, with exports concentrated in a few products, and 
Figure 2: Firm-product Sales Distributions by Exporter Scope

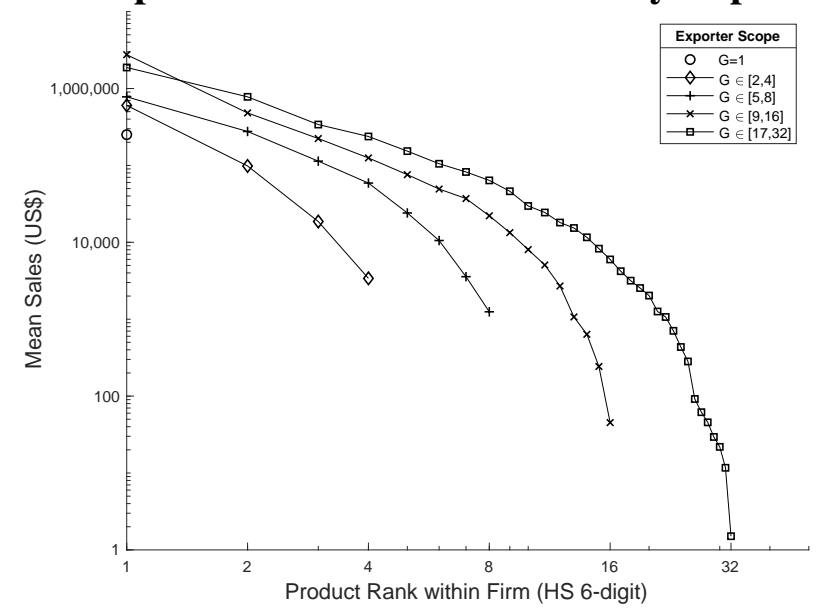

Source: SECEX 2000, manufacturing firms and their manufactured products.

Note: Products at the HS 6-digit level, shipments to Argentina. We group firms by their exporter scope $G_{\text {ARG }}=G$ in Argentina (Argentina is the most common export destination). The product rank $g$ refers to the sales rank of an exporter's product in Argentina. Mean product sales is the average of individual firm-product sales $\sum_{\omega \in\left\{\omega: G_{\mathrm{ARG}}(\omega)=G\right\}} y_{\omega \mathrm{ARG} g}^{G} / M_{\mathrm{ARG}}^{G}$, computed for all firm-products with individual rank $g$ at the $M_{\mathrm{ARG}}^{G}$ firms exporting to Argentina with scope $G_{\mathrm{ARG}}=G$.

\section{2. wide-scope exporters sell small amounts of their lowest-selling products.}

Figure 2 documents this fact. For the figure, we limit our sample to exporters at a single destination and show only firms that ship at least one product to Argentina (the most common export destination). We group the exporters by their exporter scope $G_{\mathrm{ARG}}=G$ in Argentina. Results at other export destinations are similar. ${ }^{19}$ For each scope group $G$ and for each product rank $g$, we then take the average of the log of product sales $\ln y_{\omega \text { ARG } g}^{G}$ for those firm-products in Argentina. The graph plots the average log product sales against the log product rank by exporter scope group. The figure shows that a firm's sales within a destination are concentrated in a few core products consistent with the core competency view of EN. In the model, the degree of concentration is regulated by how fast $f_{d}(g)$ and $h(g)$ change with $g$ (the elasticities $\delta_{d}$ and $\tilde{\alpha} \equiv \alpha(\sigma-1))$. Figure 2 also documents that wide-scope exporters sell more of their top-selling products than firms with few products. The model's equation (15) matches this aspect under Assumption 1.

The product ranking of sales within firms need not be globally deterministic, as $f_{d}(g)$ and $h(g)$ would suggest, but the local product rankings can differ across destinations in reality, which we model with product-specific taste shocks similar to BRS. Comparing ranks across destinations, we can assess the relative importance of core competency versus product-specific taste

\footnotetext{
${ }^{19}$ We present plots for the United States and Uruguay in Appendix B (Figure B.1). Argentina, the United States and Uruguay are the top three destinations in terms of presence of Brazilian manufacturing exporters in 2000.
} 
Table 1: Regularities

\begin{tabular}{|c|c|c|c|c|c|}
\hline & (1) & (2) & (3) & (4) & (5) \\
\hline & \multicolumn{2}{|c|}{ Fact 1.1} & Fact 1.2 & Fact 2 & Fact 3 \\
\hline & $\ln y_{\omega d 1}$ & $\ln y_{\omega d 1}$ & $\ln y_{\omega d G}$ & $\ln G_{\omega d}$ & $\ln t_{\omega d} / G_{\omega d}$ \\
\hline $\ln G_{\omega d}$ & $\begin{array}{l}1.300 \\
(.0429)\end{array}$ & $\begin{array}{l}1.272 \\
(.0397)\end{array}$ & $\begin{array}{l}-2.065 \\
(.0289)\end{array}$ & & $\begin{array}{l}.505 \\
(.0383)\end{array}$ \\
\hline LAC & $\begin{array}{l}-.161 \\
(.0397)\end{array}$ & $\begin{array}{l}-.105 \\
(.0406)\end{array}$ & & $\begin{array}{c}.450 \\
(.0198)\end{array}$ & $\begin{array}{l}-.0874 \\
(.0396)\end{array}$ \\
\hline $\ln G_{\omega d} \times \mathrm{LAC}$ & $\begin{array}{l}-.179 \\
(.0488)\end{array}$ & $\begin{array}{l}-.230 \\
(.0413)\end{array}$ & & & $\begin{array}{l}-.226 \\
(.0379)\end{array}$ \\
\hline $\mathrm{NTM}_{\omega d}$ & & $\begin{array}{l}.0464 \\
(.0367)\end{array}$ & & $\begin{array}{l}-.0495 \\
(.0124)\end{array}$ & $\begin{array}{l}.0334 \\
(.0364)\end{array}$ \\
\hline $\ln G_{\omega d} \times \mathrm{NTM}_{\omega d}$ & & $\begin{array}{c}.125 \\
(.0418)\end{array}$ & & & $\begin{array}{c}.160 \\
(.0389)\end{array}$ \\
\hline $\begin{array}{l}\text { Fixed effects } \\
\text { Controls }\end{array}$ & Firm & $\begin{array}{c}\text { Firm } \\
\text { Tariffs }\end{array}$ & Firm & $\begin{array}{l}\text { Firm } \\
\text { Tariffs }\end{array}$ & $\begin{array}{l}\text { Firm } \\
\text { Tariffs }\end{array}$ \\
\hline Observations & 46,208 & 32,486 & 46,208 & 36,647 & 32,488 \\
\hline$R^{2}$ & .544 & .539 & .743 & .596 & .512 \\
\hline
\end{tabular}

Sources: SECEX 2000, manufacturing firms and their manufactured products; WTO's Integrated Database 2000 for import tariff rates; CEPII 2000.

Note: All specifications condition on firm fixed effects. Standard errors, clustered at the firm level, in parentheses $(: p<.05,: p<.01,: p<.001)$.

shocks: for each given HS 6-digit product that a Brazilian firm sells in Argentina, we can correlate the firm-product's rank elsewhere with the firm-product's Argentinean rank. We find a correlation coefficient of .785 and a Spearman's rank correlation coefficient of .860 , indicating an important role for core competency.

To assess the first statement of Fact 1, we regress the logarithm of the revenues of the bestselling product $y_{\omega d 1}$ for firm $\omega$ to destination $d$ on log exporter scope $G_{\omega d}$, discerning effects separately for Latin American and Caribbean (LAC) and non-LAC destinations, conditional on a firm fixed effect. This regression is a version of equation (15) for a firm's core product $g=1$.

Table 1 reports the result in column 1 . The coefficient estimate on $\ln G_{\omega d}$ shows that sales of the best-selling product increase with an elasticity of 1.3 as exporter scope in a market widens. However, for LAC destinations, the elasticity is only 1.12 (1.30-0.18). In light of the model's equation (15) for $g=1$, this coefficient can be interpreted as an estimate of the scope cost elasticity $\delta_{\mathrm{LAC}}+\tilde{\alpha}$ in LAC. The variation between LAC and non-LAC destinations is closely related to our later finding that there are destination-specific elasticities of incremental marketaccess costs with respect to exporter scope. In subsection II.C below, we will assess the first 
statement of Fact 1 yet more rigorously and estimate the model's equation (15) at the individual product level for all products.

The regional indicator for LAC destinations is hard to interpret because it arguably captures differences in market-access costs relative to the rest of the world originating from both policyamenable and lasting cultural or geographic entry barriers. To proxy for a policy-related marketaccess cost component more directly, we therefore include an NTM variable in the regression. We aggregate the $N T M_{j d}$ variable over the HS 6-digit products $j$ to the firm level $\omega: N T M_{\omega d} \equiv$ $\sum_{j \in \mathbb{J}_{\omega d}=\left\{j: y_{\omega d j}>0\right\}} N T M_{j d} /\left|\mathbb{J}_{\omega d}\right|$. This NTM proxy varies between zero and one and reflects the share of HS-6 product lines with at least one core NTM that an exporter $\omega$ faces when shipping its products to destination $d$. Import tariffs may be correlated with NTMs, so we also control for the firm-level mean of the $\log$ of one plus the tariff rate $\ln \left(1+\tau_{\omega d}\right)$ for an exporter $\omega$, where $\tau_{\omega d}$ is the HS 6-digit average tariff on the products that the firm sells at the destination. We continue to include firm fixed effects. The NTM variable is only available for a subset of destinations, so we lose observations.

Column 2 of Table 1 reports the results. The coefficient estimate on $\ln G_{\omega d}$ means that the sales of the best-selling product grow larger with an elasticity of 1.27 as exporter scope widens. However, at destinations that cover a larger share of an exporter's products with NTMs, the elasticity becomes $1.40(1.27+0.13)$. In other words, more NTMs at a destination depress product sales in a similar manner as do non-LAC destinations, while the LAC indicator remains a statistically significant predictor at conventional significance levels. An interpretation is that policyamenable market-access costs such as NTMs discourage product sales markedly, in addition to lasting entry barriers reflected in regional indicators. We report in the Online Supplement (S3, Table S.1) further results, including for a breakdown by NTM types, and robustness checks.

The second statement in Fact 1 that wide-scope exporters sell their lowest-ranked products for small amounts is also consistent with our model's equation (15). The equation implies for a firm's least-selling product $g=G_{\omega d}$ that its sales fall with a firm's scope if and only if marketaccess costs decline with additional products ( $\delta_{d}$ is negative). The finding is at odds with models of multi-product firms where access costs are product-invariant or absent, such as in BRS or Mayer, Melitz and Ottaviano (2014), and underlies our choice of product-specific market-access costs. The second statement in Fact 1 closely relates to our later simulation result that falling access costs induce more trade mostly through the entry of new exporters with their first product, whereas falling product entry barriers raise trade by less than similar relative declines in variable trade costs.

To assess the second statement in Fact 1 quantitatively, we regress the lowest-ranked product's log sales $y_{\omega d G}$ on a firm's log exporter scope $G_{\omega d}$ in a destination, conditioning on fixed 
Figure 3: Exporter Scope Distribution

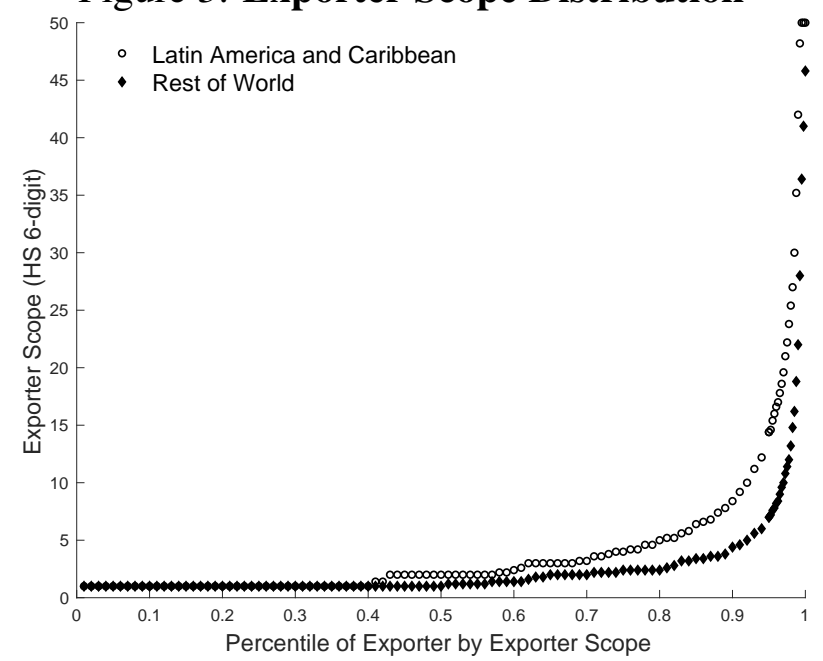

Source: SECEX 2000, manufacturing firms and their manufactured products.

Note: Products at the HS 6-digit level. The percentile of exporters by scope is calculated within a given destination. Exporter scope is the corresponding scope for a given percentile averaged across the five most common destinations within each of the two regions (LAC, and non-LAC called Rest of World).

effects for firms $\omega$, and obtain an elasticity of roughly -2.1 as shown in column 3 of Table 1 . The coefficient estimate implies that sales of the lowest-selling product fall as exporter scope at a destination widens. In light of equation (15) for $g=G_{\omega d}$, the coefficient can be interpreted as an estimate of average $\delta_{d}$ across the destinations of Brazilian exporters. Taken together with the coefficient estimate on exporter scope in column 1, the evidence so far would suggest that, on average across destinations, $\delta_{d}$ roughly equals -2.1 and the sum $\delta_{d}+\tilde{\alpha}$ about 1.3 , so $\tilde{\alpha}$ equals around 3.4. These findings are similar to our more precise subsequent results and show how we are going to use microeconomic evidence from product sales within firms to build towards aggregate quantification.

Fact 2 At each destination, there are a few wide-scope and many narrow-scope exporters.

Figure 3 plots average exporter scope in the top five destinations of a region (LAC or nonLAC) against the percentile of an exporter in terms of scope at the destination. The median exporter only ships one or two products to any given destination. Within a destination, the exporter scope distribution exhibits a concentration in the upper tail reminiscent of a Pareto distribution.

The exporter scope distribution varies between destinations. Plotted in open dots is the average exporter scope at top LAC destinations, and with solid dots the exporter scope at top non-LAC destinations. Brazilian exporters have a wider exporter scope at LAC destinations than at non-LAC destinations. To quantify the difference in exporter scope across destinations, 


\section{Figure 4: Exporter Scope and Exporter Scale}

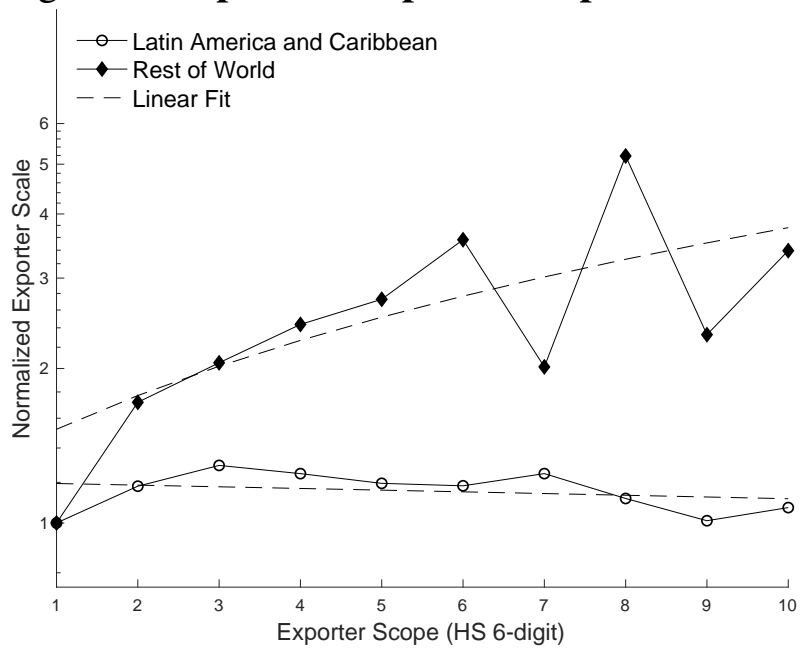

Source: SECEX 2000, manufacturing firms and their manufactured products.

Note: Products at the HS 6-digit level. Exporter scope is the number of products exported to a given destination. Exporter scale is a firm's total sales at a destination divided by its exporter scope within the destination. We normalize log exporter scale by the average log total sales of single-product exporters at the destination, so that the normalized log exporter scale for single-product exporters is one. We report mean exporter scope and mean exporter scale over the five most common destinations within a region (LAC or non-LAC). The dashed lines depict the ordinary least-squares fit.

we run a simple regression of log exporter scope $G_{\omega d}$ on an indicator for LAC destinations and condition on firm fixed effects.

Column 4 of Table 1 shows the regression results, conditional on our measure of NTMs for the products that an exporter ships to the destination and conditional on the mean log of one plus the tariff rate $\ln \left(1+\tau_{\omega d}\right)$ as well as firm fixed effects. The coefficient of the LAC indicator is positive. In light of the model's equation (14), a wider exporter scope in nearby LAC countries is consistent with a lower scope cost elasticity $\delta_{\mathrm{LAC}}+\tilde{\alpha}$ in absolute value than in the rest of the world, similar to evidence on the first statement in Fact 1. The coefficient on the NTM variable suggests that exporter scope is lower at destinations where exporters face more NTMs, a discouraging impact on exports echoing the effect for non-LAC destinations. Further results and robustness checks are available in the Online Supplement (S3, Table S.2).

Fact 3 Average product sales (exporter scale) and exporter scope exhibit varying destinationspecific degrees of correlation, with the correlation positive and highest in distant destinations.

Figure 4 plots the normalized log of average exporter scale $\ln a_{\omega d}$ at the top-five destinations in a region against the average exporter scope $G_{\omega d}$ at the top-five destinations in the region. We normalize exporter scale by the average log total sales of single-product exporters at the destination, so that the normalized log exporter scale for single-product exporters is one. An 
exporter's average product sales exhibit a strong positive correlation with exporter scope in more distant non-LAC destinations, but no detectable relationship at close-by LAC destinations. ${ }^{20}$ In light of our model's equation (16), a consistent explanation is that $\delta_{d}$ is negative and in absolute magnitude larger in nearby countries, similar to evidence from the previous two facts. Exporters to a nearby destination experience a rapid decline in market-access costs for additional products, permitting low-selling products into a nearby market more easily than into remote markets.

We can relate an exporter's average product sales and exporter scope across destinations to a destination's share of products facing NTMs, in addition to the LAC indicator. Similar to earlier specifications, we regress the dependent variable, now the log of average product sales $\ln a_{\omega d}$, on log exporter scope $\ln G_{\omega d}$ and its interaction with a LAC dummy and with the variable $N T M_{\omega d} \in[0,1]$, while controlling for the average tariff rate and for firm fixed effects.

We report the results in column 5 of Table 1. Mirroring the evidence from Figure 4, the predicted elasticity of exporter scale with respect to exporter scope is significantly higher at non-LAC destinations and at destinations where products face more core NTMs. Further results and robustness checks are available in the Online Supplement (S3, Table S.3). These facts are consistent with the interpretation that exporters to distant countries and to destinations with more NTMs face higher incremental market-access costs for additional products. Firms therefore mostly add high-selling products in distant and NTM-protected markets. As a result, widescope exporters at more distant and NTM-protected markets have, on average, higher sales per product.

\section{II.C Scale-scope-rank regressions}

We conclude our descriptive exploration of the data with an empirical assessment of Fact 1 (Figure 2) at the product level. For this purpose, we simplify the model and restrict both the marketaccess cost and the local product appeal to unity across all firms and destinations: $c_{d}=\xi_{d g}=1$. The only structural heterogeneity comes from a firm's productivity $\phi$, which we consider to be from a Pareto distribution with shape parameter $\theta$, and we define the resulting Pareto shape parameter of the firm size distribution $\tilde{\theta} \equiv \theta /(\sigma-1)$. Using equation (15), we can express firm $\omega$ 's $\log$ sales $y_{\omega d g}$ of the $g$-th product in destination $d$ as a function of the firm's log exporter scope

\footnotetext{
${ }^{20}$ The absence of a strong correlation between exporter scale and exporter scope among Brazilian firms exporting to close-by LAC countries is reminiscent of the finding by BRS that scale and scope hardly correlate among U.S. exporters to Canada. Montinari, Riccaboni and Schiavo (2017) report similar scale-scope relationships for French exporters when discerning between EU and non-EU destinations, comparable to our scale-scope relationships for Brazil and LAC vs. non-LAC destinations.
} 
$G_{\omega d}$ and the log local rank of the firm's product $g$ :

$$
\ln y_{\omega d g}=\left(\delta_{d}+\tilde{\alpha}\right) \ln G_{\omega d}-\tilde{\alpha} \ln g-f\left(1-\operatorname{Pr}_{\omega d}^{G}\right)+\ln \sigma\left[f_{d}(1) / f(1)\right] \mathbf{1}_{d \in \mathrm{LAC}}+\chi_{\omega} \mathbf{1}_{\omega}+\epsilon_{\omega d g}
$$

The function $f\left(1-\operatorname{Pr}_{\omega d}^{G}\right)=(\sigma-1) \ln \left(\phi_{\omega} / \phi_{d}^{*, G}\right)$ maps a firm's sales percentile to its underlying relative productivity. To measure $1-\operatorname{Pr}_{\omega d}^{G}$, we compute a Brazilian firm's local sales percentile among the Brazilian exporters with minimum exporter scope $G$. Given the Pareto shape parameter of the firm size distribution $\tilde{\theta} \equiv \theta /(\sigma-1)$, we adopt as a functional form $f(x)=\tilde{\theta}^{-1} \ln (x)$ and include the log percentile as a regressor. We augment the estimation equation with a combined disturbance $\chi_{\omega} \mathbf{1}_{\omega}+\epsilon_{\omega d g}$, simply recognizing that the equation will only hold with some empirical error, and condition out a firm's worldwide fixed effect $\chi_{\omega}$ (with $\mathbf{1}_{\omega}$ denoting an indicator for firm $\omega$ ). The (exhaustive) set of firm effects absorbs the worldwide average log fixed cost $\ln \sigma f(1)$.

There are concerns using estimation equation (17). The equation is misspecified if local sales shocks $\xi_{d g}$ permutate the global rank order of a firm's products and turn the order into different location-specific rankings. This misspecification makes the equation "memoryless" in that estimation does not register a firm-product's identity across locations and therefore loses account of the firm-product's ranking outside a given location $d$. Moreover, the estimation equation suffers an omitted variable bias because unobserved positive firm-destination product appeal shocks will both tend to raise exporter scope and to systematically permutate the local rank order of firm products; this omitted variable bias would expectedly distort the estimates of $\delta_{d}$. To mitigate the concerns, we estimate equation (17) in two parts by restricting the estimation sample: (i) we isolate the intercept of the graphs in Figure 2 by restricting the sample to just the best selling (or second-best selling) product, $g=1$ (or $g=2$ ), and estimate how the intercept varies with exporter scope for two location groups $G_{\omega, d \in \mathrm{LAC}}(\mathrm{LAC})$ and $G_{\omega, d \in \mathrm{ROw}}$ (non-LAC destinations); (ii) we measure the slope of the graphs in Figure 2 by restricting the sample to $G_{\omega, d \in \mathrm{LAC}}=G_{\omega, d \in \mathrm{ROW}}=2$ (or $G_{\omega, d}=16$ ). To obtain mutually consistent results from this two-part estimation, we use the estimated coefficients on $\mathbf{1}_{d \in \mathrm{LAC}}$ and $\ln \left(1-\operatorname{Pr}_{\omega d}^{G}\right)$ from the first part (i) as constraints on the second part (ii). Given the potential misspecification under any pair of restrictions, the regressions merely offer a descriptive exploration of the data.

Table 2 reports results from the two-part regression exercise under three combinations of restrictions. The baseline specification uses the restrictions $g=1$ and $G_{\omega d}=2$ for a pair of regressions under firm fixed effects (standard errors clustered at the level of 259 industries). The first variation uses the restrictions $g=2$ and $G_{\omega d}=2$ for a separate pair of firm fixed effects regressions and the second variation combines the restrictions $g=1$ and $G_{\omega d}=16$ for a final pair of firm fixed effects regressions. (Results remain broadly similar when including 
Table 2: Fit of Individual Product Sales

\begin{tabular}{lrrrrr}
\hline & $\delta_{\text {LAC }}$ & $\delta_{\text {ROW }}$ & $\tilde{\alpha}$ & $\tilde{\theta}$ & $\delta_{\text {LAC }}-\delta_{\text {ROW }}$ \\
\hline Baseline: $g=1 ; G=2$ & -1.82 & -1.61 & 3.04 & 2.35 & -.21 \\
& $(.10)$ & $(.12)$ & $(.09)$ & $(.35)$ & $(.06)$ \\
Variant 1: $g=2 ; G=2$ & -1.24 & -1.14 & 3.04 & 2.09 & -.10 \\
& $(.12)$ & $(.14)$ & $(.09)$ & $(.34)$ & $(.07)$ \\
Variant 2: $g=1 ; G=16$ & -1.41 & -1.19 & 2.62 & 2.35 & -.21 \\
& $(.12)$ & $(.13)$ & $(.11)$ & $(.35)$ & $(.06)$ \\
\hline
\end{tabular}

Source: SECEX 2000, manufacturing firms and their manufactured products.

Note: Products at the HS 6-digit level. OLS-FE firm fixed effects estimation of equation (17) for firm $\omega$ 's individual product $g$ sales at destination $d$ in two parts, (i) under a rank restriction such as $g=1$ with

$$
\ln y_{\omega d g}=\underset{(.04)}{1.22} \ln G_{\omega, d \in \mathrm{LAC}}+\underset{(.07)}{1.43} \ln G_{\omega, d \in \mathrm{ROW}}-\underset{(.06)}{.43} \ln \left(1-\operatorname{Pr}_{\omega d}^{G}\right)-\underset{(.05)}{.32} \mathbf{1}_{d \in \mathrm{LAC}}+\chi_{\omega} \mathbf{1}_{\omega}+\epsilon_{\omega d g},
$$

and (ii) under a scope restriction such as $G_{\omega d}=2$ with

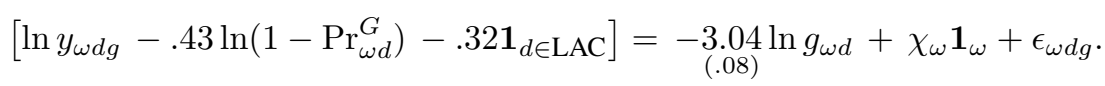

Robust standard errors from the delta method, clustered at the HS 2-digit industry level, in parentheses. Estimates of $\delta_{\text {LAC }}$ measure the scope elasticity of market-access costs for Brazilian firms shipping to other LAC destinations, $\delta_{\mathrm{ROW}}$ for Brazilian firms shipping to destinations outside LAC; $\chi_{\omega} \mathbf{1}_{\omega}$ denote firm fixed effects.

destination and HS 2-digit industry fixed effects.) As expected from the different relationships between exporter scope and scale outside LAC and within LAC (Figure 4$), \delta_{\text {LAC }}$ exceeds $\delta_{\text {ROw }}$ in absolute magnitude. Overall $\delta_{d}$ falls in the range between -1.13 and -1.82 across specifications and regions, while $\tilde{\alpha}$ lies in the range from 2.62 to 3.04 and $\tilde{\theta}$ between 2.10 and 2.35. In the baseline specification, the magnitudes of the $\delta_{d}$ estimates imply that incremental market-access costs drop at an elasticity of -1.61 when manufacturers introduce additional products in markets outside LAC, and with -1.82 within LAC. But firm-product efficiency drops off even faster with an elasticity of around 3.04 in the baseline. Adding the two fixed scope cost coefficients suggests that there are net overall diseconomies of scope with a scope elasticity of 1.22 in LAC and 1.43 in non-LAC destinations. The coefficient estimates suggest that Assumptions 1 and 2 are satisfied in our data.

We now turn from descriptive explorations to an internally consistent estimator and will use the measured parameter magnitudes to assess the importance of each margin for overall trade. 


\section{Estimation}

We adopt a method of simulated moments for parameter estimation. ${ }^{21}$ We specify the product appeal shocks $\xi_{d g}$ and the market-access costs shocks $c_{d}$ to be distributed log-normally with mean zero and respective variances $\sigma_{\xi}$ and $\sigma_{c}$. Firm productivities $\phi$ are drawn from a Pareto distribution with shape parameter $\theta .{ }^{22}$

We need to identify five parameters $\Theta=\left\{\delta, \tilde{\alpha}, \tilde{\theta}, \sigma_{\xi}, \sigma_{c}\right\}$, where $\tilde{\alpha} \equiv \alpha(\sigma-1)$ and $\tilde{\theta} \equiv$ $\theta /(\sigma-1)$. These five parameters fully characterize the relevant shapes of our functional forms and the dispersion of the three stochastic elements-Pareto distributed firm-level productivity $\phi$, the random firm-level market-access cost component $c_{d}$, and local product appeal shocks $\xi_{d g}$. Our moments are standardized relative to the median firm or top firm-product at a destination. This convention results in an estimator that is invariant to two deterministic shifters in the firms' cost and revenue functions: a destination-specific market-access cost shifter $\sigma f_{d}(1)$ and a destinationspecific revenue shifter $D_{d}$, which are both common across exporters at a destination and can be inferred from the data after estimation. ${ }^{23}$ Moreover, we specify the domestic access cost components $\xi_{\mathrm{BRA} g}$ and $c_{\mathrm{BRA}}$ to be deterministic so that every exporter sells in the home market with certainty. In our ultimate implementation of the SMM estimator, we adopt an extension to destination-specific scope elasticities of market-access costs with $\delta_{d}$ varying between LAC and non-LAC countries.

\section{III.A Moments}

At any iteration of the simulation, we use the candidate parameters $\hat{\Theta}$ to compute a simulated vector of moments $\mathbf{m}^{\operatorname{sim}}(\hat{\Theta})$, analogous to moments in the data $\mathbf{m}^{\text {data }}$. We use five sets of simulated moments. Each set captures facts 1 and 2 from Section II, as well as standard firm heterogeneity facts. We exclude moments related to Fact 3 from our set of targeted moments,

\footnotetext{
${ }^{21}$ The presence of overlaying market-access cost and product appeal shocks renders conventional estimators difficult, as they would involve the numeric evaluation of integrals. Both a firm's market-access cost shock $c_{\omega d}$ is potentially widely dispersed and a firm-product's rank $g_{\omega}$ in production can differ from the firm-product's observed local rank in sales $\left(\hat{g}_{\omega d} \equiv 1+\sum_{k=1}^{G} \mathbf{1}_{\left[y_{\omega d k}\left(\xi_{d k}\right)>y_{\omega d g}\left(\xi_{d g}\right)\right.}\right)$, especially if the product appeal shock $\xi_{d g}$ is widely dispersed. The implied stochastic permutations of exporter scopes and product ranks introduce an exacting dimensionality that is hard to handle with a maximum likelihood estimator, while the need for numerical computation of higher moments makes a general method of moments difficult to implement.

${ }^{22} \mathrm{We}$ relax the Pareto assumption in Appendix $\mathrm{F}$ and suppose that firm productivity is drawn from a log-normal distribution. We find that our parameter estimates are largely unchanged. The log-normal distribution may do a better job in describing small firm behavior, but we focus on large, productive firms, and the Pareto distribution allows for the counterfactual simulation in Section 5.

${ }^{23}$ This choice effectively removes the levels of fixed costs from the estimation, a principal object of interest in Fernandes et al. (2018). In estimation we do not use moments that aggregate over firms, such as the average firm's sales or total export sales.
} 
but use this fact to assess model fit. We now summarize the simulated moments and discuss how they contribute to parameter identification. Additional details on the moment definitions as well as the simulation algorithm can be found in Appendix D.

1. Sales of the top-selling product across firms within destinations. Based on the first statement of Fact 1, we characterize the top-selling products' sales across firms with the same exporter scope. Among firms exporting three or four products to Argentina, for example, we take the ratio of the top-selling product at the 95th percentile across firms and the top-selling product of the median firm. Our restriction to the top product and our standardization by the median firm with the same scope isolate the stochastic components from equation (15) and therefore help identify the dispersion of product appeal shocks (and partly the dispersion of the market-access cost shock).

2. Within-destination and within-firm product sales concentration. We use the second statement in Fact 1 and the ratios between the sales of given lower-ranked products and the sales of the top product to characterize the concentration of sales within firms. The comparison of sales within firms neutralizes a firm's global productivity ranking and eliminates the role of exporter scope as well as destination-specific determinants from equation (15). The within-firm within-destination sales ratios therefore help pin down the scope elasticity of product efficiency $\tilde{\alpha}$ and help identify the dispersion of product appeal shocks.

3. Within-destination exporter scope distribution. We turn to Fact 2 and compute, within destinations, the shares of exporters with certain exporter scopes. For example, we calculate the proportion of exporters to Argentina, shipping three or four products. The frequencies of firms with a given exporter scope help identify the shape parameter $\tilde{\theta}$ of the Pareto firm size distribution (and partly the dispersion of the market-access cost shock) and help pin down the scope cost elasticity $\delta+\tilde{\alpha}$, which translates productivity into exporter scope by equation (14).

4. Market presence combinations. Mirroring similar regularities documented in Eaton, Kortum and Kramarz (2011), we use the frequency of firms shipping to any permutation of Brazil's top five export destinations in LAC and the top five destinations outside of LAC. For example, we target the number of exporters that ship to Argentina and Chile, but not to Bolivia, Paraguay and Uruguay. Matching these market presence patterns helps us identify the dispersion of market-access cost shocks.

5. Within-firm export proportions between destination pairs. It is a widely documented fact that a firm's sales are positively correlated across destinations. For each firm, we pair 
its total sales to a given destination with its sales to Brazil's respective top destination in LAC or outside LAC. The ratio of a firm's total sales to two destinations depends on the firm's respective exporter scopes by equation (16) and therefore helps pin down the scope cost elasticity $\delta+\tilde{\alpha}$. The pairwise sales ratios also help identify the dispersion of product appeal shocks and market access shocks.

\section{III.B Inference}

Inference proceeds as follows. To find an estimate of $\Theta$, we first stack the differences between observed and simulated moments $\Delta \mathbf{m}(\Theta)=\mathbf{m}^{\text {data }}-\mathbf{m}^{\operatorname{sim}}(\hat{\Theta})$.

In the population, the parameter $\Theta_{0}$ satisfies $\mathbb{E}\left[\Delta \mathbf{m}\left(\Theta_{0}\right)\right]=0$, so we search for the $\hat{\Theta}$ that minimizes the weighted sum of squares, $\Delta \mathbf{m}(\Theta)^{\prime} \mathbf{W} \Delta \mathbf{m}(\Theta)$, where $\mathbf{W}$ is a positive semidefinite weighting matrix. In the population, $\mathbf{W}=\mathbf{V}^{-1}$ where $\mathbf{V}$ is the variance-covariance matrix of the moments. The population matrix is unknown, so we use the empirical analogue

$$
\hat{\mathbf{V}}=\frac{1}{N^{\text {sample }}} \sum_{n=1}^{N^{\text {sample }}}\left(\mathbf{m}^{\text {data }}-\mathbf{m}_{n}^{\text {sample }}\right)\left(\mathbf{m}^{\text {data }}-\mathbf{m}_{n}^{\text {sample }}\right)^{\prime}
$$

where $\mathbf{m}_{n}^{\text {sample }}$ are the moments from a random sample drawn with replacement of the original firms in the dataset and $N^{\text {sample }}$ is the number of those draws. ${ }^{24}$ To search for $\hat{\Theta}$ we use a derivative-free Nelder-Mead downhill simplex search. We compute standard errors using a bootstrap method that allows for sampling and simulation error. ${ }^{25}$

\section{III.C Results}

We simulate one million firms so that we obtain approximately thirty-thousand exporters. The number of simulated firms is roughly three times as large as the number of 331,528 actual Brazilian manufacturing firms and 10,215 exporters. We use an excess number of simulated firms to reduce the noise in our simulation draws and smooth out our simulated moments. Our bootstrapped standard errors are based on sampling with replacement from the original set of 10,215 exporters.

To allow for cross-destination variation, we estimate separate scope elasticities of marketaccess costs for LAC destinations $\left(\delta_{\mathrm{LAC}}\right)$ and the rest of the world $\left(\delta_{\mathrm{ROW}}\right){ }^{26}$ Table 3 presents our

\footnotetext{
${ }^{24}$ Currently, we use $N^{\text {sample }}=1,000$. We cannot invert this matrix $\hat{\mathbf{V}}$ because of adding-up constrains. Instead, we take a Moore-Penrose pseudo-inverse.

${ }^{25}$ For the bootstrap we repeat the estimation process 100 times, replacing $\mathbf{~ m}^{\text {data }}$ with $\mathbf{~ m}^{\text {bootstrap sample }}$ to generate standard errors. The bootstrapped standard errors are not centered.

${ }^{26}$ We observe a concentration of exporter presence at specific pairs of destinations within regions. For example,
} 
Table 3: Estimation Results

\begin{tabular}{lrrrrrrr}
\hline & $\delta_{\text {LAC }}$ & $\delta_{\text {ROW }}$ & $\tilde{\alpha}$ & $\tilde{\theta}$ & $\sigma_{\xi}$ & $\sigma_{c}$ & $\delta_{\text {LAC }}-\delta_{\text {ROW }}$ \\
\hline Baseline & -1.17 & -.87 & 1.77 & 1.73 & 1.82 & .58 & -.30 \\
& $(.05)$ & $(.07)$ & $(.05)$ & $(.09)$ & $(.04)$ & $(.02)$ & $(.06)$ \\
No product appeal & -1.41 & -1.18 & 2.42 & 1.00 & & .99 & -.23 \\
$\quad$ shocks $\left(\sigma_{\xi}=0\right)$ & $(.03)$ & $(.05)$ & $(.03)$ & $(.001)$ & & $(.01)$ & $(.04)$ \\
No market access & -1.20 & -.91 & 1.78 & 1.77 & 2.00 & & -.28 \\
$\quad$ cost shocks $\left(\sigma_{c}=0\right)$ & $(.05)$ & $(.08)$ & $(.03)$ & $(.11)$ & $(.03)$ & & $(.05)$ \\
\hline
\end{tabular}

Source: SECEX 2000, manufacturing firms and their manufactured products.

Note: Products at the HS 6-digit level. Standard errors from 100 bootstraps in parentheses. Estimates of $\delta_{\text {LAC }}$ measure the scope elasticity of market-access costs for Brazilian firms shipping to other LAC destinations, $\delta_{\mathrm{ROW}}$ for Brazilian firms shipping to destinations outside LAC.

baseline estimates in the first row. The baseline estimates for $\delta_{\mathrm{LAC}}$ and $\delta_{\mathrm{ROW}}$ are both negative, significantly different from zero, and also significantly different from each other. The negative sign implies that exporting an additional product to a destination is less costly in terms of market-access costs than any previous product. The difference in the estimated scope elasticities between LAC and ROW (non-LAC) destinations means that incremental market-access costs to LAC destinations fall 30 percent faster than incremental market-access costs to the rest of the world. The scope elasticity of production efficiency $\tilde{\alpha}$ is positive and significantly different from zero. The estimate of $\tilde{\alpha}=1.76$ implies that an additional product has more than proportionally higher unit production costs than any infra-marginal product. In both the LAC region and the rest of the world, the scope cost elasticity $\delta_{d}+\tilde{\alpha}$ is strictly positive and implies strictly increasing incremental scope costs (Assumption 1 is therefore empirically satisfied). Overall, the estimates from SMM are similar in broad terms to those from our baseline descriptive data exploration in the preceding section (Table 2) but all coefficients are smaller in absolute magnitude in the current baseline specification.

Our baseline estimate for $\tilde{\theta}$ is statistically significantly above 1 and below 2 (at conventional significance levels). ${ }^{27}$ The baseline estimate of the variance of firm-product appeal shocks $\sigma_{\xi}$ is approximately 2 and implies that, conditional on market-access cost shocks and firm productiv-

exporters to Paraguay frequently also export to Argentina; exporters to the United Kingdom frequently also ship to the United States. However, there is no clear association between exporting to the United Kingdom and Paraguay. In reality, there is a complex set of factors that might connect market-access costs between destinations. For example, customs unions, common markets, shared destination languages, and unified distribution systems could link market-access costs between countries. Our model does not explicitly take those potential connections into account. Instead, we implement a simplification and jointly simulate firms to identify separate moments for LAC export destinations and the rest of the world (ROW).

${ }^{27}$ Estimates of $\tilde{\theta}$ can also be compared to those from Section II.C and are quantitatively similar. 
ity, the ratio of the 75 th firm sales percentile to the 25 th firm sales percentile is over 10 . This large disparity stands in contrast to our baseline estimates for $\sigma_{c}$, which imply that the ratio of the 75 th firm sales percentile to the 25th firm sales percentile is only about 2, far less than 10 . In a model with single-product firms and different sources of heterogeneity, Eaton, Kortum and Kramarz (2011) find $\tilde{\theta} \approx 2.5$, which is larger than our estimate of 1.73 . Their estimate of $\tilde{\theta}$ captures the elasticity of substitution between firms, whereas ours reflects the elasticity of substitution between firm-product varieties. Our estimate of 1.82 for $\sigma_{\xi}$ is close to that in Eaton, Kortum and Kramarz (2011), who find that their firm-specific appeal shock has a variance of 1.69. However, our appeal shock is firm-product specific (not just firm specific), so estimates are not directly comparable.

To explore the implications of our baseline estimates for the sources of variation in firmproduct sales more systematically, we apply a log decomposition to equation (15) at the product level: 28

$$
\ln y_{\omega d g}^{G}=\underbrace{\ln c_{\omega d}+(\sigma-1) \ln \left[\phi_{\omega} / \phi_{d}^{*, G}\left(c_{\omega d}\right)\right]}_{A_{p}}+\underbrace{\left(\delta_{d}+\tilde{\alpha}\right) \ln G_{\omega d}-\tilde{\alpha} \ln g_{\omega}}_{B_{p}}+\underbrace{\ln \xi_{\omega d g}}_{C_{p}} .
$$

For LAC destinations our estimates imply that component $A_{p}$, which reflects the combined market-access costs shock and productivity for firms with identical exporter product scope, accounts for 17 percent of sales variation at LAC destinations. These shocks are exogenous, but known to a firm before it chooses its export profile. Component $B_{p}$, which accounts for both a firm-product's global production rank $g_{\omega}$ as well as the firm's local exporter scope $G_{\omega d}$, explains 37 percent of sales variation. Individual firm-product appeal shocks in component $C_{p}$ account for 50 percent of sales variations in LAC countries (and a negative covariance between $A_{p}$ and $B_{p}$ accounts for the excess prediction of variation). For non-LAC destimations the breakdown is slightly different. There component $A_{p}$ accounts for 19 percent of firm-product sales, component $B_{p}$ for 21 percent, and component $C_{p}$ for the remaining 60 percent (and covariances between components are negligibly small). The disparity between LAC and non-LAC destinations is due to the difference between $\delta_{\mathrm{LAC}}$ and $\delta_{\mathrm{ROW}}$, which for LAC destinations augments the importance of exporter scope and reduces the dependence on individual product appeal shocks.

An interpretation of component $B_{p}$ is that it shows firm-level competency (core competency in a particular firm-product and overall firm capability with regards to exporter scope), whereas component $A_{p}$ reflects idiosyncratic firm heterogeneity, and component $C_{p}$ the randomness of individual product appeal. In summary, product appeal shocks play a dominant role in firm sales. while the combination of firm-level competency and firm heterogeneity accounts for a similarly

\footnotetext{
${ }^{28}$ We standardize firm-product sales by $\sigma f_{d}(1)$ in estimation.
} 
important part of product sales. Our estimates highlight that a reduction in the scope elasticity of incremental market-access costs from their magnitude in non-LAC countries to the magnitude in LAC countries raises the importance of firm-level competency considerably.

Similarly we can run a firm-level decomposition of total sales by firms to a particular destination: 29

$$
\ln t_{\omega d}^{G}=\underbrace{(\sigma-1) \ln \left[\phi_{\omega} / \phi_{d}^{*, G}\left(c_{\omega d}\right)\right]+\left(\delta_{d}+\tilde{\alpha}\right) \ln G_{\omega d}}_{A_{f}}+\underbrace{\ln c_{\omega d}}_{B_{f}}+\underbrace{\ln \sum_{g=1}^{G} \xi_{\omega d g} g_{\omega}^{-\tilde{\alpha}}}_{C_{f}}
$$

Across all destinations, the first component $A_{f}$, which reflects firm-level heterogeneity, accounts for 11 percent of variation. The second component $B_{f}$, which stems from firmdestination heterogeneity, accounts for 5 percent of the firm sales variation. The third component $C_{f}$ captures destination-product heterogeneity and accounts for 60 percent of the firm sales variation (and the remaining firm sales variability, not accounted for by $A_{f}, B_{f}$ or $C_{f}$, is due to positive covariances between the components). By way of comparison, in their model of single-product firms Eaton, Kortum and Kramarz (2011) find that nearly 50 percent of the firm sales variation can be attributed to the destination-specific fixed costs behind $B_{f}$. In contrast, the product channel $C_{f}$ in our model with firm-product-destination shocks attributes much of the apparent firm-level variation to product-specific shocks.

In two departures from our baseline specification, we re-estimate the model dropping one source of heterogeneity at a time. We first omit product appeal shocks, and then drop marketaccess cost shocks. We report the resulting estimates in the second and third rows of Table 3. When we omit product appeal shocks (setting $\sigma_{\xi}=0$ ), the estimated magnitudes of the scope elasticities $\delta_{d}$ and $\tilde{\alpha}$ markedly increase. In addition, the estimated dispersion of market-access costs increases and the estimate of the shape parameter of the Pareto firm size distribution $\tilde{\theta}$ hits the lower bound, implying maximal dispersion in firm sizes. Intuitively, the estimator attempts to compensate for the lacking product-level heterogeneity by raising the cross-firm dispersion with a possibly low Pareto shape parameter and by raising the cross-destination variation through market-access cost dispersion. Those salient changes in parameter estimates underscore the importance of specifying product appeal shocks. ${ }^{30}$ Interestingly, however, the regional difference in the scope elasticity of market-access costs $\hat{\delta}_{L A C}-\hat{\delta}_{R O W}$ remains similar to that under our

\footnotetext{
${ }^{29}$ We again standardize firm-product sales by $\sigma f_{d}(1)$ in estimation.

${ }^{30}$ In the Online Supplement S6 we adopt a limiting parametrization that forces all firms to become single-product exporters, approximating Eaton, Kortum and Kramarz (2011). The limit case results in an estimate of the Pareto shape parameter of 3.8 and a market-access cost variance below that in the baseline. In light of that limit case, the evidence from the multi-product case with no appeal shocks suggests that firm-product-destination data necessitate firm-product-destination heterogeneity for estimation.
} 
baseline estimation. When we omit market-access cost shocks (setting $\sigma_{c}=0$ ), coefficient estimates are affected only in minor ways (and not statistically different from previous estimates), except for the estimated variance of product appeal shocks that now takes on some of the variation that otherwise the market access cost shocks would absorb. ${ }^{31}$

Relating our results back to the findings from Table 2, which were based on simple log linear estimators dropping both sources of heterogeneity (product appeal shocks and marketaccess cost shocks), we find qualitatively similar results. This broad similarity across estimators suggests that both SMM and its simpler counterparts identify comparable principal variation in the data but the quantitative differences indicate the importance of heterogeneity in product appeal and, to some extent, market-access costs.

To assess the sensitivity of our results to potential heterogeneity in product types and heterogeneity in destinations, we repeat estimation for numerous alternative specifications: we demean firm-product sales at the HS 6-digit level by average Brazilian exports at the HS 2-digit level, we restrict the sample to firms in high-tech manufacturing industries, we separate Mercosur member countries from other LAC destinations, and we drop both Argentina and the United States from the sample. We find our estimates broadly confirmed and report the details of the sensitivity exercises in the Online Supplement (S7). To document the properties of our SMM, we also report results from Monte Carlo simulations of our estimator in the Online Supplement S5.

\section{III.D Model fit}

To gauge the fit of our estimates, we plot simulated data using the baseline parameter estimates (from the first row of Table 3) alongside the actual data. We first assess how well we capture features of the data that our simulated moments target directly. Figure 5 shows our targeted moments and illustrates the close fit of our simulated data. The simulated data are depicted with (solid and dashed) lines in Figures 5A and 5B. The simulated data match our Facts 1 and 2 closely as shown with the data plots in individual dots (the data plots replicate those in Figures 2 and 3). Figure 5A presents the within-firm distribution of product sales in Argentina for firms with different exporter scopes. Figure 5B shows the exporter scope distributions, averaging over the five most common destinations in the LAC and ROW (non-LAC) regions.

\footnotetext{
${ }^{31} \mathrm{We}$ cannot compare the goodness of fit in meaningful ways across specifications because the moments used under the restrictions differ from the baseline estimation. For $\sigma_{\xi}=0$, we have to limit the set of moments 2 to the median because there is no variation by percentile in the simulation. For $\sigma_{c}=0$, we have to exclude the set of moments 4 and 5. Those caveats notwithstanding, we find an almost hundred-fold increase in the SMM criterion function when setting $\sigma_{\xi}=0$, and a ten-fold increase when setting $\sigma_{c}=0$. The markedly worse fit of the model, especially when omitting product-destination appeal shocks, speaks to the importance of those sources of heterogeneity for the empirical specification.
} 
Figure 5: Fit of Targeted Moments

\section{(A) Firm-product Sales Distribution}

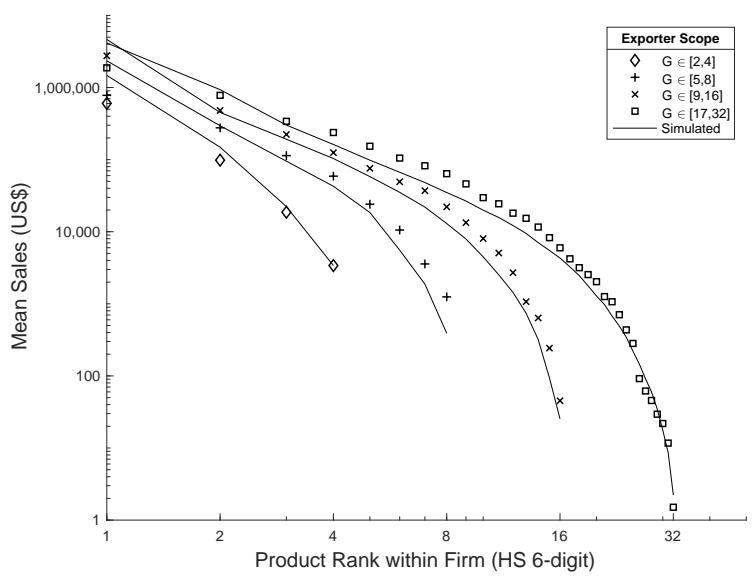

(B) Exporter Scope Distribution

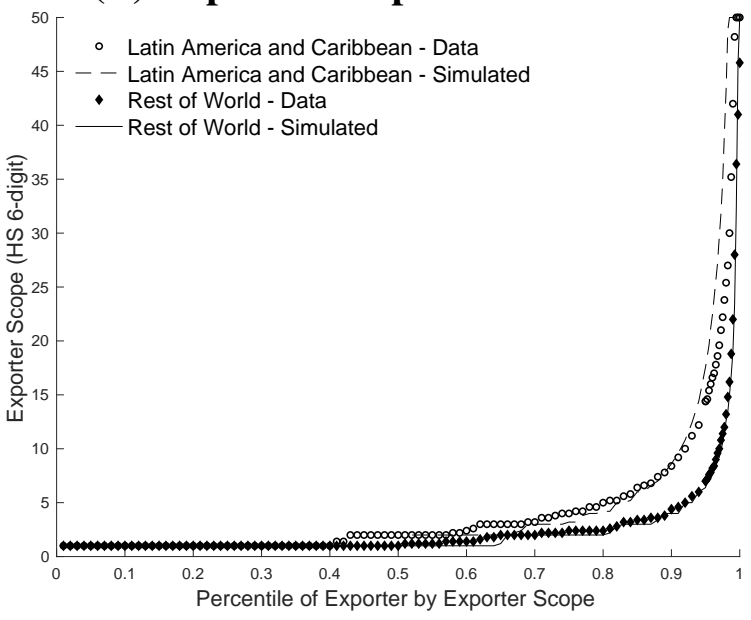

Source: SECEX 2000, manufacturing firms and their manufactured products.

Note: Products at the HS 6-digit level. Panel A replicates Figure 2 and panel B Figure 3. Predicted curves based on simulations in Section D.A, using the baseline parameter estimates in Table 3. Panel A shows shipments to Argentina, grouping firms by their local exporter scope and firm-products by their local sales rank. Panel B shows the exporter scope by percentile, averaged across the five most common destinations within each of the two regions LAC and Rest of World (non-LAC).

Figure 6: Fit of Non-Targeted Moments

(A) Exporter Scope and Scale

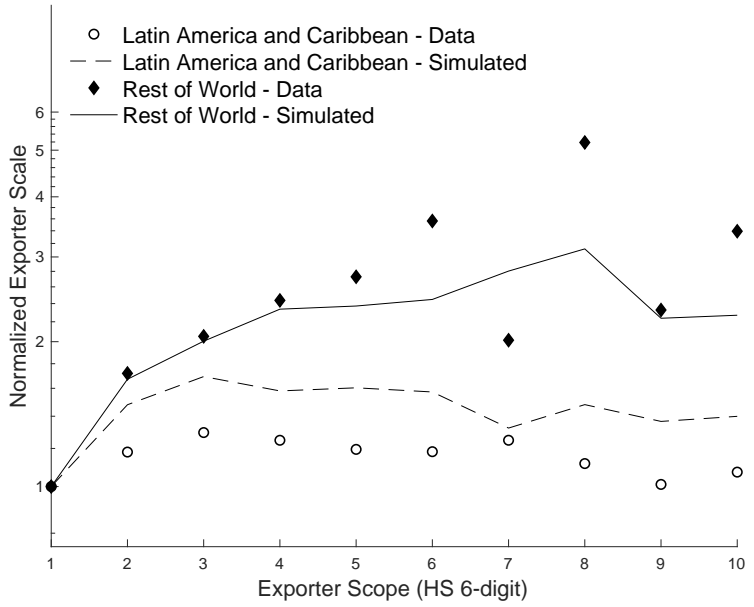

(B) Export Sales Distribution

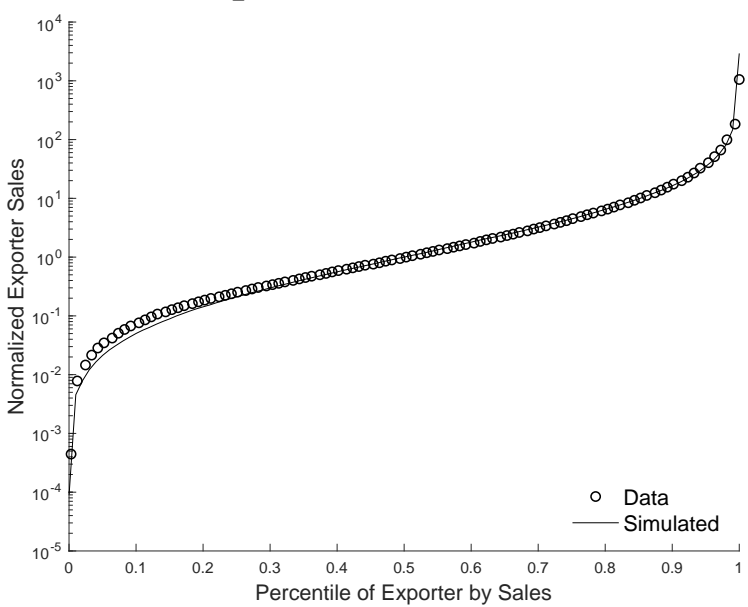

Source: SECEX 2000, manufacturing firms and their manufactured products.

Note: Products at the HS 6-digit level. Panel A replicates Figure 4 and shows exporter scale (a firm's total sales at a destination divided by its exporter scope at the destination) on a log scale plotted against exporter scope, averaging a variable over the five most common destinations within each of the two regions LAC and Rest of World (non-LAC) and normalizing scale by the average total sales of single-product exporters at the destination. Predicted curves based on simulations in Appendix D.A, using the baseline parameter estimates in Table 3. Panel B shows total firm exports by percentile, averaging a firm's total exports over the five most common destinations within each of the two regions and normalizing total sales by the median firm's total at the destination. 
We now turn to regularities in the data that our simulated moments in the estimation routine did not target. We deliberately excluded from our estimation any moments that relate to Fact 3. As Figure 6A documents, our simulated firms (shown with dashed and solid lines) nevertheless line up with the observed data (shown with dots that replicate Figure 4). Our estimates pinpoint clearly different scale-scope relationships between LAC destinations and ROW (non-LAC) destinations. Figure 6B plots the distribution of total sales by percentile within destinations. Our estimation routine includes simulated moments that relate to the distribution of sales across firm-products (within firms), to the distribution of exporter scope (within destinations), and to the proportion of total sales between pairs of destinations (within firms). None of those moments fully captures the distribution of total sales across firms (within destinations) because sales depend on all three sources of stochastic variation in the model: firm productivity, market-access cost draws and product appeal shocks. Even though our SMM estimator did consequently not fully target the total sales distribution, Figure 6B documents that we find a close fit between our simulated firms and the data.

\section{III.E Policy relevance}

In our model, fixed costs of exporting $G$ products to destination $d$ take the form of equation (5), which depends on both the fixed cost of introducing the first product at an export market $f_{d}(1)$ and the elasticity of additional products' fixed costs with respect to exporter scope $\delta_{d}$. We take our estimates for $\sigma, \theta$, and $\alpha$ and minimize deviations between the model and data to find the set of $\delta_{d}$ that best match our empirical moments for each destination country reached by 60 or more Brazilian exporters. This procedure yields $\delta_{d}$ estimates for 74 countries.

To evaluate the policy relevance of the $f_{d}(1)$ and $\delta_{d}$ estimates, we study the extent to which they are correlated with policy variables or lasting geographic and economic factors. For this purpose, we revisit our measures of the share of HS 6-digit product lines covered by a core NTM from Section II and take the unweighted country-level mean at destination $d: N T M_{d} \equiv$ $\sum_{j \in \mathbb{J}} N T M_{j d} /|\mathbb{J}|$. This NTM proxy varies between zero and one and reflects the share of HS-6 product lines with at least one core NTM that any exporter to the destination faces on average. Similarly for the tariff controls, we use the arithmetic mean of the log of one plus the import tariffs at the destination country level for Brazil as the source country. From the CEPII gravity database we use further bilateral and multilateral variables for Brazil as the source country in the year 2000: the destination's distance to Brazil, as well as destination population, destination gross domestic product (GDP), and destination area. To capture policy relevant regional characteristics more closely than a geographic dummy such as for LAC can, we use an indicator for Mercosur countries. Mercosur is Brazil's main preferential trade agreement in 2000. We define 
Table 4: Market-access Costs, NTMs, and Geography

\begin{tabular}{lcccccc}
\hline & $f_{d}(1)$ & $f_{d}(1)$ & $f_{d}(1)$ & $\delta_{d}$ & $\delta_{d}$ & $\delta_{d}$ \\
\hline mean NTM $_{d}$ & -.528 & -1.110 & .0345 & -.480 & -.486 & -.418 \\
& $(.964)$ & $(.943)$ & $(.339)$ & $(.160)$ & $(.176)$ & $(.188)$ \\
mean Log (1+Tariff) $)_{\mathrm{BRA}, d}$ & & -.250 & -.0720 & & -.0155 & .00749 \\
& & $(.0684)$ & $(.0762)$ & & $(.0105)$ & $(.0129)$ \\
Mercosur $_{d}$ & & & -.0427 & & & -.0763 \\
& & & $(.384)$ & & & $(.0584)$ \\
Log Distance $_{\mathrm{BRA}, d}$ & & & -.276 & & & -.101 \\
& & & $(.146)$ & & & $.0730)$ \\
Log Population $_{d}$ & & & .265 & & & .00383 \\
& & & $.132)$ & & & $(.0420)$ \\
Log GDP $_{d}$ & & & $(.0793)$ & & & .0495 \\
& & & -.123 & & & $-.0234)$ \\
Log Area $_{d}$ & 13.50 & 14.02 & $(.0618)$ & & & $(.0296)$ \\
Constant & $(.384)$ & $(.410)$ & $(1.670$ & -1.003 & -.998 & -.278 \\
& 54 & 54 & 53 & 46 & 46 & 45 \\
Observations $_{R^{2}}$ & .009 & .187 & .836 & .143 & .143 & .240 \\
\hline
\end{tabular}

Sources: SECEX 2000, manufacturing firms and their manufactured products (estimates of $f_{d}(1)$ and $\delta_{d}$ ); UNCTAD TRAINS 1999-2001 as augmented by Kee, Nicita and Olarreaga (2009) for NTM proxy; WTO's Integrated Database 2000 for import tariff rates; CEPII 2000.

Notes: Destination-country aggregates over products at the HS 6-digit level. Standard errors in parentheses $(: p<.05,: p<.01,: p<.001)$.

Mercosur to include only the original members Argentina, Paraguay and Uruguay (and Brazil) from 1994.32

Table 4 reports results from regressions of $f_{d}(1)$ and $\delta_{d}$ on the NTM proxy, on the mean of the log of one plus the tariff rate, and on geography controls. The NTM proxy is not a statistically significant predictor of firms' destination-specific market-access cost $f_{d}(1)$ for their first product (their initial entry cost), regardless of regression specification. In a short regression, with only the NTM proxy and import tariffs as regressors, lower tariffs at the destination predict higher initial entry cost $f_{d}(1)$, but that association is potentially spurious given omitted geographic variables. In a long regression that also controls for destination-country characteristics, import tariffs are no longer statistically significant predictors, while higher GDP predicts higher

\footnotetext{
${ }^{32}$ We exclude the Mercosur associates Chile from 1996 and Bolivia from 1997 because those countries were not full members in 2000. Bolivia is in an accession process since 2012, while Chile never requested membership. Brazil is also part of ALADI (Asociación Latinoamericana de Integración), which seeks to foster trade throughout Latin America since 1980, but there was no substantive progress in harmonizing NTMs by 2000.
} 
initial market-entry cost $f_{d}(1)$. An interpretation is that Brazil's exporters face higher marketaccess cost for their first product in more industrialized countries (where import tariffs tend to be relatively low).

There is little prior evidence on predictors of firm-level market access cost, and the little evidence is mixed. Eaton, Kortum and Kramarz (2011) infer from French data patterns that entry cost rise systematically but less than proportionally with market size, reminiscent of the positive association between GDP and $f_{d}(1)$ in our Brazilian data. For one particular market access cost component, the cost of reaching consumers through advertising, Arkolakis (2010, online data appendix) reports that the cost of reaching additional consumers in a market falls with the population of the market. Conditional on GDP, we cannot find a statistically significant relation between population and $f_{d}(1)$. Irarrazabal, Moxnes and Opromolla (2015) fail to find a significant association between variable transport cost and destination GDP, whereas the WTO (2012) reports that the relative contribution of trade barriers to the overall level of protection tends to increase with GDP per capita. For our subsequent analysis and simulations we infer from our evidence, and mixed prior results, that initial entry cost $f_{d}(1)$ are not clearly associated with policy-related variables.

In contrast, the scope-elasticity of market-access costs $\delta_{d}$ is strongly and statistically significantly related to the NTM proxy (at conventional significance levels). Even after controlling for a destination country's import tariffs (which are not statistically significant at conventional levels) and GDP (which is a statistically significant predictor), there is a salient and significant negative relationship between the prevalence of NTMs in a destination country and the scopeelasticity of Brazilian exporter's market-access cost. The negative sign is consistent with the interpretation that, in a destination with many NTMs, exporters face a more convex market-access cost schedule that discourages the entry of additional products more strongly than at a destination with few NTMs. Strikingly, the scope-elasticity of market-access costs is not significantly related to import tariffs conditional on the presence of NTMs (even though bilateral Brazilspecific import tariffs abroad are arguably more precisely measured than the destination-level NTM proxies). We take these findings as evidence that policy-related foreign market conditions, beyond conventional tariffs, shape the differences between market-access cost schedules across destinations and proceed to study the impact of reducing market-access barriers.

\section{Aggregation and Equilibrium}

To aggregate the model we specify a Pareto distribution of firm productivity following Helpman, Melitz and Yeaple (2004) and Chaney (2008). This assumption yields convenient functional 
forms that are independent of our other assumptions on the specific functional forms of marketaccess costs and the marginal cost schedule in equation (6), and the distribution of cost shocks and product appeal shocks. We specify the cumulative distribution function $\operatorname{Pr}=1-\left(b_{s}\right)^{\theta} / \phi^{\theta}$ over the support $\left[b_{s},+\infty\right)$, where $\theta$ is the Pareto shape parameter, common across all source countries, and more advanced countries are thought to have a higher location parameter $b_{s}$. The shape parameter of the Pareto firm size distribution is $\tilde{\theta} \equiv \theta /(\sigma-1)$. In Appendix $\mathrm{F}$ (and in Online Supplement S8) we discuss an alternative setup where firm productivity is drawn from a log-normal distribution.

The resulting conditional probability density function of the distribution of entrants is then

$$
\mu\left(\phi \mid \phi_{s d}^{*}, \theta\right)=\left\{\begin{array}{cl}
\theta\left(\phi_{s d}^{*}\right)^{\theta} / \phi^{\theta+1} & \text { if } \phi \geq \phi_{s d}^{*} \\
0 & \text { otherwise }
\end{array}\right.
$$

We use the shorthand $\phi_{s d}^{*}$ for the productivity cutoff but note that $\phi_{s d}^{*}\left(c_{d}\right)$ depends on a firm's access cost realization by (10). Integrating over the density of the market-access cost distribution, we obtain $M_{s d}$, the measure of firms that sell to destination $d$ from source country $s$

$$
M_{s d}=\kappa \frac{J_{s} b_{s}^{\theta}}{\left[f_{s d}(1) / D_{s d}\right]^{\tilde{\theta}}}
$$

by (10). The parameter

$$
\kappa \equiv \int_{c_{d}} c_{d}^{-\tilde{\theta}} \mathrm{d} F\left(c_{d}\right)
$$

reflects the expected access deterring effect of the firm-destination specific market-access cost component $c_{d}$ on the mass of active exporters at a destination.

We denote aggregate bilateral sales from country $s$ to $d$ with $T_{s d}$. The corresponding average expected sales per firm are defined as $\bar{T}_{s d}$, so that $T_{s d}=M_{s d} \bar{T}_{s d}$ and

$$
\bar{T}_{s d} \equiv \int_{c_{d}} \bar{T}_{s d}\left(c_{d}\right) \mathrm{d} F\left(c_{d}\right)
$$

where $\bar{T}_{s d}\left(c_{d}\right)$ is the mean expected sales per firm for a given market-access cost draw $c_{d}$. Similarly, we define average market-access costs as

$$
\bar{F}_{s d} \equiv \int_{c_{d}} \bar{F}_{s d}\left(c_{d}\right) \mathrm{d} F\left(c_{d}\right)
$$

where $\bar{F}_{s d}\left(c_{d}\right)$ is the mean market-access cost for a given draw $c_{d \cdot}{ }^{33}$

\footnotetext{
${ }^{33} \bar{T}_{s d}\left(c_{d}\right)$ and $\bar{F}_{s d}\left(c_{d}\right)$ follow from integrating over firm productivity conditional on exporting.
} 
For aggregation we require the following two assumptions to hold, so that sales per firm are positive and finite.

Assumption 2 (Pareto probability mass in low tail). The Pareto shape parameter satisfies $\tilde{\theta}>$ 1.

Assumption 3 (Bounded market-access costs and product efficiency). Incremental marketaccess costs and product efficiency satisfy $\sum_{G=1}^{\infty} f_{s d}(G)^{-(\tilde{\theta}-1)} h(G)^{-\theta} \in(0,+\infty)$.

Lemma 1 Suppose Assumptions 1, 2 and 3 hold. Then for all $s, d \in\{1, \ldots, N\}$, average sales per firm are a constant multiple of average market-access costs:

$$
\bar{T}_{s d}=\frac{\tilde{\theta} \sigma}{\tilde{\theta}-1} \bar{F}_{s d}
$$

Proof. See Appendix A.A.

Despite our rich micro-foundations at the firm-product level and idiosyncratic shocks by destination, in the aggregate the share of market-access costs in bilateral exports $\bar{F}_{s d} / \bar{T}_{s d}$ only depends on parameters $\theta$ and $\sigma$, while mean market-access costs $\bar{F}_{s d}$ vary by source and destination country. Bilateral average sales can be summarized with a function only of the parameters $\theta$ and $\sigma$ and the properties of mean market-access costs $\bar{F}_{s d}$.

Finally, we can use the measure of exporters $M_{s d}$ from equation (19), expression (22) for average sales and the definition of the revenue shifter $D_{s d}$ in (7) to derive the share of products from country $s$ in country $d$ 's expenditure:

$$
\lambda_{s d}=\frac{M_{s d} \bar{T}_{s d}}{\sum_{k} M_{k d} \bar{T}_{k d}}=\frac{J_{s}\left(b_{s}\right)^{\theta}\left(w_{s} \tau_{s d}\right)^{-\theta} f_{s d}(1)^{-\tilde{\theta}} \bar{F}_{s d}}{\sum_{k} J_{k}\left(b_{k}\right)^{\theta}\left(w_{k} \tau_{k d}\right)^{-\theta} f_{k d}(1)^{-\tilde{\theta}} \bar{F}_{k d}},
$$

where $f_{s d}(1)^{-\tilde{\theta}} \bar{F}_{s d}=\sum_{G=1}^{\infty} f_{s d}(G)^{-(\tilde{\theta}-1)} h(G)^{-\theta}$ by Lemma 1 (see equation (A.3) in Appendix A.A). Our framework generates a bilateral gravity equation. As in Eaton and Kortum (2002) and Chaney (2008), the elasticity of trade with respect to variable trade costs is $-\theta .{ }^{34}$ The difference between our model, in terms of bilateral trade flows, and the framework of Eaton and Kortum (2002) is that market-access costs influence bilateral trade similar to Chaney (2008) in the aggregate. At the firm-product level, however, our framework provides rigorously quantifiable foundations for the relevant market-access costs. The gravity relationship (23) clarifies how those micro-founded market-access cost components relate to aggregate bilateral trade through

\footnotetext{
${ }^{34}$ In our model, as in Chaney (2008), the elasticity of trade with respect to trade costs is the negative Pareto shape parameter, whereas it is the negative Fréchet shape parameter in Eaton and Kortum (2002).
} 
the weighted $\operatorname{sum} \sum_{G=1}^{\infty} f_{s d}(G)^{-(\tilde{\theta}-1)} h(G)^{-\theta}$. We thus offer a tool to evaluate the responsiveness of overall trade to changes in individual market-access cost components.

The partial elasticity $\eta_{\lambda, f(g)}$ of trade with respect to a product $g$ 's access cost component is $-(\tilde{\theta}-1)$ times the product's share $h(g)^{-\theta}$ in the weighted sum. To assess the relative importance of the extensive margin of product entry, relative to firm entry with the core product, we can compare elasticities using the ratio

$$
\frac{\eta_{\lambda, f(g)}}{\eta_{\lambda, f(1)}}=\frac{f_{s d}(g)^{-(\tilde{\theta}-1)} h(g)^{-\theta}}{f_{s d}(1)^{-(\tilde{\theta}-1)}}
$$

This ratio simplifies to the function $g^{-\delta_{s d}(\tilde{\theta}-1)-\alpha \theta}$ in our parametrization. The power is strictly negative if and only if $\delta_{s d}+\tilde{\alpha}>\delta_{s d} / \tilde{\theta}$. It therefore depends on the sign and magnitude of $\delta_{s d}$ whether the elasticity of trade with respect to an additional product's incremental market-access cost is higher or lower than the elasticity of firm entry.

We can also compute mean exporter scope in a destination. For the average number of products to be finite we will need the following necessary assumption.

Assumption 4 (Strongly increasing combined incremental scope costs). Combined incremental scope costs satisfy $\sum_{G=1}^{\infty} z_{s d}\left(G, c_{d}\right)^{-\tilde{\theta}} \in(0,+\infty)$.

This assumption is in general more restrictive than Assumption 1. It requires that combined incremental scope costs $Z(G)$ increase in $G$ at a rate asymptotically faster than $1 / \tilde{\theta}$ (a result that follows from the ratio rule, see Rudin 1976, ch. 3). Mean exporter scope in a destination is ${ }^{35}$

$$
\bar{G}_{s d}=\kappa f_{s d}(1)^{\tilde{\theta}} \sum_{G=1}^{\infty} z_{s d}(G)^{-\tilde{\theta}}
$$

For our parameterized example, the expression implies that mean exporter scope is invariant to destination market size. ${ }^{36}$

\footnotetext{
${ }^{35}$ The expression is derived (omitting firm access cost $f_{s d}(1)$ and integration over $c_{d}$ for brevity) using
}

$$
\bar{G}_{s d}=\int_{\phi_{s d}^{*}} G_{s d}(\phi) \theta \frac{\left(\phi_{s d}^{*}\right)^{\theta}}{(\phi)^{\theta+1}} \mathrm{~d} \phi=\left(\phi_{s d}^{*}\right)^{\theta} \theta\left[\int_{\phi_{s d}^{*}}^{\phi_{s d}^{*, 2}} \phi^{-(\theta+1)} \mathrm{d} \phi+\int_{\phi_{s d}^{*, 2}}^{\phi_{s d}^{*, 3}} 2 \phi^{-(\theta+1)} \mathrm{d} \phi+\ldots\right] .
$$

Completing the integration, rearranging terms and using equation (11), we obtain (25), where we use the shorthand $z_{s d}(G) \equiv z_{s d}\left(G, c_{d}\right) / c_{d}=f_{s d}(G) h(G)^{\sigma-1}$.

${ }^{36}$ To directly test that mean exporter scope is largely unresponsive to destination market size we present this relationship in Figure B.2 (Appendix B.A). This implication as well as the robust scope and sales distributions are related to the Pareto assumption. Another implication of the Pareto assumption is that the relationship between the number of exporters shipping to a destination and the destination market size becomes linear in logs-a salient feature of both our Brazilian and French exporter data (Eaton, Kortum and Kramarz 2004). 
Table 5: Parametric Functional Forms

\begin{tabular}{ll}
\hline Assumption & Parameter values \\
\hline 1. Strictly increasing combined incremental scope costs & $\delta_{s d}+\tilde{\alpha}>0$ \\
2. Pareto probability mass in low tail & $\tilde{\theta}>1$ \\
3. Bounded market-access costs & $\delta_{s d}+\tilde{\alpha}>\left(\delta_{s d}+1\right) / \tilde{\theta}$ \\
4. Strongly increasing combined incremental scope costs & $\delta_{s d}+\tilde{\alpha}>1 / \tilde{\theta}$ \\
\hline
\end{tabular}

Note: Functional forms $f_{s d}(g)=f_{s d} \cdot g^{\delta_{s d}}$ and $h(g)=g^{\alpha}$ by (6); definitions $\tilde{\alpha} \equiv \alpha(\sigma-1)$ and $\tilde{\theta} \equiv \theta /(\sigma-1)$.

We turn to the model's equilibrium. Total sales of a country $s$ equal its total sales across all destinations (including domestic sales):

$$
Y_{s}=\sum_{k=1}^{N} \lambda_{s k} T_{k}
$$

where $T_{k}$ is consumer expenditure at destination $k$. Additionally, Lemma 1 implies that a country's total expense for market-access costs is a constant (source country invariant) share of bilateral exports. This result implies that the share of wages and profits in total income is constant (source country invariant) and given by

$$
w_{s} L_{s}=\frac{\tilde{\theta} \sigma-1}{\tilde{\theta} \sigma} Y_{s} \quad \text { and } \quad \pi_{s} L_{s}=\frac{1}{\tilde{\theta} \sigma} Y_{s} .
$$

See Appendix A.B for a derivation.

Assumptions 1 through 4 guarantee that the quantitative predictions in equations (14)-(15) are well defined. Table 5 reports the equivalent parameter restrictions of those necessary assumptions under our functional forms (6). ${ }^{37}$ We relate these predictions to empirical regularities in Section II and to the structural equations for estimation in Section III. As above, we define $\tilde{\alpha} \equiv \alpha(\sigma-1)$ and $\tilde{\theta} \equiv \theta /(\sigma-1)$ to simplify notation.

This summary concludes the presentation of equilibrium conditions when trade is balanced $\left(Y_{d}=T_{d}\right)$. We relax the assumption of balanced trade in our calibration and defer the discussion of the full solution to Appendix E.

\footnotetext{
${ }^{37}$ Assumption 4 implies Assumption 1 but it depends on the sign of $\delta_{s d}$ whether Assumption 3 implies Assumption 1 (or Assumption 4). The necessary conditions for equilibrium existence can be summarized compactly with

$$
\min \left\{\delta_{s d}(\tilde{\theta}-1), \delta_{s d} \tilde{\theta}\right\}+\alpha \theta>1 \text { and } \tilde{\theta}>1 .
$$

By parametrization (6), the combined market-access cost function $f_{s d}(1)^{-\tilde{\theta}} \bar{F}_{s d}(\nu) \equiv f_{s d}(1)^{\tilde{\theta}-1} \sum_{G=1}^{\infty} G^{-\nu}$ contains a Riemann zeta function $\zeta(\nu) \equiv \sum_{G=1}^{\infty} G^{-\nu}$ for a real parameter $\nu \equiv \tilde{\theta}\left[\delta_{s d}+\tilde{\alpha}\right]+\delta_{s d}$.
} 


\section{General-equilibrium Counterfactuals}

We counterfactually bring down destination-specific market-access costs and conduct simulations to quantify the implied impact on bilateral trade under our baseline estimates (first row of Table 3). As mentioned before, Brazil is close to the world median in terms of exports per capita, so we consider our baseline parameter estimates as informative for global trade. Our main counterfactual exercise harmonizes market-access cost schedules across destinations. We reduce the market-access cost for an additional product (not counting a firm's first product) at distant destinations to the level at nearby destinations. In a broad sense, this exercise helps apprise the importance of multi-product exporters when it comes to the reduction of market-access costs for additional products. Examples of relevant market-access costs for additional products are health regulations and safety standards, certifications and licenses.

To perform the counterfactual experiments, we add three elements to our model, similar to Eaton, Kortum and Kramarz (2011). (i) We introduce intermediate inputs as in Eaton and Kortum (2002). In particular, we assume that the production of each product uses a CobbDouglas aggregate of labor and a composite of all other manufactured products with cost $P_{d}$. The labor share in manufacturing production is $\beta$, and the share of intermediate inputs $1-\beta$. The total input cost is therefore $w_{d}=W_{d}^{\beta} P_{d}^{1-\beta}$, where we now think of $w_{d}$ as the input cost and $W_{d}$ as the wage. (ii) There is a non-manufacturing sector in each country as in Alvarez and Lucas (2007) that combines manufactures with labor, in a Cobb-Douglas production function, where manufactures have a share $\gamma$ in GDP. The price of final output in country $d$ is proportional to $P_{d}^{\gamma} W_{d}^{1-\gamma}$. We state the resulting equations in Appendix A. (iii) We allow for a manufacturing trade deficit $B_{d}$, and for an overall trade deficit $B_{d}^{T}$ in goods and services. Both deficits are set to their observed levels in 2000.

We compute the share of manufacturing in GDP for each country using data on GDP, manufacturing production and trade (as described in Appendix B.B). We set the labor share in manufacturing production to $\beta=.330$, the sample average for countries with available information (Appendix B.B). To compute the impact of a counterfactual change in market-access costs, we use the Dekle, Eaton and Kortum (2007a) methodology (details in Appendix E). The merit of this method is that it requires no information on the initial level of technology, iceberg trade costs, and market-access costs. Instead, we can compute the changes in all equilibrium variables using the percentage change in the underlying parameter of interest (market-access cost parameters in our case).

For our primary results we consider a baseline value of $\theta=2.59$ from Crozet and Koenig 
Table 6: Percentage Change in Simulated Welfare $(\theta=2.59)$

\begin{tabular}{|c|c|c|c|c|c|c|c|c|c|}
\hline \multirow[b]{3}{*}{ Country } & \multicolumn{4}{|c|}{ Counterfactual } & \multirow[b]{3}{*}{ Country } & \multicolumn{4}{|c|}{ Counterfactual } \\
\hline & (1) & (2) & (3) & (4) & & (1) & (2) & (3) & (4) \\
\hline & $\Delta f(g)$ & $\Delta f(g)_{C}$ & $\Delta \delta$ & $\Delta \delta_{C}$ & & $\Delta f(g)$ & $\Delta f(g)_{C}$ & $\Delta \delta$ & $\Delta \delta_{C}$ \\
\hline Armenia & .75 & .51 & .84 & .57 & Kuwait & 2.68 & 1.52 & 2.99 & 1.69 \\
\hline Australia & 1.29 & .76 & 1.44 & .85 & Kyrgyzstan & 1.46 & .88 & 1.63 & .98 \\
\hline Austria & 2.72 & .71 & 3.03 & .80 & Latvia & 2.14 & .43 & 2.38 & .49 \\
\hline Azerbaijan & 1.31 & .69 & 1.47 & .77 & Lithuania & 2.12 & .46 & 2.37 & .52 \\
\hline BelgmLuxNthl & 3.82 & 1.37 & 4.26 & 1.53 & Malta & 5.30 & 2.27 & 5.92 & 2.54 \\
\hline Bolivia & 1.09 & .58 & 1.22 & .64 & Mexico & 2.62 & .54 & 2.91 & .60 \\
\hline Brazil & .68 & .64 & .76 & .71 & Morocco & 1.61 & 1.50 & 1.80 & 1.67 \\
\hline Bulgaria & 1.95 & .68 & 2.17 & .76 & Norway & 1.88 & .59 & 2.10 & .66 \\
\hline Canada & 2.83 & .49 & 3.16 & .55 & Oman & 2.74 & 2.80 & 3.06 & 3.12 \\
\hline Chile & 1.52 & 1.39 & 1.70 & 1.56 & Poland & 1.91 & .57 & 2.13 & .64 \\
\hline ChinaHKG & 1.78 & 1.06 & 1.99 & 1.19 & Portugal & 2.13 & .50 & 2.38 & .56 \\
\hline Colombia & .88 & .80 & .98 & .89 & Romania & 2.15 & .64 & 2.40 & .71 \\
\hline CostaRica & .66 & .43 & .74 & .48 & RussianFed & 2.20 & 1.15 & 2.45 & 1.28 \\
\hline Cyprus & 2.95 & 1.38 & 3.29 & 1.54 & Senegal & 1.52 & 1.16 & 1.70 & 1.29 \\
\hline Ethiopia & .81 & .60 & .90 & .67 & Slovenia & 3.50 & .93 & 3.90 & 1.04 \\
\hline Finland & 2.21 & .76 & 2.46 & .85 & SouthKorea & 1.89 & 1.02 & 2.11 & 1.14 \\
\hline FranceMonaco & 1.77 & .61 & 1.97 & .68 & Spain & 1.73 & .50 & 1.93 & .56 \\
\hline Germany & 1.93 & .79 & 2.15 & .88 & SriLanka & .76 & .26 & .85 & .30 \\
\hline Hungary & 4.68 & 1.32 & 5.22 & 1.47 & Sweden & 2.02 & .71 & 2.26 & .80 \\
\hline IndMalSgThai & 5.10 & 2.98 & 5.68 & 3.32 & TrinidadTbg & .67 & .32 & .75 & .36 \\
\hline India & 2.09 & 1.35 & 2.34 & 1.51 & Tunisia & 2.73 & 2.60 & 3.05 & 2.90 \\
\hline Iran & .15 & .06 & .17 & .07 & Turkey & 1.23 & 1.02 & 1.37 & 1.14 \\
\hline Ireland & 5.03 & 1.99 & 5.60 & 2.23 & UK & 1.62 & .76 & 1.81 & .85 \\
\hline Israel & 1.64 & 1.35 & 1.83 & 1.51 & USA & .89 & .59 & .99 & .66 \\
\hline Italy & 1.49 & .52 & 1.66 & .58 & Ukraine & 1.68 & .46 & 1.87 & .51 \\
\hline Japan & .50 & .32 & .56 & .35 & Uruguay & .97 & .68 & 1.09 & .75 \\
\hline Jordan & 1.80 & 1.17 & 2.01 & 1.30 & VietNam & 2.58 & .79 & 2.88 & .88 \\
\hline Kazakhstan & 2.04 & 1.46 & 2.27 & 1.63 & Yemen & 1.05 & .57 & 1.17 & .64 \\
\hline \multirow[t]{2}{*}{ Kenya } & 1.31 & 1.02 & 1.46 & 1.13 & RestOfWorld & 4.73 & 4.94 & 5.28 & 5.51 \\
\hline & & & & & Mean & 2.02 & 1.02 & 2.26 & 1.13 \\
\hline
\end{tabular}

Note: Counterfactual experiments (1) and (2) reduce $f(g)$ by 15 percent, and experiments (3) and (4) reduce $\delta$ by thirty percent. Counterfactual experiments (1) and (3) reduce market-access costs everywhere, experiments (2) and (4) reduce market-access costs only at destinations outside a source country's own continent, with ROW treated as a different continent. Experiments use baseline parameter estimates of $\Theta=\{\delta, \tilde{\alpha}, \tilde{\theta}\}=$ $\{-1.16,1.76,1.72\}$ from Table 3. Pareto shape parameter $\theta=2.59$ imputed from Crozet and Koenig (2010) and estimates in Table 3. See Appendix B.B for data construction. Following Dekle, Eaton and Kortum (2007a), we collapse (i) Hong Kong, Macao and mainland China, (ii) Belgium, Luxembourg and the Netherlands, (iii) Indonesia, Malaysia, Singapore, and Thailand and (iv) France and Monaco into single markets. 
(2010), which we obtain by averaging across 34 industries. ${ }^{38}$ For all other starting parameter values, we use our baseline estimates from row 1 in Table 3 .

\section{V.A Changes in total market-access costs}

We initially decrease all market-access costs for all products $\left(f_{d}\right)$ by 15 percent to all international destinations. In this and all following experiments, we do not change any domestic trade costs and set the change in total domestic access costs to $\hat{F}_{s s}=1$. Table 6 shows the results of the counterfactual exercise in terms of changes in welfare (see Appendix E for derivations). The results of the first experiment are labeled as counterfactual (1) in Table 6.

In a second experiment, we reduce market-access costs only to countries not on the same continent by 15 percent. The results are shown as counterfactual (2) in Table 6 . This experiment, while crude, highlights changes in market-access costs to distant locations. ${ }^{39}$ In both exercises, we see significant increases in welfare. Considering a simple average across all 58 countries in our sample, welfare increases by 2.0 percent in the first counterfactual experiment and by 1.0 percent in the second counterfactual experiment.

\section{V.B Changes in incremental market-access costs}

In our third and fourth counterfactual experiments we evaluate scenarios under which marketaccess costs only for incremental products are brought down. This counterfactual stands in for eliminating various non-tariff measures and directly utilizes our baseline results from Table 3. Those baseline results show that the incremental market-access costs of shipping additional products to LAC destination drop nearly 30 percent faster with exporter scope than the incremental market-access costs elsewhere. We conduct a counterfactual experiment with a 30percent drop in the scope elasticity of market-access costs. Since $\delta$ is negative, the experiment amounts to a 30-percent increase in the absolute value of $\delta$. Note that we do not alter the cost of a firm's initial market entry with its first product. This 30-percent increase in the absolute value of $\delta$ is applied to all destinations in counterfactual (3) but only to destinations in other continents, which proxy for distant countries, in counterfactual (4).

In both counterfactual experiments (3) and (4) we see results broadly in line with those from dropping overall market-access costs. Dropping the incremental export costs to all foreign

\footnotetext{
${ }^{38}$ Crozet and Koenig (2010) obtain results for $\sigma$, we obtain $\theta$ using our estimated value for $\tilde{\theta}$. Eaton, Kortum and Kramarz (2011) find an estimate of $\theta=4.87$. In a related set of models, Eaton and Kortum (2002), Bernard et al. (2003) and Simonovska and Waugh (2014) find estimates of $\theta$ between 3.60 and 8.28.

${ }^{39}$ While lumping countries by continents is an admittedly imprecise way of classifying nearby and distant locations, most preferential trade agreements in 2000 link countries within continents (78 percent of the country pairs within a preferential trade agreement) or World Bank regions (82 percent of the country pairs).
} 
destinations increases average welfare by 2.3 percent and to destinations on different continents by 1.1 percent. While these increases in welfare may seem small, they operate only through multi-product firms and are unrelated to the entry costs of exporting the first product. A 30percent drop in the scope elasticity of incremental market-access costs for multi-product firms has an effect that is broadly similar to reducing market-access costs for all firms by 15 percent.

\section{V.C Changes in tariffs}

Finally, to compare changes in market-access costs to changes in conventional variable trade costs, we evaluate the welfare gains from the elimination of all tariffs. Under the assumption that remaining tariffs today represent around 4 percent of the value of exports, we experiment with a counterfactual decline of 4 percentage points in variable trade costs to mimic the elimination of tariffs. ${ }^{40}$ Using our parameter estimates, we find an average welfare gain across markets of approximately 1.8 percent; this is broadly comparable to the gains from reductions in incremental market-access costs.

Our estimate of $\theta=2.59$ comes from French firm level data used by Crozet and Koenig (2010). Alternatively, we can use Simonovska and Waugh (2014), who aggregate trade flows from 123 countries. Their various estimates of $\theta$ range from 2.79 to 4.46 , with their preferred specification producing $\theta=4.41$. Using that latter estimate, our counterfactual experiment (4), in which we reduce only incdremental market-access costs to distant destinations, results in an average welfare increase of 0.8 percent across destinations. Similarly, eliminating all tariffs increases welfare by 1.7 percent. In summary, our counterfactual experiments with plausible reductions of market-access costs result in welfare gains of a similar magnitude as the elimination of remaining tariffs.

\section{Conclusion}

We develop a model that accounts for pertinent facts on multi-product exporters, which we document using detailed Brazilian data. The model allows us to estimate market-access costs under rigorous microfoundations that regulate the entry of exporters and their products. Trade frictions such as market-access costs are vital elements in trade theories with heterogeneous firms, and they are important objects of study for aggregate outcomes in international trade and openeconomy macroeconomics. Our estimates indicate that additional products farther from a firm's

\footnotetext{
${ }^{40}$ Novy (2013) finds that the average total variable trade costs for a set of OECD countries in terms of tariff equivalents is 94 percent in 2000; the same countries have ad-valorem tariff rates of approximately 4 percent (Anderson and Neary 2005).
} 
core competency incur higher unit production costs but also that there are economies of scope in market-access costs for additional products. The elasticity of market-access costs with respect to additional products is almost one-third lower in nearby destinations. We conduct counterfactual exercises that accordingly reduce the scope elasticity of market-access costs by one-third and find welfare gains similar in magnitude to a complete elimination of currently remaining tariffs. Results of these counterfactual exercises are reminiscent of surveys for numerous countries (OECD 2005, Ch. 1) and evidence on product trade (Reyes 2011), which suggest that non-tariff measures deter the market access of small and narrow-scope firms more heavily.

While we have incorporated many available dimensions of the trade data, more can be done. Our approach leaves unexplored recently available information on unit prices and export behavior over time, for example. Such additional information may prove valuable in understanding more precisely the patterns of product market access and exporter expansions. Similarly, we leave specific mechanisms that may shape determinants of market-access cost open for further investigation. 


\section{References}

Allanson, Paul, and Catia Montagna. 2005. "Multiproduct Firms and Market Structure: An Explorative Application to the Product Life Cycle." International Journal of Industrial Organization, 23(7-8): 587597.

Allen, Treb. 2014. "Information Frictions in Trade." Econometrica, 82(6): 2041-83.

Almunia, Miguel, Pol Antràs, David Lopez-Rodriguez, and Eduardo Morales. 2018. "Venting Out: Exports During a Domestic Slump.” NBER Working Paper, 25372.

Alvarez, Fernando E., and Robert E. Jr. Lucas. 2007. "General Equilibrium Analysis of the EatonKortum Model of International Trade." Journal of Monetary Economics, 54(6): 1726-68.

Álvarez, Roberto, Hasan Faruq, and Ricardo A. López. 2013. "Is Previous Export Experience Important for New Exports?” Journal of Development Studies, 49(3): 426-41.

Amador, João, and Luca David Opromolla. 2013. "Product and Destination Mix in Export Markets." Review of World Economics/Weltwirtschaftliches Archiv, 149(1): 23-53.

Amiti, Mary, Oleg Itskhoki, and Jozef Konings. 2014. "Importers, Exporters, and Exchange Rate Disconnect." American Economic Review, 104(7): 1942-78.

Anderson, James E., and J. Peter Neary. 1996. “A New Approach to Evaluating Trade Policy.” Review of Economic Studies, 63(1): 107-25.

Anderson, James E., and J. Peter Neary. 2003. “The Mercantilist Index of Trade Policy.” International Economic Review, 44(2): 627-49.

Anderson, James E., and J. Peter Neary. 2005. Measuring the restrictiveness of international trade policy. Cambridge and London: MIT Press.

Arkolakis, Costas. 2010. "Market Penetration Costs and the New Consumers Margin in International Trade.” Journal of Political Economy, 118(6): 1151-1199.

Arkolakis, Costas, and Marc-Andreas Muendler. 2011. "The Extensive Margin of Exporting Products: The Continuum Case." University of California, San Diego, unpublished manuscript.

Arkolakis, Costas, and Marc-Andreas Muendler. 2013. "Exporters and Their Products: A Collection of Empirical Regularities.” CESifo Economic Studies, 59(2): 223-248.

Arkolakis, Costas, Arnaud Costinot, and Andrés Rodríguez-Clare. 2012. "New Trade Models, Same Old Gains?” American Economic Review, 102(1): 94-130.

Armenter, Roc, and Miklos Koren. 2014. "A Balls-and-Bins Model of Trade." American Economic Review, 104(7): 2127-51.

Atkeson, Andrew, and Ariel T. Burstein. 2008. "Pricing-to-Market, Trade Costs, and International Relative Prices." American Economic Review, 98(5): 1998-2031. 
Baldwin, Richard, Simon Evenett, and Patrick Low. 2009. "Beyond Tariffs: Multilateralizing Nontariff RTA Commitments.” In Multilateralizing Regionalism: Challenges for the Global Trading System. , ed. Richard Baldwin and Patrick Low, Chapter 3, 79-141. Cambridge and New York: Cambridge University Press.

Bernard, Andrew B., Andreas Moxnes, and Karen Helene Ulltveit-Moe. 2018. "Two-sided Heterogeneity and Trade." Review of Economics and Statistics, 100(3): 424-439.

Bernard, Andrew B., J. Bradford Jensen, Stephen J. Redding, and Peter K. Schott. 2009. “The Margins of U.S. Trade.” American Economic Review: Papers and Proceedings, 99(2): 487-493.

Bernard, Andrew B., Jonathan Eaton, J. Bradford Jensen, and Samuel Kortum. 2003. "Plants and Productivity in International Trade.” American Economic Review, 93(4): 1268-90.

Bernard, Andrew B., Stephen J. Redding, and Peter K. Schott. 2011. "Multiproduct Firms and Trade Liberalization.” Quarterly Journal of Economics, 126(3): 1271-1318.

Bown, Chad P. 2011. "Taking Stock of Antidumping, Safeguards, and Countervailing Duties, 19902009.” World Economy, 34(12): 1995-1998.

Brambilla, Irene. 2009. "Multinationals, Technology, and the Introduction of Varieties of Goods." Journal of International Economics, 79(1): 89-101.

Broda, Christian, and David E. Weinstein. 2006. "Globalization and the Gains from Variety." Quarterly Journal of Economics, 121(2): 541-85.

Chaney, Thomas. 2008. "Distorted Gravity: The Intensive and Extensive Margins of International Trade." American Economic Review, 98(4): 1707-21.

Chaney, Thomas. 2014. "The Network Structure of International Trade." American Economic Review, 104(11): 3600-3634.

Cherkashin, Ivan, Svetlana Demidova, Hiau Loo Kee, and Kala Krishna. 2015. "Firm Heterogeneity and Costly Trade: A New Estimation Strategy and Policy Experiments." Journal of International Economics, 96(1): 18-36.

Coeurdacier, Nicolas, and Hélène Rey. 2013. "Home Bias in Open Economy Financial Macroeconomics." Journal of Economic Literature, 51(1): 63-115.

Crozet, Matthieu, and Pamina Koenig. 2010. "Structural Gravity Equations with Intensive and Extensive Margins.” Canadian Journal of Economics, 43(1): 41-62.

Das, Sanghamitra, Mark J. Roberts, and James R. Tybout. 2007. "Market Entry Costs, Producer Heterogeneity, and Export Dynamics.” Econometrica, 75(3): 837-873.

Dekle, Robert, Jonathan Eaton, and Samuel Kortum. 2007a. "Unbalanced Trade." American Economic Review: Papers and Proceedings, 97(2): 351-55.

Dekle, Robert, Jonathan Eaton, and Samuel Kortum. 2007b. “Unbalanced trade.” American Economic Review, 97(2): 351-355. 
Dhingra, Swati. 2013. "Trading Away Wide Brands for Cheap Brands." American Economic Review, 103(6): 2554-84.

Di Giovanni, Julian, Andrei A. Levchenko, and Isabelle Mejean. 2014. "Firms, Destinations, and Aggregate Fluctuations." Econometrica, 82(4): 1303-40.

Eaton, Jonathan, and Samuel Kortum. 2002. "Technology, Geography, and Trade." Econometrica, 70(5): 1741-79.

Eaton, Jonathan, and Samuel Kortum. 2010. "Technology in the Global Economy: A Framework for Quantitative Analysis." University of Chicago, unpublished manuscript.

Eaton, Jonathan, David Jinkins, James Tybout, and Daniel Yi Xu. 2016. “Two-sided Search in International Markets.” Society for Economic Dynamics 2016 Meeting Papers.

Eaton, Jonathan, Samuel Kortum, and Brent Neiman. 2016. “Obstfeld and Rogoff's International Macro Puzzles: A Quantitative Assessment." Journal of Economic Dynamics and Control, 72(0): 523.

Eaton, Jonathan, Samuel Kortum, and Francis Kramarz. 2004. "Dissecting Trade: Firms, Industries, and Export Destinations.” American Economic Review: Papers and Proceedings, 94(2): 150-54.

Eaton, Jonathan, Samuel Kortum, and Francis Kramarz. 2011. "An Anatomy of International Trade: Evidence from French Firms." Econometrica, 79(5): 1453-98.

Eckel, Carsten, and J. Peter Neary. 2010. "Multi-Product Firms and Flexible Manufacturing in the Global Economy.” Review of Economic Studies, 77(1): 188-217.

Eckel, Carsten, Leonardo Iacovone, Beata Javorcik, and J. Peter Neary. 2016. "Testing the CoreCompetency Model of Multi-product Exporters.” Review of International Economics, 24(4): 699-716.

Egger, Peter, Joseph Francois, Miriam Manchin, and Douglas Nelson. 2015. "Non-tariff Barriers, Integration and the Transatlantic Economy." Economic Policy, 0(83): 539-73.

Eurostat. 2008. "NACE Rev. 2." Office for Official Publications of the European Communities.

Evenett, Simon J. 2009. “Global Trade Alert: Motivation and Launch.” World Trade Review, 8(4): 60709.

Feenstra, Robert C. 1995. "Estimating the Effects of Trade Policy." In Handbook of international economics. Vol. 3 of Handbooks in Economics, , ed. Gene M. Grossman and Kenneth Rogoff, Chapter 30, 1553-95. Amsterdam, New York and Oxford: Elsevier, North-Holland.

Feenstra, Robert C., and Hong Ma. 2008. "Optimal Choice of Product Scope for Multiproduct Firms under Monopolistic Competition." In The Organization of Firms in a Global Economy. , ed. Elhanan Helpman, Dalia Marin and Thierry Verdier, Chapter 6, 173-199. Cambridge, Mass.: Harvard University Press.

Feenstra, Robert C., Robert E. Lipsey, Haiyan Deng, Alyson C. Ma, and Hengyong Mo. 2005. “World Trade Flows: 1962-2000.” NBER Working Paper, 11040. 
Fernandes, Ana M., Peter J. Klenow, Sergii Meleshchuk, Martha D. Pierola, and Andrés Rodríguez-Clare. 2018. “The Intensive Margin in Trade.” NBER Working Paper, 25195.

Fitzgerald, Doireann. 2012. "Trade Costs, Asset Market Frictions, and Risk Sharing." American Economic Review, 102(6): 2700-2733.

Gopinath, Gita, and Oleg Itskhoki. 2010. "Frequency of Price Adjustment and Pass-Through." Quarterly Journal of Economics, 125(2): 675-727.

Haveman, Jon. 2017. “Industry Concordances.” www.macalester.edu/research/economics/page/haveman/ trade.resources/tradeconcordances.html, Macalester College, Saint Paul.

Head, Keith, Thierry Mayer, et al. 2013. "Gravity equations: Toolkit, cookbook, workhorse.” Handbook of international economics, 4: 131-195.

Helpman, Elhanan, Marc J. Melitz, and Stephen R. Yeaple. 2004. "Export versus FDI with Heterogeneous Firms." American Economic Review, 94(1): 300-316.

Hottman, Colin J., Stephen J. Redding, and David E. Weinstein. 2016. "Quantifying the Sources of Firm Heterogeneity.” Quarterly Journal of Economics, 131(3): 1291-1364.

Hsieh, Chang-Tai, and Peter J. Klenow. 2009. "Misallocation and Manufacturing TFP in China and India." Quarterly Journal of Economics, 124(4): 1403-1448.

Instituto Brasileiro de Geografia e Estatística. 2000. "Combined SECEX-RAIS Data.”

Irarrazabal, Alfonso, Andreas Moxnes, and Luca David Opromolla. 2015. "The Tip of the Iceberg: A Quantitative Framework for Estimating Trade Costs." Review of Economics and Statistics, 97(4): 77792.

Kee, Hiau Looi, Alessandro Nicita, and Marcelo Olarreaga. 2009. "Estimating Trade Restrictiveness Indices.” Economic Journal, 119(534): 172-99.

Mayer, Thierry, and Soledad Zignago. 2011. "Notes on CEPII's distances measures: The GeoDist database."

Mayer, Thierry, Marc J. Melitz, and Gianmarco I. P. Ottaviano. 2014. "Market Size, Competition, and the Product Mix of Exporters." American Economic Review, 104(2): 495-536.

McKenzie, Lionel W. 1960. "Matrices with Dominant Diagonal in Economic Theory." In Mathematical Methods in the Social Sciences. Proceedings of the first Stanford symposium 1959, , ed. Kenneth J. Arrow, Samuel Karlin and Patrick Suppes, Chapter 2, 47-62. Stanford, Calif.: Stanford University Press.

Melitz, Marc J. 2003. "The Impact of Trade on Intra-Industry Reallocations and Aggregate Industry Productivity." Econometrica, 71(6): 1695-1725.

Montinari, Letizia, Massimo Riccaboni, and Stefano Schiavo. 2017. "Innovation, Trade and Multiproduct Firms." University of Trento, unpublished manuscript.

Morales, Eduardo, Gloria Sheu, and Andrés Zahler. 2019. "Extended Gravity." Review of Economic Studies, 86(6): 2668-2712. 
Moxnes, Andreas. 2010. “Are Sunk Costs in Exporting Country Specific?” Canadian Journal of Economics, 43(2): 467-493.

Niu, Zhaohui, Chang Liu, Saileshsingh Gunessee, and Chris Milner. 2018. "Non-tariff and Overall Protection: Evidence across Countries and over Time." Review of World Economics/Weltwirtschaftliches Archiv, 154(4): 675-703.

Nocke, Volker, and Stephen Yeaple. 2014. "Globalization and Multiproduct Firms." International Economic Review, 55(4): 993-1018.

Novy, Dennis. 2013. "Gravity Redux: Measuring International Trade Costs with Panel Data." Economic Inquiry, 51(1): 101-21.

Obstfeld, Maurice, and Kenneth Rogoff. 2001. "The Six Major Puzzles in International Macroeconomics: Is There a Common Cause?” In NBER macroeconomics annual 2000. Vol. 15, , ed. Ben S. Bernanke and Kenneth Rogoff, Chapter 6, 339-90. Cambridge and London: MIT Press.

OECD. 2005. Looking beyond Tariffs: The Role of Non-tariff Barriers in World Trade. OECD Trade Policy Studies, Paris and Washington, D.C.: OECD.

Panzar, John C., and Robert D. Willig. 1977. "Economies of Scale in Multi-Output Production." Quarterly Journal of Economics, 91(3): 481-493.

Panzar, John C., and Robert D. Willig. 1981. "Economies of Scope." American Economic Review, 71(2): 268-272.

Qiu, Larry D., and Wen Zhou. 2013. "Multiproduct Firms and Scope Adjustment in Globalization.” Journal of International Economics, 91(1): 142-53.

Reyes, José-Daniel. 2011. "International Harmonization of Product Standards and Firm Heterogeneity in International Trade." World Bank Policy Research Working Paper, 5677.

Rudin, Walter. 1976. Principles of mathematical analysis. . 3rd ed., New York, New York: McGraw and Hill.

Shepherd, Ben. 2007. "Product Standards, Harmonization, and Trade: Evidence from the Extensive Margin.” World Bank Policy Research Working Paper, 4390.

Simonovska, Ina, and Michael E. Waugh. 2014. "The Elasticity of Trade: Estimates and Evidence." Journal of International Economics, 92(1): 34-50.

Thomas, Catherine. 2011. "Too Many Products: Decentralized Decision Making in Multinational Firms." American Economic Journal: Microeconomics, 3(1): 280-306.

Timoshenko, Olga A. 2015. "Product Switching in a Model of Learning." Journal of International Economics, 95(2): 233-49.

UNCTAD. 2010. Non-tariff Measures: Evidence from Selected Developing Countries and Future Research Agenda. New York and Geneva: United Nations.

UNIDO. 2005. “INDSTAT3 2005 ISIC Rev. 2 User's Guide.” unido.org/doc/3531, Vienna. 
United Nations. 2000. "UN Comtrade Database.” comtrade.un.org, New York.

UNStats. 2017. "HS Code Crosswalks." United Nations Statistics Division, Trade Statistics Branch (TSB),

Van Wincoop, Eric, and Francis E. Warnock. 2010. "Can Trade Costs in Goods Explain Home Bias in Assets?” Journal of International Money and Finance, 29(6): 1108-23.

World Bank. 2009. World Development Indicators 2009. Washington, D.C.: World Bank.

WTO. 2012. Trade and public policies: A closer look at non-tariff measures in the 21st century. World Trade Report, Geneva: World Trade Organization.

WTO. 2016. "Tariff Analysis Online.” World Trade Organization. 


\section{Appendix}

\section{A Proofs}

\section{A.A Proof of Lemma 1}

We will show that, conditional on a market-access cost draw $c_{d}$, average sales are proportional to average market-access costs:

$$
\bar{F}_{s d}\left(c_{d}\right)=\frac{\tilde{\theta}-1}{\tilde{\theta} \sigma} \bar{T}_{s d}\left(c_{d}\right) .
$$

With this result, we can then integrate (A.1) over the market-access cost distribution to establish Lemma 1 after aggregation across firms:

$$
\bar{F}_{s d}=\int \bar{F}_{s d}\left(c_{d}\right) \mathrm{d} F\left(c_{d}\right)=\int \frac{\tilde{\theta}-1}{\tilde{\theta} \sigma} \bar{T}_{s d}\left(c_{d}\right) \mathrm{d} F\left(c_{d}\right)=\frac{\tilde{\theta}-1}{\tilde{\theta} \sigma} \bar{T}_{s d} .
$$

We now prove (A.1). We drop the argument $c_{d}$ for brevity. Expected total sales per firm in $s$ shipping to $d$ are

$$
\begin{aligned}
\bar{T}_{s d} & =\int_{\phi_{s d}^{*}} \mathbb{E}\left[t_{s d}(\phi, \boldsymbol{\xi})\right] \mu\left(\phi \mid \phi_{s d}^{*}, \theta\right) \mathrm{d} \phi \\
& =\int_{\phi_{s d}^{*}} \sigma f_{s d}(1)\left(\frac{\phi}{\phi_{s d}^{*}}\right)^{\sigma-1} \sum_{g=1}^{G_{s d}(\phi)} h(g)^{-(\sigma-1)} \mathbb{E}\left[\xi_{s d g}\right] \cdot \theta \frac{\left(\phi_{s d}^{*}\right)^{\theta}}{(\phi)^{\theta+1}} \mathrm{~d} \phi \\
& =\int_{\phi_{s d}^{*}} \sigma f_{s d}(1)\left(\frac{\phi}{\phi_{s d}^{*}}\right)^{\sigma-1} \sum_{g=1}^{G_{s d}(\phi)} h(g)^{-(\sigma-1)} \cdot \theta \frac{\left(\phi_{s d}^{*}\right)^{\theta}}{(\phi)^{\theta+1}} \mathrm{~d} \phi
\end{aligned}
$$

by optimal total exports (13) and the independence of product appeal $\xi_{\text {sdg }}$ and firm productivity $\phi$. Consider the term $\int_{\phi_{s d}^{*}} \phi^{\sigma-1-(\theta+1)} \sum_{g=1}^{G_{s d}(\phi)} h(g)^{-(\sigma-1)} \mathrm{d} \phi$. Rewrite the term as a piecewise integral

$$
\begin{aligned}
\int_{\phi_{s d}^{*}} \sum_{g=1}^{G_{s d}(\phi)} \frac{\phi^{\sigma-1-(\theta+1)}}{h(g)^{\sigma-1}} \mathrm{~d} \phi & =\int_{\phi_{s d}^{*}}^{\phi_{s d}^{*, 2}} \sum_{g=1}^{1} \frac{\phi^{\sigma-1-(\theta+1)}}{h(g)^{\sigma-1}} \mathrm{~d} \phi+\int_{\phi_{s d}^{*, 2}}^{\phi_{s d}^{* 3}} \sum_{g=1}^{2} \frac{\phi^{\sigma-1-(\theta+1)}}{h(g)^{\sigma-1}} \mathrm{~d} \phi+\ldots \\
& =\frac{1}{h(1)^{\sigma-1}} \int_{\phi_{s d}^{*}}^{\infty} \phi^{\sigma-1-(\theta+1)} \mathrm{d} \phi+\frac{1}{h(2)^{\sigma-1}} \int_{\phi_{s d}^{*, 2}}^{\infty} \phi^{\sigma-1-(\theta+1)} \mathrm{d} \phi+\ldots \\
& =\frac{1}{h(1)^{\sigma-1}} \frac{\left(\phi_{s d}^{*}\right)^{(\sigma-1)-\theta}}{\theta-(\sigma-1)}+\frac{1}{h(2)^{\sigma-1}} \frac{\left(\phi_{s d}^{*, 2}\right)^{(\sigma-1)-\theta}}{\theta-(\sigma-1)}+\ldots
\end{aligned}
$$


for $\theta>\sigma-1$. Using the definitions of $\phi_{s d}^{*}, \phi_{s d}^{*, 2}$, etc. from (11), we have

$$
\int_{\phi_{s d}^{*}} \sum_{g=1}^{G_{s d}(\phi)} \frac{\phi^{\sigma-1-(\theta+1)}}{h(g)^{\sigma-1}} \mathrm{~d} \phi=\frac{1}{\theta-(\sigma-1)}\left(\frac{f_{s d}(1)}{\left(\phi_{s d}^{*}\right)^{\sigma-1}}\right)^{\tilde{\theta}-1} \sum_{G=1}^{\infty} \frac{f_{s d}(G)^{-(\tilde{\theta}-1)}}{h(G)^{\theta}}
$$

with $\tilde{\theta} \equiv \theta /(\sigma-1)$. Therefore

$$
\bar{T}_{s d}=\frac{\tilde{\theta} \sigma}{\tilde{\theta}-1} f_{s d}(1)^{\tilde{\theta}} \sum_{G=1}^{\infty} f_{s d}(G)^{-(\tilde{\theta}-1)} h(G)^{-\theta}
$$

proving the first equality in (22). The expression is finite by Assumption 3.

Average market-access costs paid by firms in $s$ selling to $d$ are

$$
\begin{aligned}
\bar{F}_{s d} & =\int_{\phi_{s d}^{*}}^{\phi_{s d}^{*, 2}} F_{s d}(1) \theta \frac{\left(\phi_{s d}^{*}\right)^{\theta}}{\phi^{\theta+1}} \mathrm{~d} \phi+\int_{\phi_{s d}^{*, 2}}^{\phi_{s d}^{*, 3}} F_{s d}(2) \theta \frac{\left(\phi_{s d}^{*}\right)^{\theta}}{\phi^{\theta+1}} \mathrm{~d} \phi+ \\
& =F_{s d}(1)\left(\phi_{s d}^{*}\right)^{\theta}\left[\left(\phi_{s d}^{*}\right)^{-\theta}-\left(\phi_{s d}^{*, 2}\right)^{-\theta}\right]+F_{s d}(2)\left(\phi_{s d}^{*}\right)^{\theta}\left[\left(\phi_{s d}^{*, 2}\right)^{-\theta}-\left(\phi_{s d}^{*, 3}\right)^{-\theta}\right]+\ldots
\end{aligned}
$$

Using the definition $F_{s d}\left(G_{s d}\right)=\sum_{g=1}^{G_{s d}} f_{s d}(g)$ and collecting terms with a common $\phi_{s d}^{*, G}$ we can rewrite the above expression as

$$
\bar{F}_{s d}=f_{s d}(1)+\left(\phi_{s d}^{*, 2}\right)^{-\theta}\left(\phi_{s d}^{*}\right)^{\theta} f_{s d}(2)+\left(\phi_{s d}^{*, 3}\right)^{-\theta}\left(\phi_{s d}^{*}\right)^{\theta} f_{s d}(3)+\ldots
$$

Using the definition of $\phi_{s d}^{*, G}$ from equation (11) in the above equation we get

$$
\begin{aligned}
\bar{F}_{s d} & =f_{s d}(1)+\left(\frac{f_{s d}(2)^{1 /(\sigma-1)} h(2)}{f_{s d}(1)^{1 /(\sigma-1)} h(1)}\right)^{-\theta} f_{s d}(2)+\ldots \\
& =\left[f_{s d}(1)+f_{s d}(1)^{\tilde{\theta}}\left(f_{s d}(2)^{1 /(\sigma-1)} h(2)\right)^{-\theta} f_{s d}(2)+\ldots\right] \\
& =f_{s d}(1)^{\tilde{\theta}}\left[f_{s d}(1)^{-(\tilde{\theta}-1)}+f_{s d}(2)^{-(\tilde{\theta}-1)} h(2)^{-\theta}+\ldots\right] \\
& =f_{s d}(1)^{\tilde{\theta}} \sum_{G=1}^{\infty} f_{s d}(G)^{-(\tilde{\theta}-1)} h(G)^{-\theta} \\
& =\frac{\tilde{\theta}-1}{\tilde{\theta} \sigma} \bar{T}_{s d} .
\end{aligned}
$$

This proves the second equality in (22). The ratio $\bar{F}_{s d} / \bar{T}_{s d}$ is a destination invariant constant.

\section{A.B Share of wages and profits}

We show that the share of wages and profits in total income is constant (source country invariant). Note that the share of net profits from bilateral sales is the share of gross variable profits in total sales $1 / \sigma$, less the market-access costs paid, divided by total sales $(\tilde{\theta}-1) / \tilde{\theta} \sigma$. Thus, using the result of Lemma $1, \pi_{s d} L_{d} / T_{s d}=1 / \sigma-(\tilde{\theta}-1) /(\tilde{\theta} \sigma)=1 /(\tilde{\theta} \sigma)$. Total profits for 
country $s$ are $\pi_{s} L_{s}=\sum_{k} \lambda_{s k} T_{k} /(\tilde{\theta} \sigma)$, where $\sum_{k} \lambda_{s k} T_{k}$ is the country's total income by (26) and $T_{k}$ is consumer expenditure at destination $k$. Profit income and wage income can therefore be expressed as constant shares of total income, as in the main text, equation (27).

\section{B Data}

\section{B.A Brazilian exporter-product-destination data}

We identify an exporter's sector from the firm's reported CNAE four-digit industry (for 654 industries across all sectors of the economy) in the administrative RAIS records (Relação Anual de Informações Sociais) from the Brazilian labor ministry in 2000. The level of detail in CNAE is comparable to the NAICS 2007 five-digit level. To map from the HS 6-digit codes to ISIC revision 2 at the two-digit level we use an extended SITC-to-ISIC concordance, augmenting an OECD concordance for select manufacturing industries to all industries. ${ }^{41}$

As Table B.1 shows in columns 5 and 6, our Brazilian manufacturer sample for the year 2000 includes 10,215 firms with shipments of 3,717 manufactured products at the 6-digit Harmonized System level to 170 destinations, and a total of 162,570 exporter-destination-product observations. ${ }^{42}$ Exporters shipping multiple products dominate. They ship more than 90 percent of all exports from Brazil, and their global top-selling product accounts for 60 percent of Brazilian exports worldwide. We report the top exporting products of Brazilian firms in the Online Supplement $\mathrm{S} 4 .^{43}$

To compute medians and means for regional aggregates and the world as a whole in Table B.1 (columns 3 to 6), we treat each aggregate as if it were a single destination and collapse all product shipments to different countries within the aggregate into a single product shipment. In most data treatments in the text, in contrast, we analyze these variables country by country, consistent with our main hypothesis that market-access determinants of trade matter repeatedly destination by destination.

The median exporter is relatively small, with sales to the rest of the world totaling around US\$ 89,000. The mean exporter, in contrast, sells around US\$ 3.7 million abroad, more than 40 times as much as the median exporter. Exporter scope and exporter scale exhibit similarly stark differences between mean and median. The median Brazilian manufacturer sells two products worldwide, but the mean scope per firm is 5.3 products. The median Brazilian exporter has a product scale of around US\$ 37,000 per product, but the mean exporter scale per exporter is US\$ 705,000, or around 20 times as high as that for the median firm.

The importance of the top-selling product at multi-product exporters and the mean-median ratios are similar across destinations. To investigate the robustness across countries, we select Brazil's top two export destinations in terms of presence of Brazilian manufacturing exporters

\footnotetext{
${ }^{41}$ Our SITC-to-ISIC concordance is available at URL econ.ucsd.edu/muendler/resource.

${ }^{42} \mathrm{We}$ remove export records with zero value from the Brazilian data, which include shipments of commercial samples but also potential reporting errors, and lose 408 of initially 162,978 exporter-destination-product observations. Our results on exporter scope do not materially change when including or excluding zero-shipment products from the product count.

${ }^{43}$ The top-5 selling products of Brazilian exporters at the 6-digit level are: 1. Airplanes heavier than 2 tons, 2. Chemical woodpulp, 3. Soybean oilcake, 4. Passenger vehicles with engines above 1,500 cc, 5. Transmissions.
} 
Table B.1: Sample Characteristics by Destination

\begin{tabular}{lrrrrr}
\hline & \multicolumn{5}{c}{ From Brazil } \\
\cline { 2 - 6 } to destination $d$ & $\begin{array}{r}\text { Argentina } \\
(1)\end{array}$ & $\begin{array}{r}\text { USA } \\
(2)\end{array}$ & $\begin{array}{r}\text { non-OECD } \\
(3)\end{array}$ & $\begin{array}{r}\text { OECD } \\
(4)\end{array}$ & $\begin{array}{r}\text { World } \\
(5)\end{array}$ \\
\hline \# of Firms $(M)$ & 4,590 & 3,083 & 8,485 & 5,391 & 10,215 \\
\# of Destinations $(N)$ & 1 & 1 & 141 & 29 & 170 \\
\# of HS-6 products $(G)$ & 2,814 & 2,144 & 3,516 & 2,887 & 3,717 \\
\# of Observations & 21,623 & 10,775 & 119,872 & 42,698 & 162,570 \\
Destination share in Tot. exp. & 0.144 & 0.257 & 0.384 & 0.616 & 1 \\
Firm shares in Total exports & & & & & \\
Single-prod. firms & 0.086 & 0.123 & 0.076 & 0.132 & 0.090 \\
Multi-prod. firms' top prod. & 0.555 & 0.662 & 0.560 & 0.630 & 0.597 \\
Multi-prod. firms' other prod. & 0.359 & 0.215 & 0.364 & 0.239 & 0.313 \\
Median Total exp. $\left(T_{d}(m)\right)$ & 0.068 & 0.120 & 0.063 & 0.137 & 0.089 \\
Median Exp. scope $\left(G_{d}(m)\right)$ & 2 & 1 & 2 & 2 & 2 \\
Median Exp. scale $\left(a_{d}(m)\right)$ & 0.031 & 0.068 & 0.026 & 0.068 & 0.037 \\
Mean Total exports $\left(\bar{t}_{d}\right)$ & 1.192 & 3.170 & 1.718 & 4.344 & 3.720 \\
Mean Exp. scope $\left(\bar{G}_{d}\right)$ & 4.711 & 3.494 & 5.151 & 4.146 & 5.277 \\
Mean Exp. scale $\left(\bar{a}_{d}\right)$ & 0.251 & 0.806 & 0.325 & 1.082 & 0.706 \\
\hline
\end{tabular}

Source: SECEX 2000 manufacturing firms and their manufactured products at the HS 6-digit level, destinations linked to WTF (Feenstra et al. 2005) and Unido Industrial Statistics (UNIDO 2005).

Note: Each aggregate region (World, OECD, non-OECD) treated as a single destination, collapsing product shipments to different countries into single product shipment. Products at the HS 6-digit level. Exports in US\$ million fob. Firms' exporter scale (US\$ million fob) is the scope-weighted arithmetic mean of exporter scales. OECD includes all OECD members in 1990. Argentina is Brazil's top export destination in terms of presence of Brazilian manufacturing exporters in 2000 , the United States second to top.

(Argentina and United States), as well as the non-OeCD and OeCD aggregates. Our theory emphasizes the importance of exporting behavior within destinations. Within single countries, the mean manufacturer's exports exceed the median manufacturer's exports by similarly large factors as in the aggregate, between 14 (in Argentina, column 1) and 26 (in the United States, column 2). In the non-OECD aggregate (column 3), exports of the mean firm exceed the exports of the median firm by a factor of about 30 . The same mean-median ratio of about 30 prevails in the OECD aggregate.

Figure B.1 documents Fact 1 for the United States and Uruguay, complementing Figure 2 for Argentina in the text. Argentina, the United States and Uruguay are the top three destinations in terms of presence of Brazilian manufacturing exporters in 2000. In each plot, we limit our sample to exporters and their shipments to the respective destination and group the exporters by their local exporter scope $G$. For each scope group $G$ and for each product rank $g$, we then take the average of the $\log$ of product sales $\ln y_{\omega d g}^{G}$ for those firm-products over all destinations. The graphs for the United States and Uruguay confirm Fact 1 in that a few core products dominate local sales and in that the least-selling products sell for smaller amounts the wider the firm's 
Figure B.1: U.S. and Uruguayan Within-firm Sales Distributions
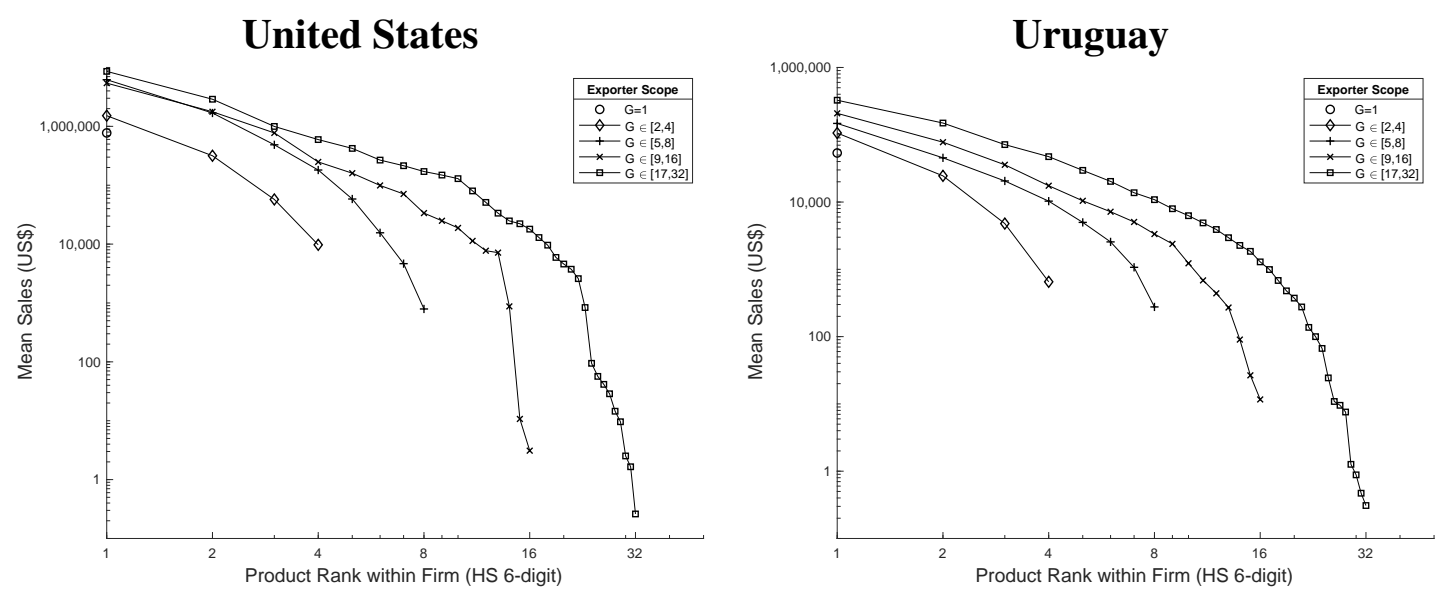

Source: SECEX 2000, manufacturing firms and their manufactured products.

Note: Products at the HS 6-digit level, shipments to the United States and Uruguay. We group firms by their exporter scope $G_{d}=G$ at a destination $d$ (United States or Uruguay). The product rank $g$ refers to the sales rank of an exporter's product in that destination. Mean product sales is the average of individual firm-product sales $\sum_{\omega \in\left\{\omega: G_{d}(\omega)=G\right\}} y_{\omega d g}^{G} / M_{d}^{G}$, computed for all firm-products with individual rank $g$ at the $M_{d}^{G}$ firms exporting to the destination with scope $G_{d}=G$.

exporter scope.

We further investigate the striking similarity of firm scope choices across destinations by relating the mean number of products to destination market size. Figure B. 2 shows a scatter plot of the log mean exporter scope $\bar{G}_{s d}$ against the log of total GDP at the destination. The depicted fitted line, from an ordinary least squares regression, has a slope that is not significantly different from zero at conventional levels. In other words, most of the variation in firms' exports to destinations of different size is due to variation in the firms' mean scale per product. At the firm level, the Brazilian data exhibit destination-presence patterns that resemble those in the French and U.S. firm-destination data. Similar to Eaton, Kortum and Kramarz (2011), for instance, the elasticity of the number of firms with respect to the number of export destinations is about -2.5 , just as for French exporters.

\section{B.B Data for counterfactual analysis}

For bilateral trade and trade balances in manufactured products, we use World Trade Flow (WTF) data in U.S. dollars for the year 2000 (Feenstra et al. 2005). To mitigate the effect of entrepot trade, we follow Dekle, Eaton and Kortum (2007a) and collapse (i) Hong Kong, Macao and mainland China, (ii) Belgium, Luxembourg and the Netherlands, and (iii) Indonesia, Malaysia, Singapore, and Thailand into single entities. In 2000, import information for India is missing from WTF. We obtain information for India in 2000 from UN Comtrade . We keep only manufactured products from the WTF data, using a concordance from the OECD at the SITC revision-2 4-digit level to determine manufactured products, and exclude agricultural and mining merchandise. By our construction, the world's trade balance is zero.

For information on GDP, manufacturing value added and the overall trade balances in goods 


\section{Figure B.2: Mean Exporter Scope and GDP by Destination}

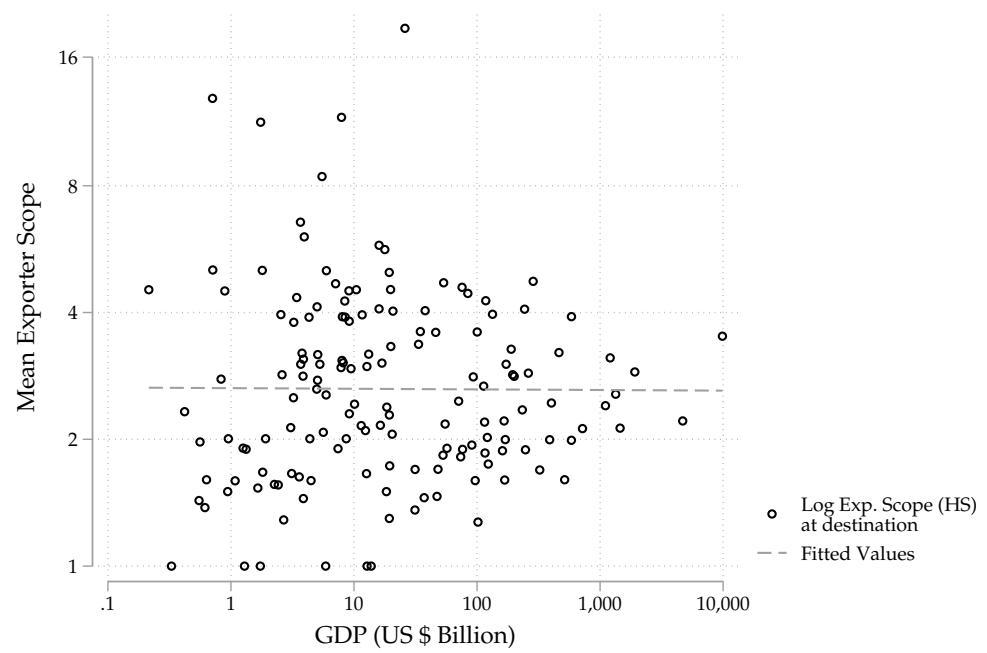

Source: SECEX 2000 manufacturing firms and their manufactured products at the HS 6-digit level, destinations linked to CEPII Statistics

and services in 2000 we use the World Bank's World Development Indicators 2009 (WDI). India included, our initial WTF sample has 132 countries that can be matched to the WDI data, and we collapse bilateral trade for the rest of the world by trade partner into a 133rd observation. We compute GDP and manufacturing value added for the rest of the world as the WDI reported world total less the sample total of our 132 matched countries. We set the overall trade balances in goods and services for the rest of the world so that the world total is zero.

We obtain the labor share in manufacturing production $\beta$ from UNIDO (2005) at the ISIC rev. 2 level. UNIDO offers both manufacturing value added and manufacturing gross production for 51 of our sample countries and the rest of the world. Averaging the ratio of manufacturing value added to manufacturing output in 2000 over these countries yields $\beta=.330$. This worldwide $\beta$ estimate enters our computation of $\gamma_{d}$ by (E.8).

We need information on manufacturing absorption. Following Eaton, Kortum and Kramarz (2011), we infer manufacturing absorption as manufacturing output (from UNIDO 2005) plus the trade deficit (from WTF). The UNIDO data for manufacturing output are considerably less complete than either WTF or WDI. We obtain manufacturing output for Brazil from the Brazilian statistical agency IBGE (2010). Our final country sample for which we have manufacturing absorption contains 57 countries. By the model in Appendix E, $\gamma_{d}$ is given by (E.8). We use our WTF-WDI-UNIDO data to calculate $\gamma_{d}$ for 57 countries. For the rest of the world, we set $\gamma_{d}$ to the average of our sample $(\gamma=.244)$ and back out manufacturing absorption from (E.8). 


\section{Nested Utility}

We can generalize the model to consumer preferences with different elasticities of substitution within and between nests

$$
\left(\sum_{k=1}^{N} \int_{\omega \in \boldsymbol{\Omega}_{k d}} X_{k d}(\omega)^{\frac{\sigma-1}{\sigma}} \mathrm{d} \omega\right)^{\frac{\sigma}{\sigma-1}} \quad \text { with } X_{k d}(\omega) \equiv\left(\sum_{g=1}^{G_{k d}(\omega)} \xi_{k d g}(\omega)^{\frac{1}{\varepsilon}} x_{k d g}(\omega)^{\frac{\varepsilon-1}{\varepsilon}}\right)^{\frac{\varepsilon}{\varepsilon-1}}
$$

for $\varepsilon, \sigma>1$ and $\varepsilon \neq \sigma$. Under this generalization, a firm's individual products can be less substitutable among themselves than with outside products (if $\varepsilon<\sigma$ ) or more substitutable $(\varepsilon>\sigma)$. In the latter case, a firm's additional products cannibalize sales of its infra-marginal products.

To see the cannibalization effect, consider the consumer's first-order conditions by which demand for the $g$-th product of firm $\omega$ in market $d$ is

$x_{s d g}(\omega)=p_{s d g}(\omega)^{-\varepsilon} P_{s d}\left(\omega ; G_{s d}\right)^{\varepsilon-\sigma} P_{d}^{\sigma-1} \xi_{s d g} T_{d} \quad$ with $P_{s d}\left(\omega ; G_{s d}\right)^{-(\varepsilon-1)} \equiv \sum_{g=1}^{G_{s d}(\omega)} p_{s d g}(\omega)^{-(\varepsilon-1)}$

where $p_{s d g}(\omega)$ is the price of that product. A cannibalization effect results if $\varepsilon>\sigma$ because $P_{s d}\left(\omega ; G_{s d}\right)$ strictly decreases in exporter scope for $\varepsilon>1$, so wider exporter scope diminishes infra-marginal sales and reduces $x_{s d g}(\omega)$ for $\varepsilon>\sigma$. (For the converse case with $\sigma>\varepsilon$, wider exporter scope would boost infra-marginal sales and raise $x_{s d g}(\omega)$.) The cannibalization effect is symmetric for all products, so relative sales of a firm's existing products are not affected by the introduction of additional products. This constancy of relative sales in our model does not carry over to models with CES-preferences and a countable number of firms such as Feenstra and $\mathrm{Ma}$ (2008) or to models with non-CES preferences such as Mayer, Melitz and Ottaviano (2014) and Dhingra (2013). Hottman, Redding and Weinstein (2016) study the cannibalization effect using data on overall expenditure shares and prices; they compute both intra-firm and inter-firm elasticities of substitution separately.

We show for nested utility in the Online Supplement that markups would still depend on the outer-nest elasticity only and remain constant. In the presence of cannibalization, the interpretation of some composite parameters would change and reflect elasticities in the inner nest while other composite parameters would reflect elasticities of the outer nest. Under cannibalization, we can redefine the product efficiency index and the combined incremental scope costs as:

$$
H\left(G_{s d}\right) \equiv\left(\sum_{g=1}^{G_{s d}(\omega)} h(g)^{-(\varepsilon-1)}\right)^{-\frac{1}{\varepsilon-1}} \quad \text { and } \quad z_{s d}\left(G_{s d}, c_{d}\right) \equiv \frac{c_{d} f_{s d}\left(G_{s d}\right)}{H\left(G_{s d}\right)^{-(\sigma-1)}-H\left(G_{s d}-1\right)^{-(\sigma-1)}} .
$$

With these new definitions, the expressions for firm product sales (12) and for aggregate bilateral trade (22) in Lemma 1 remain unaltered. For remaining details on the generalized model see the Online Supplement S1. 


\section{Simulation Algorithm and Moments}

\section{D.A Simulation algorithm}

Given a candidate estimate $\Theta$, we simulate the export behavior for $J^{\text {sim }}=1,000,000$ hypothetical Brazilian firms $\omega=1, \ldots, J^{\text {sim }}$ shipping to destinations $d=1, \ldots, N$ using our model ( $N$ is the observed number of destinations). In order to maintain the stochastic components unchanged as we search over $\Theta$, prior to the simulation routine we draw (i) $J^{\text {sim }}$ independent realizations of the firm's productivity percentile $\left(\phi_{\omega} / \phi^{*}\right)$ from the standard uniform distribution, (ii) $J^{\text {sim }} \times N$ independent realizations of the firm-specific market-access costs $c_{\omega d}$ from the standard log-normal distribution, and (iii) $J^{\text {sim }} \times N \times \bar{G}$ independent realizations of individual product appeal shocks $\xi_{\omega d g}$ from the standard log-normal distribution (where $\bar{G}$ is the maximum observed exporter scope of any firm at any destination).

A given iteration of the model simulation requires a set of candidate parameters $\Theta$ and the number of Brazilian firms selling to each destination $M_{d}$. An iteration of the simulation proceeds in the following steps.

(i). Scale the $J^{\text {sim }} \times N$ standard log-normal market-access cost draws by the current candidate dispersion parameter $\sigma_{c}$. Then, for each Brazilian firm $\omega$ and any destination $d$, compute the entry-relevant adjusted firm productivity parameter

$$
\phi_{\omega d} \equiv c_{\omega d}^{-1} \cdot\left(\phi_{\omega} / \phi^{*}\right)^{-1 / \tilde{\theta}}
$$

using the standard uniform firm productivity percentile $\left(\phi_{\omega} / \phi^{*}\right)$.

(ii). Back out the local entry threshold $\phi_{d}^{*}$ at destination $d$ using the observed number $M_{d}$ of Brazilian exporters at the destination and the known number of Brazilian firms $M_{\mathrm{BRA}}$,

$$
\frac{M_{d}}{M_{\mathrm{BRA}}}=\frac{1}{J^{\text {sim }}} \sum_{\omega=1}^{J^{\mathrm{sim}}} \mathbf{1}\left\{\phi_{\omega d}>\phi_{d}^{*}\right\} .
$$

The local entry cutoff $\phi_{d}^{*}$ depends on the mean of the $c_{\omega d}$ realizations. The cutoff is lower when the market-access cost draws are lower on average.

To obtain $M_{\mathrm{BRA}}$ we merge the RAIS database of the formal-sector universe of Brazilian firms in 2000 with the SECEX export database. We find that 3.1 percent of Brazilian manufacturing firms export a manufactured product. ${ }^{44}$

\footnotetext{
${ }^{44}$ The exporter share of 3.1 percent may seem low, but the Brazilian RAIS database includes all formal-sector firms and establishments with at least one employee. In contrast, censuses and surveys in most developing and some industrialized countries truncate their target population of firms from below with thresholds up to 20 employees. Truncation of the Brazilian manufacturing firm sample at a threshold of at least 10 employees would raise the exporter share to 10.7 percent. Truncation at a 20-employee threshold would raise the exporter share to 17.9 percent. The estimates in Table 3 are not sensitive to this convention. Using the alternative assumption that 10 percent of Brazilian firms export does not alter the reported results appreciably.
} 
(iii). Generate a firm-product-destination indicator $\mathbf{1}_{\omega d g}$ for each firm $\omega$ that exports its $g$-th product to destination $d$. For this purpose, compute the local product-level entry cutoffs

$$
\phi_{d}^{*, G} \equiv G^{\delta+\tilde{\alpha}} \phi_{d}^{*}
$$

Given the cutoffs, the firm-product-destination indicators are $\mathbf{1}_{\omega d g}=\mathbf{1}\left\{\phi_{\omega d}>\phi_{d}^{*, g}\right\}$. Compute the exporter scope for each firm $\omega$ at a destination $d$,

$$
G_{\omega d}=\sum_{g=1}^{\bar{G}} \mathbf{1}_{\omega d g}
$$

(iv). Scale the $J^{\operatorname{sim}} \times N \times \bar{G}$ standard log-normal product appeal draws by the current candidate dispersion parameter $\sigma_{\xi}$. Then generate the sales of a firm $\omega$ 's $g$-th ranked product at destination $d$, where the firm has an exporter scope $G_{\omega d}$ :

$$
y_{\omega d g}^{G}=\mathbf{1}_{\omega d g} \cdot G_{\omega d}^{\delta+\tilde{\alpha}} \cdot g_{\omega}^{-\tilde{\alpha}} \cdot \frac{\phi_{\omega d}}{\phi_{d}^{*, G}} \cdot \xi_{\omega d g}=\mathbf{1}_{\omega d g} \cdot g_{\omega}^{-\tilde{\alpha}} \cdot \frac{\left(\phi_{\omega} / \phi^{*}\right)^{-1 / \tilde{\theta}}}{\phi_{d}^{*} / c_{\omega d}} \cdot \xi_{\omega d g} .
$$

This expression for product revenue $y_{\omega d g}^{G}$ omits the destination-specific market-access cost shifter $\sigma f_{d}(1)$ and the destination-specific revenue shifter $D_{d}$ (which does not enter $\phi_{d}^{*}$ in the simulation). Both shifters are common across exporters at a destination and firm invariant in our simulation, because we normalize relevant moments by the according destination-specific median or extremum. See the following subsection for the definition of moments.

(v). At each destination $d$ and for every firm $\omega$, rank order the firm's products by their local sales $y_{\omega d g}^{G}$ and compute the local rank for each firm-product $g$ as

$$
\hat{g}_{\omega d} \equiv 1+\sum_{k=1}^{G_{\omega d}} \mathbf{1}\left\{y_{\omega d k}\left(\xi_{d k}\right)>y_{\omega d g}\left(\xi_{d g}\right)\right\}
$$

In general, the local rank will differ from the firm-level rank in production $\hat{g}_{\omega d} \neq g_{\omega}$ due to the product appeal shock $\xi_{\omega d g}$.

\section{D.B Moments}

We now define and discuss the moments used in the simulated method of moments algorithm. To isolate the parameters that are relevant for the shapes of our functional forms and the dispersion of the stochastic components, we adopt moments that are comparable across destinations by neutralizing destination-specific shifters with adequate factors of proportionality, based on the destination median or a destination extremum. To separately identify $\delta_{\text {LAC }}$ and $\delta_{\text {ROw, we use sets }}$ of moments for both LAC and ROW (non-LAC) destinations. 


\section{D.B.1 Within-destination sales of top-selling products across firms}

Our first set of moments compares the sales $y_{\omega d 1}^{G}$ of the firms' top-selling products $\hat{g}_{\omega d}=1$ across firms within a destination $d$. We compute these moments for groups of firms that share the same exporter scope $G_{\omega d} \in G$. Within each destination, we start with single-product firms (firms with an exporter scope $G_{\omega d}=1$ ) and rank order the firms by their single product's sales from largest to smallest within the destination $d$. From the rank order of product sales we pick firms at select percentiles $P(\omega)=p$, overusing higher percentiles to match mostly upper-tail behavior (however still retaining some moments as low as the 25 th percentile). Then we repeat the computations for the group of firms with an exporter scope of two or three products sold $\left(G_{\omega d} \in\{2,3\}\right)$, and again rank only their top-selling products by sales across firms within destination, and so forth. Normalizing with the sales of the top-product at the median firm $P(\omega)=.5$ within an exporter-scope group $G_{\omega d}=G$, we obtain a first set of moments

$$
\begin{aligned}
M 1_{p d}^{G} \equiv \ln \left(\frac{y_{P(\omega)=p, d 1}^{G}}{y_{P(\omega)=.5, d 1}^{G}}\right), \quad & p \in\{.95, .90, .85, .80, .70, .60, .25\} \\
& G \in\{\{1\}\{2,3\}\{4,5,6\}\{7, \ldots\}\} .
\end{aligned}
$$

This procedure would provide us with $7 \times 4 \times N$ moments for $N$ destinations. For simplicity, we use the weighted geometric average across LAC and non-LAC destinations and obtain just $7 \times 4 \times 2$ moments $M 1_{p d}^{G}$.

The sales dispersion across the firms' top-selling products is driven by the product appeal realization and partly by a firm's market-access cost draw because product sales are larger on average in markets with higher access costs (see step (iv) of the algorithm).

\section{D.B.2 Within-destination and within-firm product sales concentration}

The second set of moments compares the sales $y_{\omega d 1}^{G}$ of a firm's top-selling product and the sales $y_{\omega d \hat{g}}^{G}$ of the same firm's $\hat{g}_{\omega d}$-th ranked product within a destination $d$. We compute these moments for groups of firms that share the same global scope $\max _{d}\left\{G_{\omega d}\right\} \in G$ across all destinations. For all firms that have a global scope of $\max _{d}\left\{G_{\omega d}\right\} \in G$, within each destination we compute the firm $\omega$ 's sales ratio $y_{\omega d \hat{g}}^{\max } G / y_{\omega d 1}^{\max G}$ for the following three groups of lower-ranked products $\hat{g} \in\{\{2,3\}\{4,5,6\}\{7, \ldots\}\}$. For each group of lower-ranked products, we then pool over all destinations within a region and pool over all scope groups the sales ratios $y_{\omega d \hat{g}}^{\max G} / y_{\omega d 1}^{\max G}$, rank order the sales ratios $y_{\omega d \hat{g}}^{\max G} / y_{\omega d 1}^{\max G}$ from highest to lowest and pick firm observations at select percentiles $P(\omega)=p$. We obtain the second set of moments

$$
\begin{array}{ll}
M 2_{p d}^{\hat{g}} \equiv \ln \left(\frac{y_{P(\omega)=p, d \hat{g}}^{G}}{y_{P(\omega)=p, d 1}^{G}}\right), \quad & p \in\{.90, .75, .50, .25, .10\}, \\
\hat{g} & \in\{\{2,3\}\{4,5,6\}\{7, \ldots\}\} .
\end{array}
$$

We compute the moments separately for LAC and non-LAC destinations, so this procedure generates $5 \times 3 \times 2$ moments $M 2_{p d}^{\hat{g}}$.

The comparison of sales within firms of a given global scope implicitly conditions on the firm's global productivity percentile $\left(\phi_{\omega} / \phi^{*}\right)$, and the comparison within destinations removes 
Table D.1: Firm Counts of Destination Strings

\begin{tabular}{lrllr}
\hline \multicolumn{2}{c}{ Latin America and Caribbean (LAC) } & & \multicolumn{2}{c}{ Rest of World (non-LAC) } \\
\cline { 1 - 2 } \cline { 5 - 5 } Destination String & \# Firms & & Destination String & \# Firms \\
ARG & 1,683 & & USA & 1,651 \\
ARG-URY & 499 & & USA-DEU & 236 \\
ARG-URY-CHL & 307 & & USA-DEU-ITA & 52 \\
ARG-URY-CHL-PRY & 214 & & USA-DEU-ITA-GBR & 87 \\
ARG-URY-CHL-PRY-BOL & 585 & & USA-DEU-ITA-GBR-ESP & 138 \\
Other & 4,817 & & Other & 3,322 \\
Total & 8,105 & & Total & 5,486 \\
\hline
\end{tabular}

Source: SECEX 2000, manufacturing firms and their manufactured products.

Note: Strings denote Argentina (ARG), Uruguay (URY), Chile (CHL), Paraguay (PRY) and Bolivia (BOL); United States (USA), Germany (DEU), Italy (ITA), the United Kingdom (GBR) and Spain (ESP). Those are the top five destinations within LAC and within non-LAC in terms of Brazilian manufacturing firm presence with manufactured product exports.

destination specific variation including a firm's market access shock at a destination (see step (iv) of the algorithm). The within-firm and within-destination sales ratio $y_{\omega d \hat{g}}^{\max G} / y_{\omega d 1}^{\max G}$ therefore varies with $\tilde{\alpha}$ and captures the product appeal shock dispersion.

\section{D.B.3 Within-destination exporter scope distribution}

The third set of moments characterizes the exporter scope distribution by destination. We count the exporters with an exporter scope of at least $G_{\omega d} \geq G$ at every destination and compute their share in the total number of exporters at the destination. We obtain a third set of moments

$$
M 3_{d}^{G} \equiv \frac{\sum_{\omega \in \boldsymbol{\Omega}_{d}} \mathbf{1}\left\{G_{\omega d} \geq G\right\}}{\sum_{\omega \in \boldsymbol{\Omega}_{d}} 1\left\{G_{\omega d} \geq 1\right\}}, \quad G \in\{2,4,6,8,12,16\} .
$$

This procedure would provide us with $6 \times N$ moments for $N$ destinations. For simplicity, we use the weighted geometric average separately across LAC and non-LAC destinations and obtain just $6 \times 2$ moments $M 3_{d}^{G}$.

The within-destination share of firms with a given exporter scope addresses the parameter $\tilde{\theta}$ of the firm productivity distribution and also the scope cost elasticity $\delta+\tilde{\alpha}$, which translates productivity into exporter scope (see steps (ii) and (iii) of the algorithm). The share of firms with a given exporter scope captures the dispersion of market-access cost draws in addition because exporter scope is larger on average in markets with lower access costs.

\section{D.B.4 Market presence combinations}

For the fourth set of moments, we take the top five export destinations within LAC and within non-LAC in terms of the presence of Brazilian manufacturing exporters. We calculate the shares 
of exporters that sell to any of the permutations of those five destinations. The top five most common destinations within LAC are Argentina (ARG), Uruguay (URY), Chile (CHL), Paraguay (PRY) and Bolivia (BOL), within non-LAC they are the United States (USA), Germany (DEU), Italy (ITA), the United Kingdom (GBR) and Spain (ESP). We summarize the possible permutations with strings of up to five destinations. For example, the single-destination string ARG means selling to Argentina but to no other among the top five destinations in LAC; the string ARG-URY means selling to Argentina and Uruguay but not to Chile, Paraguay or Bolivia. See Table D.1 for frequencies of select permutations. This collection of destination combinations produces a total of $2 \times 2^{5}=64$ moments, denoted $M 4_{\{d\} \text {-сомв. }}$.

These moments reflect every firm $\omega$ 's exact destination combination and therefore help assess the dispersion of market-access cost draws.

\section{D.B.5 Within-firm export proportions between destination pairs}

The fifth set of moments compares a firm $\omega$ 's total exports $t_{\omega d}$ to a destination $d$ and its total exports to Argentina for LAC ( $\left.t_{\omega \mathrm{ARG}}\right)$ or the United States for non-LAC ( $\left.t_{\omega \mathrm{USA}}\right)$. We compute the total export ratios $t_{\omega d} / t_{\omega \mathrm{ARG}}$ and $t_{\omega d} / t_{\omega \mathrm{USA}}$ by destination $d$ and firm $\omega$ for the four destinations Uruguay, Chile, Paraguay and Bolivia in LAC (which together with Argentina are the top five LAC destinations in terms of presence of Brazilian manufacturing exporters) and for the four destinations Germany, Italy, United Kingdom and Spain in non-LAC (which together with the United are the five most common non-LAC destinations). Within each region LAC and nonLAC we then rank order the firms by their export ratios $t_{\omega d} / t_{\omega \mathrm{ARG}}$ and $t_{\omega d} / t_{\omega \mathrm{USD}}$ from largest to smallest for each of the four close-to-top destinations. From the rank order of product sales we pick firms at select percentiles $P(\omega)=p$. Normalizing with the exports ratio at the median firm $P(\omega)=.5$, we obtain the fifth set of moments

$$
\begin{aligned}
M 5_{p d_{\mathrm{LAC}}} \equiv \ln \left(\frac{t_{P(\omega)=p, d} / t_{P(\omega)=p, \mathrm{ARG}}}{t_{P(\omega)=.5, d} / t_{P(\omega)=.5, \mathrm{ARG}}}\right), \quad p \in\{.95, .90, .85, .70, .60, .25\} \\
\quad d_{\mathrm{LAC}} \in\{\mathrm{URY}, \mathrm{CHL}, \mathrm{PRY}, \mathrm{BOL}\} .
\end{aligned}
$$

and

$$
\begin{aligned}
& M 5_{p d_{\text {non-LAC }}} \equiv \ln \left(\frac{t_{P(\omega)=p, d} / t_{P(\omega)=p, \text { USA }}}{t_{P(\omega)=.5, d} / t_{P(\omega)=.5, \mathrm{USA}}}\right), \quad p \in\{.95, .90, .85, .70, .60, .25\} \\
& d_{\text {non-LAC }} \in\{\text { DEU, ITA, GBR, ESP }\}
\end{aligned}
$$

This procedure generates $6 \times 4 \times 2$ moments $M 5_{p d_{\mathrm{LAC}}}$ and $M 5_{p d_{\text {non-LAC }}}$.

The exports ratio between destination pairs captures the dispersion of market-access cost draws, which alter exporter scope and therefore total sales, and the ratio captures the dispersion of product appeal shocks, which change product sales directly. A firm's total sales ratio depends on the firm's respective scope cost elasticity $\delta+\tilde{\alpha}$ by equation (16). 


\section{E Counterfactuals and Calibration}

We follow a procedure similar to Alvarez and Lucas (2007), Dekle, Eaton and Kortum (2007a) and Eaton, Kortum and Kramarz (2011), and extend our framework to a setting with:

- immobile labor between countries, but mobile labor between sectors, so there is a single wage $W_{s}$ in country $s$;

- an input bundle that consists of labor and intermediate goods, so such an input costs

$$
w_{s}=W_{s}^{\beta} P_{s}^{1-\beta}
$$

- a non manufacturing, non-traded final-product sector that only requires labor input and produces with a Cobb-Douglas combination of the non-manufacturing and manufacturing sectors, so final good prices are

$$
P_{s}^{f}=P_{i}^{\gamma} W_{i}^{1-\gamma}
$$

- market-access costs that require labor at the export destination and are homogeneous of degree $1-\tilde{\theta}$ in foreign wages, so we can rewrite

$$
f_{s d}(1) \bar{F}_{s d}=W_{d}^{1-\tilde{\theta}} \tilde{F}_{s d}
$$

where $\tilde{F}_{s d}$ denotes mean market-access cost costs in terms of labor units;

- unchanging trade deficits in manufacturing and non-manufacturing sectors;

- technological parameters and labor endowments that are time invariant.

Using equation (23) for current trade shares $\lambda_{s d}$, we can express counterfactual trade shares as

$$
\lambda_{s d}^{\prime}=\frac{\lambda_{s d}\left(\hat{W}_{s}^{\beta} \hat{P}_{s}^{1-\beta}\right)^{-\theta} \hat{\tau}_{s d}^{-\theta} \widehat{\tilde{F}}_{s d}}{\sum_{k} \lambda_{k d}\left(\hat{W}_{k}^{\beta} \hat{P}_{k}^{1-\beta}\right)^{-\theta} \hat{\tau}_{k d}^{-\theta} \widehat{\widetilde{F}}_{k d}} .
$$


The price index (3) can be derived as

$$
\begin{aligned}
P_{d}^{1-\sigma} & =\sum_{k} \int_{c_{d}}\left[\int_{\phi_{k d}^{*}\left(c_{d}\right)}\left[\sum_{g=1}^{G_{k d}(\phi)}\left(\tilde{\sigma} \frac{w_{k}}{\phi / h(g)} \tau_{k d}\right)^{1-\sigma}\right] \frac{\theta\left(\phi_{k d}^{*}\left(c_{d}\right)\right)^{\theta}}{\phi^{\theta+1}} \mathrm{~d} \phi\right] \mathrm{d} F\left(c_{d}\right) \\
& =\sum_{k}\left(\tilde{\sigma} w_{k} \tau_{k d}\right)^{1-\sigma} J_{k} b_{k}^{\theta} \theta \int_{c_{d}}\left[\int_{\phi_{k d}^{*}\left(c_{d}\right)}\left[\sum_{g=1}^{G_{k d}(\phi)} \frac{h(g)^{1-\sigma}}{\phi^{2-\sigma+\theta}}\right] \mathrm{d} \phi\right] \mathrm{d} F\left(c_{d}\right) \\
& =\sum_{k}\left(\tilde{\sigma} w_{k} \tau_{k d}\right)^{1-\sigma} J_{s} b_{s}^{\theta} \theta\left[\frac{1}{\theta-(\sigma-1)}\left(\frac{f_{s d}(1)}{\left(\phi_{s d}^{*}\right)^{\sigma-1}}\right)^{\tilde{\theta}-1} \sum_{G=1}^{\infty} \frac{f_{s d}(G)^{-(\tilde{\theta}-1)}}{h(G)^{\theta}}\right] \int_{c_{d}} c_{d}^{-\tilde{\theta}} \mathrm{d} F\left(c_{d}\right) \\
& =\sum_{k}\left(\tilde{\sigma} w_{k} \tau_{k d}\right)^{1-\sigma} J_{s} b_{s}^{\theta} \theta\left[\frac{1}{\theta-(\sigma-1)}\left(\left(\frac{P_{d}}{\tilde{\sigma} \tau_{s d} w_{s}}\right)^{\sigma-1} \frac{T_{d}}{\sigma}\right)^{\tilde{\theta}-1} \bar{F}_{k d} f_{k d}(1)^{-\tilde{\theta}}\right] \kappa .
\end{aligned}
$$

The second step uses equation (19). The third step uses Lemma 1 to replace the integral term. The fourth step uses the $\log$-normal distribution of $c_{d}$ as well as equations (10) and (19). Finally, collecting terms and solving for $P_{d}^{-\theta}$ yields

$$
P_{d}^{-\theta}=\kappa\left(T_{d}\right)^{\tilde{\theta}-1} \frac{\sigma^{-(\tilde{\theta}-1)} \tilde{\sigma}^{-\theta}}{1-1 / \tilde{\theta}} \sum_{k} J_{k} b_{k}^{\theta}\left(W_{k}^{\beta} P_{k}^{1-\beta}\right)^{-\theta} \tau_{k d}^{-\theta} W_{d}^{-(\tilde{\theta}-1)} \tilde{F}_{k d},
$$

which can be restated in terms of relative changes as ${ }^{45}$

$$
\hat{P}_{d}=\left[\sum_{k} \lambda_{k d}\left(\hat{W}_{k}^{\beta} \hat{P}_{k}^{1-\beta}\right)^{-\theta} \hat{\tau}_{k d}^{-\theta} \widehat{\tilde{F}}_{k d}\right]^{-1 / \theta}\left(\frac{\hat{T}_{d}}{\hat{W}_{d}}\right)^{1 / \theta-1 /(\sigma-1)} .
$$

As regards notation, $\hat{x}$ denotes a gross relative change: $\hat{x} \equiv x^{\prime} / x$, where $x^{\prime}$ is the new value. The above result is a system of equations that determines relative changes of prices as a function of relative changes in wages. To complete the procedure, we follow Eaton, Kortum and Kramarz

${ }^{45}$ We can use expression (E.6) together with equation (23) to obtain

$$
P_{d}^{-\theta}=\left(T_{d}\right)^{\tilde{\theta}-1} \frac{(\sigma)^{-(\tilde{\theta}-1)}(\tilde{\sigma})^{-\theta}}{1-1 / \tilde{\theta}} \frac{J_{d} b_{d}^{\theta}\left(W_{d}^{\beta} P_{d}^{1-\beta}\right)^{-\theta} W_{d}^{-(\tilde{\theta}-1)} \tilde{F}_{d d}}{\lambda_{d d}} .
$$

Thus changes in real wage are

$$
\widehat{\left(\frac{W_{d}}{P_{d}}\right)}=\left(\widehat{\lambda_{d d}}\right)^{-1 / \theta} \frac{\left(\widehat{T_{d}} / \widehat{W}_{d}\right)^{\frac{1-\tilde{\theta}}{\theta}}}{\left(\widehat{\tilde{F}_{d d}}\right)^{-1 / \theta}}
$$

We consider $\widehat{\tilde{F}_{d d}}=1$ in our counterfactual exercise, so this expression differs for domestic access costs from a similar one in Arkolakis, Costinot and Rodríguez-Clare (2012) inasmuch as changes in the ratio $\widehat{T_{d}} / \widehat{W_{d}}$ reflect changes in the ratio of total absorption to wages (which is not one due to non-zero deficits). 
(2011, Appendix E). Total manufacturing absorption is

$$
T_{d}=\gamma_{d} \cdot \underbrace{\left(Y_{d}^{T}+B_{d}^{T}\right)}_{\begin{array}{c}
\text { final demand } \\
\text { (labor income + profits) }
\end{array}}+(1-\beta) \cdot \underbrace{\frac{\sigma-1}{\sigma} Y_{d}}_{\begin{array}{c}
\text { demand for intermediates } \\
\text { by manufacturing sector }
\end{array}},
$$

where $Y_{d}^{T}$ is total GDP of country $d$, including labor income and profits, $B_{d}^{T}$ is the current account deficit and $Y_{d}$ output of the manufacturing sector. We allow the share $\gamma_{d}$ of manufacturing value added in GDP to be country specific. Manufacturing expenditure equals $T_{d}=Y_{d}+B_{d}$, where $B_{d}$ is the trade deficit in the manufacturing sector. We can therefore solve for $T_{d}$ and $Y_{d}$ and obtain

$$
\begin{aligned}
T_{d} & =\frac{\gamma_{d}\left(Y_{d}^{T}+B_{d}^{T}\right)-(1-\beta)(1-1 / \sigma) B_{d}}{1 / \sigma+\beta(1-1 / \sigma)}, \\
Y_{d} & =\frac{\gamma_{d}\left(Y_{d}^{T}+B_{d}^{T}\right)-B_{d}}{1 / \sigma+\beta(1-1 / \sigma)} .
\end{aligned}
$$

We assume $\gamma_{d}$ is time invariant, so we solve equation (E.8) for $\gamma_{d}$ using 2000 baseline data.

To summarize, using the Dekle, Eaton and Kortum (2007a) algorithm, we can compute how given relative changes in market-access costs $\widehat{\tilde{F}}_{k d}$ lead to $\hat{\lambda}_{s d}, \hat{P}_{d}, \hat{W}_{d}$. Denoting future variables with a prime, we find $T_{d}^{\prime}, Y_{d}^{\prime}$ by inspecting equations (E.5), (E.6) and imposing the market clearing condition

$$
Y_{s}^{\prime} L_{s}=\sum_{k=1}^{N} \lambda_{s k}^{\prime} T_{k}^{\prime}
$$

\section{F Varying the Productivity Distribution}

While we can allow for flexible forms of the firm-destination market-access cost distribution and the firm-product-destination appeal shock distribution, a critical assumption for closed-form general equilibrium (in Section IV) and counterfactuals (in Section V) is that the firm-specific productivity shock is Pareto distributed. For our SMM estimation routine, however, the Pareto assumption can be easily relaxed to allow for a different and more general distribution of productivity. We show in this Appendix that using the empirically plausible log-normal distribution (Fernandes et al. 2018) in our SMM estimator yields similar parameter estimates for firm scope and scale. In addition, aggregate trade patterns remain similar, arguably because the bulk of trade is conducted by the largest firms.

We first present our computation strategy using a general distribution for firm productivity, and then show the results of our estimation routine using a log-normal distribution. In the Online Supplement S8 we discuss implications for aggregates and counterfactual simulations when changing the firm productivity distribution to a non-Pareto distribution such as the lognormal distribution of productivity. 


\section{F.A Computation strategy}

Consider firms in a common source country $s$. Each firm gets a productivity draw $\phi$, destination cost shock $c_{d}$ and a destination-product product demand shock $\xi_{d g}$.

Firms export to destination $d$ only if $\phi>\phi_{d}^{*}\left(c_{d}\right)$, where

$$
\phi_{d}^{*}\left(c_{d}\right)^{\sigma-1}=c_{d} \underbrace{\frac{f_{d}(1)}{D_{d}}}_{\bar{D}_{d}} .
$$

We compute $\bar{D}_{d}$ to match the number of observed exporters at destination $d$. The productivity cutoff for market entry with at least $G$ products is

$$
\phi_{d}^{* G}\left(c_{d}\right)^{\sigma-1}=\phi_{d}^{*}\left(c_{d}\right)^{\sigma-1} G^{\delta_{d}} G^{\tilde{\alpha}},
$$

where $\tilde{\alpha} \equiv \alpha(\sigma-1)$.

We then compute sales $y_{d g}\left(\phi, c_{d}, \xi_{d g}\right)$ of a product of rank $g$ to destination $d$ (for a firm with productivity draw $\phi$, destination cost shock $c_{d}$ and a destination-product product demand shock $\left.\xi_{d g}\right)$. Following similar derivations as for our main analysis, we find that a firm that sells $G$ products to destination $d$ has product-level sales

$$
y_{d g}\left(\phi, c_{d}, \xi_{d g}\right)=\sigma c_{d} f_{d}(1) G^{\delta_{d}} G^{\tilde{\alpha}}\left(\frac{\phi}{\phi_{d}^{* G}\left(c_{d}\right)}\right)^{\sigma-1} g^{-\tilde{\alpha}} \xi_{d g} .
$$

Our SMM estimation procedure only uses relative comparisons in sales, so $\sigma c_{d} f_{d}(1)$ drops from all computations.

As before we can therefore express product sales as:

$$
\begin{aligned}
y_{d g}\left(\phi, c_{d}, \xi_{d g}\right) & =\sigma c_{d} f_{d}(1) G^{\delta_{d}} G^{\tilde{\alpha}}\left(\frac{\phi}{\phi_{d}^{* G}\left(c_{d}\right)}\right)^{\sigma-1} g^{-\tilde{\alpha}} \xi_{d g} \\
& =\sigma c_{d} f_{d}(1) G^{\delta_{d}} G^{\tilde{\alpha}} \frac{(\phi)^{\sigma-1}}{\phi_{d}^{*}\left(c_{d}\right)^{\sigma-1} G^{\delta_{d}} G^{\tilde{\alpha}}} g^{-\tilde{\alpha}} \xi_{d g} \\
& =\sigma c_{d} f_{d}(1) \frac{(\phi)^{\sigma-1}}{\phi_{d}^{*}\left(c_{d}\right)^{\sigma-1}} g^{-\tilde{\alpha}} \xi_{d g} .
\end{aligned}
$$

\section{F.B Comparison of results}

For computation we assume that all random variables are drawn from independent log-normal distributions with the following parameters: $\phi \sim \log N\left(-\sigma_{\phi}^{2} / 2, \sigma_{\phi}^{2}\right), c_{d} \sim \log N\left(-\sigma_{c}^{2} / 2, \sigma_{c}^{2}\right)$, and $\xi \sim \log N\left(0, \sigma_{\xi}^{2}\right)$. Note that if $\phi$ is $\log$-normal then $\phi^{\sigma-1}$ is distributed $\log$-normal with $\phi^{\sigma-1} \sim \log N\left(0, \sigma_{\phi}^{2}(\sigma-1)^{2}\right)$. We define the variance $\tilde{\sigma}_{\phi} \equiv \sigma_{\phi}^{2}(\sigma-1)^{2}$ and estimate it in lieu of $\sigma$ and $\sigma_{\phi}$ before.

Table F.1 shows a comparison of the estimates under Pareto distribued and log-normally distributed firm productivity. The results are relatively similar in general, and the difference 
Table F.1: Estimation Results for Log-normal Productivity

\begin{tabular}{lccccccc}
\hline & $\delta_{\text {LAC }}$ & $\delta_{\text {ROW }}$ & $\tilde{\alpha}$ & $\tilde{\theta} / \tilde{\sigma}_{\phi}$ & $\sigma_{\xi}$ & $\sigma_{c}$ & $\delta_{\text {LAC }}-\delta_{\text {ROW }}$ \\
\hline Baseline & -1.17 & -.87 & 1.77 & 1.73 & 1.82 & .58 & -.30 \\
$\quad$ Pareto productivity & $(.05)$ & $(.07)$ & $(.05)$ & $(.09)$ & $(.04)$ & $(.02)$ & $(.06)$ \\
Baseline & -1.20 & -.90 & 1.90 & 1.90 & 1.73 & .69 & -.30 \\
$\quad$ Log-normal productivity & $(.04)$ & $(.06)$ & $(.04)$ & $(.04)$ & $(.03)$ & $(.02)$ & $(.07)$ \\
\hline
\end{tabular}

Source: SECEX 2000, manufacturing firms and their manufactured products.

Note: Products at the HS 6-digit level. Standard errors from 30 bootstraps in parentheses. Estimates of $\delta_{\text {LAC }}$ measure the scope elasticity of market-access costs for Brazilian firms shipping to other LAC destinations, $\delta_{\mathrm{ROW}}$ for Brazilian firms shipping to destinations outside LAC.

between $\delta_{\text {LAC }}$ and $\delta_{\text {ROW }}$ in particular is virtually unchanged between specifications.

Figures F.1 and F.2 compare the targeted moments between Pareto and log-normally distributed firm productivity. The SMM estimators under either specification of the productivity distribution do a reasonably similar job. Figures F.3 and F.4 compare the non-targeted moments between using Pareto and log-normally distributed firm productivity. Again, both SMM estimators appear to do a reasonably similar job, but SMM for Pareto productivity performs better in matching the relationship between exporter scope and scale for non-LAC countries. The superior performance of SMM under Pareto appears to be driven by the fact that the Pareto distribution can do a better job at explaining extremes, which heavily influence the means. 


\section{Figure F.1: Fit of Targeted Moments under Pareto Productivity}

\section{(A) Firm-product Sales Distribution}

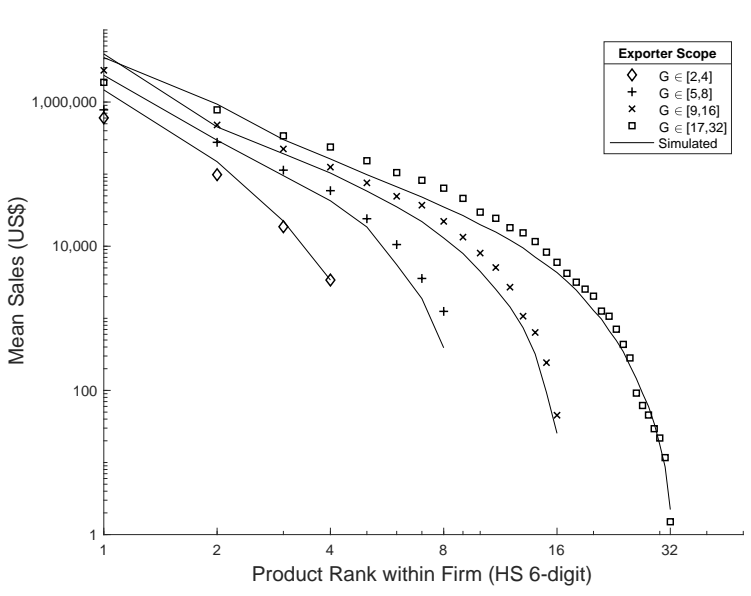

(B) Exporter Scope Distribution

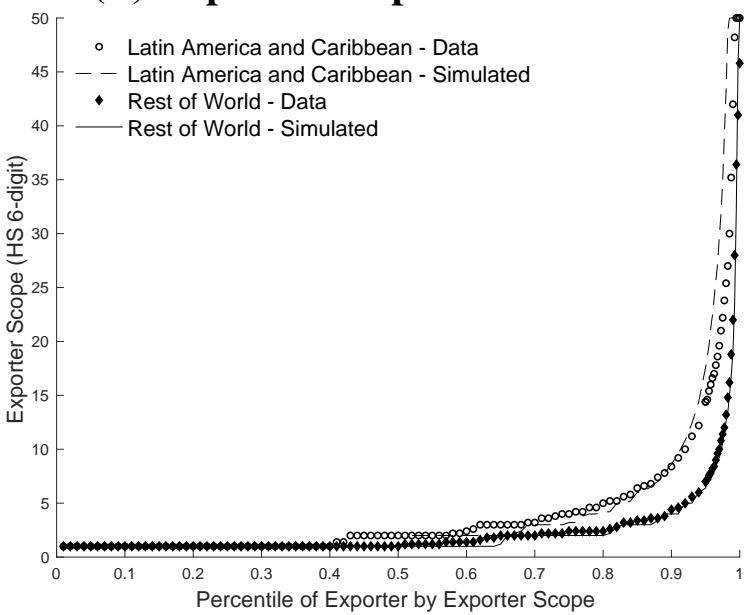

Figure F.2: Fit of Targeted Moments under Log-normal Productivity

\section{(A) Firm-product Sales Distribution}

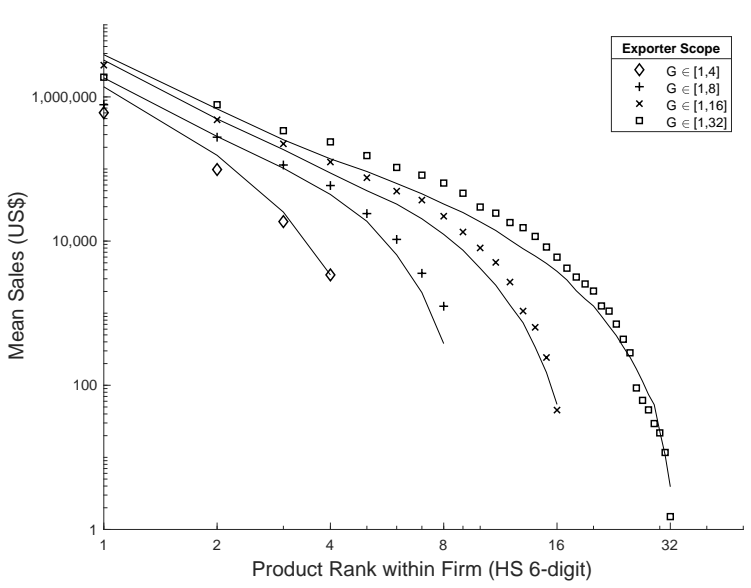

(B) Exporter Scope Distribution

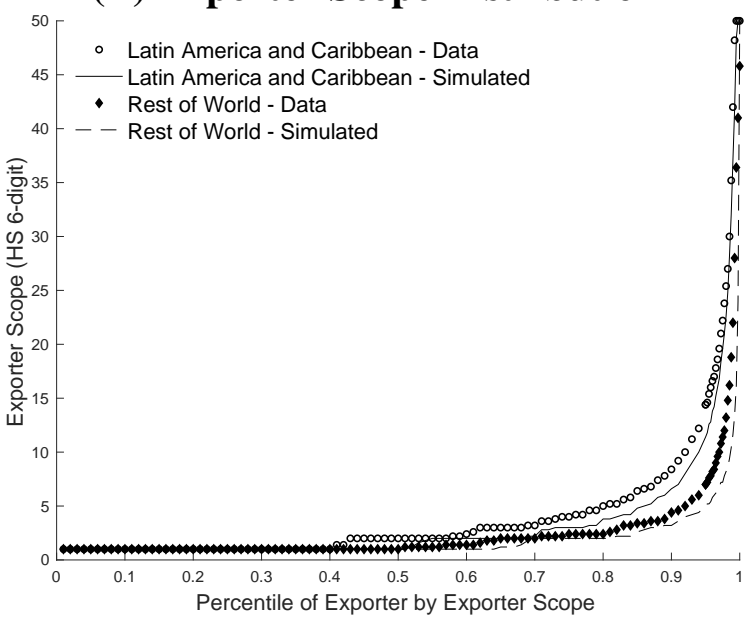

Source: SECEX 2000, manufacturing firms and their manufactured products.

Note: Products at the HS 6-digit level. The upper two panels for Pareto productivity are the same as in Figure 5, and data plots replicate those in Figures 2 and 3. Panel A shows shipments to Argentina, grouping firms by their local exporter scope and firm-products by their local sales rank. Panel B shows the exporter scope by percentile, averaged across the five most common destinations within each of the two regions LAC and Rest of World (non-LAC) 
Figure F.3: Fit of Non-Targeted Moments under Pareto Productivity

(A) Exporter Scope and Scale

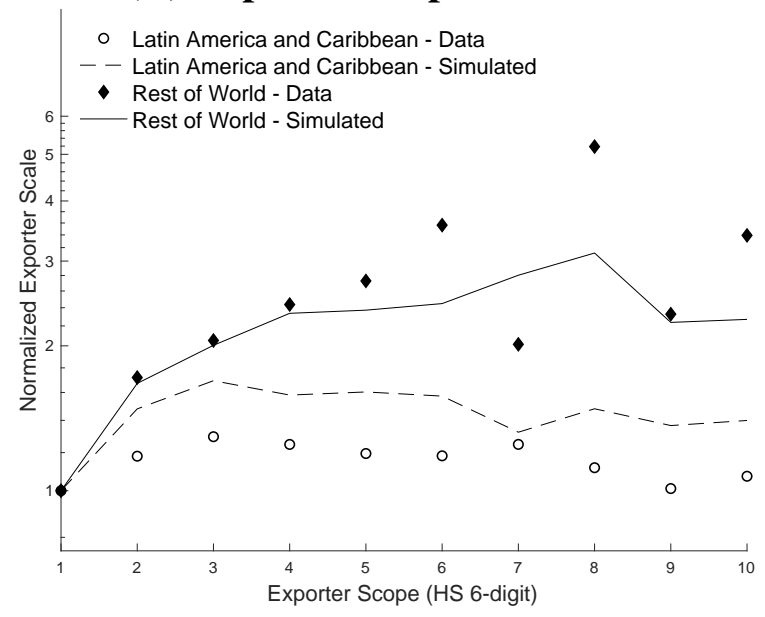

(B) Export Sales Distribution

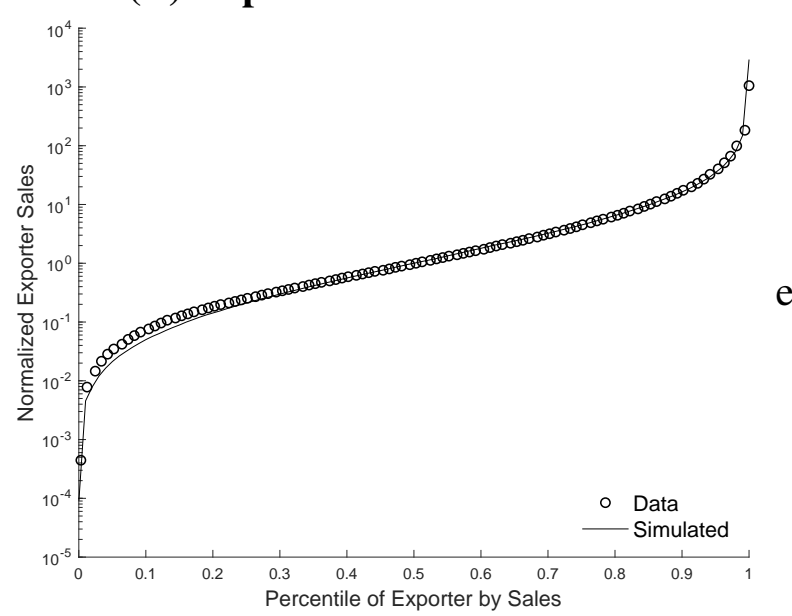

Figure F.4: Fit of Non-Targeted Moments under Log-normal Productivity

(A) Exporter Scope and Scale

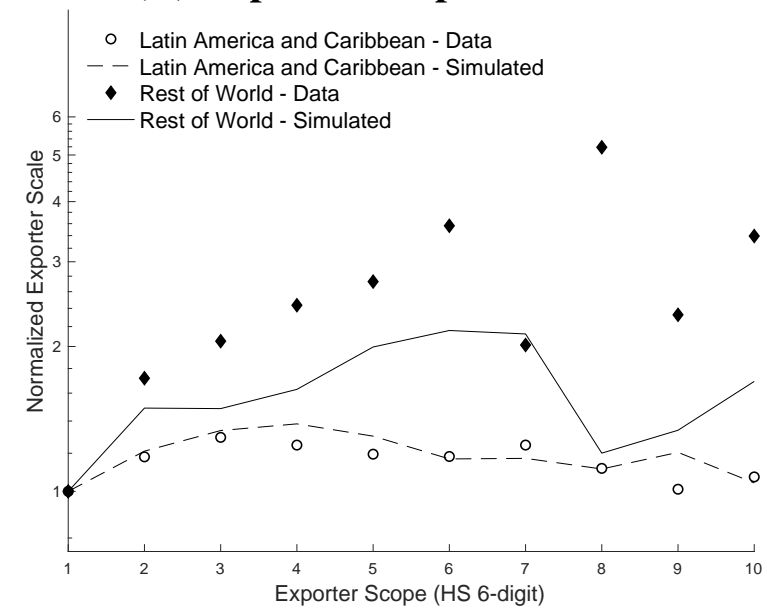

(B) Export Sales Distribution

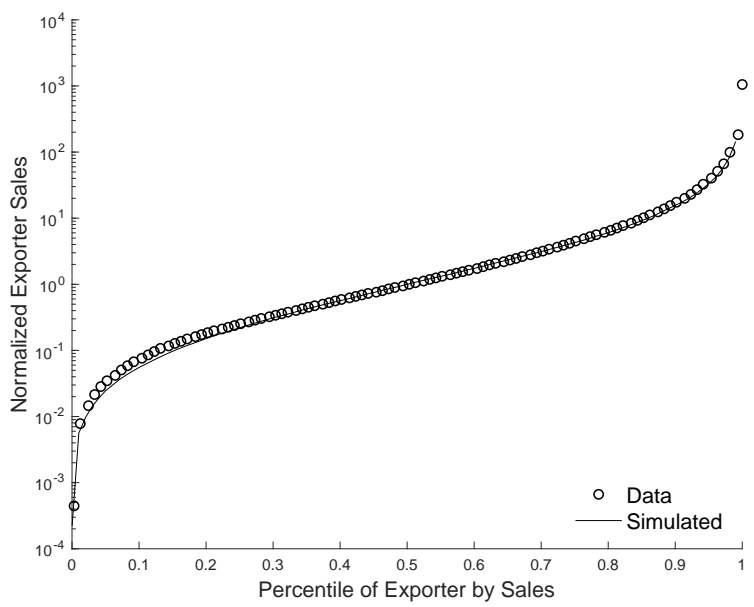

Source: SECEX 2000, manufacturing firms and their manufactured products.

Note: Products at the HS 6-digit level. The upper two panels for Pareto productivity are the same as in Figure 6, and data plots in the left panels A replicate the data plot in Figure 4. Predicted curves based on simulations in Section D.A, using the baseline parameter estimates in Table 3. Panels A show exporter scale (a firm's total sales at a destination divided by its exporter scope at the destination) on a log scale plotted against exporter scope, averaging a variable over the five most common destinations within each of the two regions LAC and Rest of World (nonLAC) and normalizing scale by the average total sales of single-product exporters at the destination. Panels B show total firm exports by percentile, averaging a firm's total exports over the five most common destinations within each of the two regions and normalizing total sales by the median firm's total at the destination. 


\section{Online Supplement to}

\section{The Extensive Margin of Exporting Products: A Firm-level Analysis}

Costas Arkolakis, Yale University, CESifo and NBER

July 8, 2020

Sharat Ganapati, Georgetown University and CESifo

Marc-Andreas Muendler, UC San Diego, CESifo and NBER

This Online Supplement is organized in seven sections. Section S1 generalizes the model of the main paper (henceforth AGM) to nested consumer preferences (as previewed in Appendix C to AGM). Each inner nest holds the products in a firm's product line with an elasticity of substitution that differs from that of the outer nest over product lines of different firms. In Section S2, we accommodate market penetration costs as in Arkolakis (2010) and show that our simulated methods of moments estimator is invariant to marketing costs at the level of product lines. Section S3 presents detailed reduced form evidence covering non-tariff measures (NTMs). Section S4 presents tabulations of the underlying Brazilian export data for 2000. In Section S5 we report Monte Carlo simulations that assess identification under our estimation routine. We turn to special cases of our model in Section S6, where we consider in particular a limit case that approximates the single-product benchmark model by Eaton, Kortum and Kramarz (2011). Section S7 offers a variety of robustness checks for our main estimates, using alternative assumptions and restricted samples. Section S8 summarizes conceptual challenges that would arise in counterfactual exercises with log-normally distributed firm productivity.

\section{S1 Nested Preferences with Different Elasticities}

We analyze a generalized version of the AGM model of multi-product firms that allows for within-firm cannibalization effects. The main result is that the qualitative properties of the AGM model are retained: the size distribution of firm sales and the distribution of the firms' numbers of products is consistent with regularities in Brazilian exporter data as well as other data sets. More importantly, the general equilibrium properties of the model do not depend on the inner nests' elasticity (the elasticity across the products of a given firm's product composite) so that the general equilibrium of the model can be easily characterized using the tools of Dekle, Eaton and Kortum (2007a).

While the model is highly tractable, the introduction of one more demand elasticity adds a further degree of freedom. This degree of freedom can be disciplined using independent estimates for the outer and inner nests' elasticities, such as those of Broda and Weinstein (2006). Under an according parametrization, the model can be used for counterfactual exercises that simulate the impact of changes in trade costs on the firm size distribution and the distribution of the firms' numbers of products.

In the following subsection we present and solve the generalized model. We derive its aggregate properties in subsection $\mathrm{S} 1.2$. Subsection S1.3 concludes the presentation of the model with nested preferences. 


\section{S1.1 Model}

There is a countable number of countries. We label the source country of an export shipment with $s$ and the export destination with $d$.

We adopt a two-tier nested CES utility function for consumer preferences. ${ }^{46}$ Each inner nest of consumer preferences aggregates a firm's products with a CES utility function and an elasticity of substitution $\varepsilon$. Using marketing terminology, the product composite of the inner nest can be called a firm's product line or product mix. The product lines of different firms are then aggregated using an outer CES utility nest with an elasticity $\sigma$. Each firm offers a countable number of products but there is a continuum of firms in the world. We assume that every product line is uniquely offered by a single firm, but a firm may ship different product lines to different destinations. Formally, the representative consumer's utility function at destination $d$ is given by

$$
U_{d}=\left(\sum_{s} \int_{\Omega_{s d}}\left(\sum_{g=1}^{G_{s d}(\omega)} q_{s d g}(\omega)^{\frac{\varepsilon-1}{\varepsilon}}\right)^{\frac{\sigma-1}{\sigma} \frac{\varepsilon}{\varepsilon-1}} \mathrm{~d} \omega\right)^{\frac{\sigma}{\sigma-1}}
$$

where $q_{s d g}(\omega)$ is the quantity consumed of the $g$-th product of firm $\omega$, producing in country $s$. $\Omega_{s d}$ is the set of firms from source country $s$ selling to country $d$.

The representative consumer's first-order conditions imply that demand for the $g$-th product of firm $\omega$ in market $d$ is

$$
q_{s d g}(\omega)=p_{s d g}(\omega)^{-\varepsilon} P_{s d}\left(\omega ; G_{s d}\right)^{\varepsilon-\sigma} P_{d}^{\sigma-1} T_{d}
$$

where $p_{s d g}(\omega)$ is the price of that product,

$$
P_{s d}\left(\omega ; G_{s d}\right) \equiv\left[\sum_{g=1}^{G_{s d}(\omega)} p_{s d g}(\omega)^{-(\varepsilon-1)}\right]^{-1 /(\varepsilon-1)}
$$

is the ideal price index for the product line of firm $\omega$ selling $G_{s d}(\omega)$ products in market $d$, and

$$
P_{d} \equiv\left[\sum_{s} \int_{\Omega_{s d}} P_{s d}\left(\omega ; G_{s d}\right)^{-(\sigma-1)} \mathrm{d} \omega\right]^{-1 /(\sigma-1)}
$$

is the ideal consumer price index in market $d . T_{d}$ is total consumption expenditure.

\footnotetext{
${ }^{46}$ Atkeson and Burstein (2008) use a similar nested CES form in a heterogeneous-firms model of trade but their outer nest refers to different industries and the inner nests to different firms within the industry. Eaton and Kortum (2010) present a stochastic model with nested CES preferences to characterize the firm size distribution and their products under Cournot competition. In our model, firms do not strategically interact with other firms. This property of the model allows us to characterize general equilibrium beyond the behavior of individual firms.
} 


\section{S1.1.1 Firm optimization}

We assume that the firm has a linear production function for each product. A firm with overall productivity $\phi$ faces an efficiency $\phi / h(g)$ in producing its $g^{\prime}$ th product, where $h(g)$ is an increasing function with $h(1)=1$. We call the firm's total number of products $G_{s d}$ at destination $d$ its exporter scope at $d$. Productivity is the only source of firm heterogeneity so that, under the model assumptions below, firms of the same type $\phi$ from country $s$ face an identical optimization problem in every destination $d$. Since all firms with productivity $\phi$ will make identical decisions in equilibrium, it is convenient to name them by their common characteristic $\phi$ from now on. ${ }^{47}$

The firm also incurs local entry costs to sell its $g$-th product in market $d: f_{s d}(g)>0$ for $g>1$, with $f_{s d}(0)=0$. These incremental product-specific fixed costs may increase or decrease with exporter scope. The overall entry cost for market $d$ is denoted by $F_{s d}(G) \equiv \sum_{g=1}^{G} f_{s d}(g)$ and strictly increases in exporter scope by definition.

Profits of a firm with productivity $\phi$ from country $s$ that sells products $g=1, \ldots, G_{s d}$ in $d$ at prices $p_{s d g}$ are

$$
\pi_{s d}(\phi)=\sum_{g=1}^{G_{s d}}\left(p_{s d g}-\frac{w_{s}}{\phi / h(g)} \tau_{s d}\right) p_{s d g}^{-\varepsilon} \cdot P_{s d}\left(\phi ; G_{s d}\right)^{\varepsilon-\sigma} P_{d}^{\sigma-1} T_{d}-F_{s d}\left(G_{s d}\right) .
$$

We consider the first-order conditions with respect to the prices $p_{s d g}$ of each product $g$, consistent with an optimal product-line price $P_{s d}\left(\phi ; G_{s d}\right)$, and also with respect to exporter scope $G_{s d}$. As shown in Appendix S-A to this Online Supplement, the first-order conditions with respect to prices imply a constant markup over marginal cost for all products equal to $\tilde{\sigma} \equiv \sigma /(\sigma-1)$.

Using the constant markup rule in demand for the $g$-th product of a firm with exporter scope $G_{s d}$ yields optimal sales of the product

$$
p_{s d g}(\phi) q_{s d g}(\phi)=\left(\tilde{\sigma} \frac{w_{s} \tau_{s d}}{\phi / h(g)}\right)^{-(\varepsilon-1)} P_{s d}\left(\phi ; G_{s d}\right)^{\varepsilon-\sigma} P_{d}^{\sigma-1} T_{d}
$$

Using this result and the definition of $P_{s d}\left(\phi ; G_{s d}\right)$, we can rewrite profits that a firm generates at destination $d$ selling $G_{s d}$ products as

$$
\begin{aligned}
\pi_{s d}\left(\phi ; G_{s d}\right) & =P_{s d}\left(\phi ; G_{s d}\right)^{-(\sigma-1)} \frac{P_{d}^{\sigma-1} T_{d}}{\sigma}-F_{s d}\left(G_{s d}\right) \\
& =H\left(G_{s d}\right)^{-(\sigma-1)}\left(\tilde{\sigma} w_{s} \tau_{s d}\right)^{-(\sigma-1)} \frac{\phi^{\sigma-1} P_{d}^{\sigma-1} T_{d}}{\sigma}-F_{s d}\left(G_{s d}\right),
\end{aligned}
$$

where

$$
H\left(G_{s d}\right) \equiv\left[\sum_{g=1}^{G_{s d}} h(g)^{-(\varepsilon-1)}\right]^{-1 /(\varepsilon-1)}
$$

\footnotetext{
${ }^{47}$ To simplify the exposition, we assume here that firms face no other idiosyncratic cost components, whereas the AGM model also allows for a destination specific market-access cost shock $c_{d}$ so that a firm in that model is characterized by a pair of shocks $\left(\phi, c_{d}\right)$. The derivations here can be readily generalized to such idiosyncratic market-access costs.
} 
is the firm's product efficiency index.

Similar to Assumption 1 in AGM, we impose the following assumption, which is necessary for optimal exporter scope to be well defined.

Assumption S.1 Parameters are such that $Z_{s d}(G)=f_{s d}(G) /\left[H(G)^{-(\sigma-1)}-H(G-1)^{-(\sigma-1)}\right]$ strictly increases in $G$.

The expression for $Z_{s d}(G)$ reduces to $Z_{s d}(G)=f_{s d}(G) h(G)^{\sigma-1}$ when $\varepsilon=\sigma$. In that case, Assumption S.1 is identical to the one considered in AGM.

For a firm to enter a destination market, its productivity has to exceed a threshold $\phi_{s d}^{*}$, where $\phi_{s d}^{*}$ is implicitly defined by zero profits for the first product:

$$
P_{d}^{\sigma-1} T_{d}\left[P_{s d}\left(\phi_{s d}^{*} ; 1\right)\right]^{-(\sigma-1)}=\sigma f_{s d}(1) .
$$

Using the convention $h(1)=1$ for $G=1$ in (S.3) yields

$$
\left(\phi_{s d}^{*}\right)^{\sigma-1}=\sigma f_{s d}(1) \frac{\left(\tilde{\sigma} w_{s} \tau_{s d}\right)^{\sigma-1}}{P_{d}^{\sigma-1} T_{d}} .
$$

Similarly, we can define the threshold productivity of selling $G$ products in market $d$. The firm is indifferent between introducing a $G$-th product or stopping with an exporter scope of $G-1$ at the product-entry threshold $\phi_{s d}^{*, G}$ if

$$
\pi_{s d}\left(\phi_{s d}^{*, G} ; G\right)-\pi_{s d}\left(\phi_{s d}^{*, G} ; G-1\right)=0 .
$$

Using equations (S.3) and (S.4) in this profit equivalence condition, we can solve out for the implicitly defined product-entry threshold $\phi_{s d}^{*, G}$, at which the firm sells $G_{s d}$ or more products,

$$
\left(\phi_{s d}^{*, G}\right)^{\sigma-1}=\frac{\left(\phi_{s d}^{*}\right)^{\sigma-1}}{H\left(G_{s d}\right)^{-(\sigma-1)}-H\left(G_{s d}-1\right)^{-(\sigma-1)}} \frac{f_{s d}\left(G_{s d}\right)}{f_{s d}(1)}=\frac{\left(\phi_{s d}^{*}\right)^{\sigma-1}}{f_{s d}(1)} Z_{s d}\left(G_{s d}\right)
$$

where we define $\phi_{s d}^{*, 1} \equiv \phi_{s d}^{*}$. So, under Assumption S.1, the profit equivalence condition (S.5) implies that the product-entry thresholds $\phi_{s d}^{*, G}$ strictly increase with $G$ and more productive firms will weakly raise exporter scope compared to less productive firms.

Export sales can be written succinctly as

$$
\begin{aligned}
t_{s d}(\phi) & =\left(\tilde{\sigma} \frac{w_{s} \tau_{s d}}{\phi}\right)^{1-\varepsilon} P_{d}^{\sigma-1} T_{d} \sum_{g=1}^{G_{s d}} h(g)^{1-\varepsilon}\left[P_{d}\left(G_{s d}(\phi)\right)\right]^{\varepsilon-\sigma} \\
& =\sigma f_{s d}(1)\left(\frac{\phi}{\phi_{s d}^{*}}\right)^{\sigma-1} H\left(G_{s d}(\phi)\right)^{-(\sigma-1)}
\end{aligned}
$$

using equation (S.4). This sales relationship is similar in both models with $\varepsilon \neq \sigma$ and models with $\varepsilon=\sigma$. The only difference between the two types of models is that $H\left(G_{s d}\right)$ depends on $\varepsilon$ by (S.3). If the term $H\left(G_{s d}\right)$ converges to a constant for $G_{s d} \rightarrow \infty$, then export sales are Pareto 
distributed in the upper tail if $\phi$ is Pareto distributed. Similar to Proposition 1 in the main text, we can state

Proposition S.1 Suppose Assumption S.1 holds. Then for all s, d:

- exporter scope $G_{s d}(\phi)$ is positive and weakly increases in $\phi$ for $\phi \geq \phi_{s d}^{*}$;

- total firm exports $t_{s d}(\phi)$ are positive and strictly increase in $\phi$ for $\phi \geq \phi_{s d}^{*}$.

Proof. The first statement follows directly from the discussion above. The second statement follows because $H\left(G_{s d}(\phi)\right)^{-(\sigma-1)}$ strictly increases in $G_{s d}(\phi)$ and $G_{s d}(\phi)$ weakly increases in $\phi$ so that $t_{s d}(\phi)$ strictly increases in $\phi$ by (S.7).

Similar to AGM, we define exporter scale (an exporter's mean sales) in market $d$ as

$$
a_{s d}(\phi)=\sigma f_{s d}(1)\left(\frac{\phi}{\phi_{s d}^{*}}\right)^{\sigma-1} \frac{H\left(G_{s d}(\phi)\right)^{1-\sigma}}{G_{s d}(\phi)}
$$

Under a mild condition, exporter scale $a_{s d}(\phi)$ increases with $\phi$ and thus with a firm's total sales $t_{s d}(\phi)$. The following sufficient condition ensures that exporter scale increases with total sales.

Case $\mathbf{C 1}$ The function $Z_{s d}(g)$ strictly increases in $g$ with an elasticity

$$
\frac{\partial \ln Z_{s d}(g)}{\partial \ln g}>1
$$

Case $\mathrm{C} 1$ is more restrictive than Assumption S.1 in that the condition not only requires $Z_{s d}$ to increase with $g$ but that the increase be more than proportional. We can formally state the following result.

Proposition S.2 If $Z_{s d}(g)$ satisfies Case C1, then sales per export product $a_{s d}(\phi)$ strictly increase at the discrete points $\phi=\phi_{s d}^{*}, \phi_{s d}^{*, 2}, \phi_{s d}^{*, 3}, \ldots$

Proof. Compared to AGM, $Z_{s d}(g)$ is defined in more general terms, but it enters the relevant relationships in the same way as in AGM before. Case C1 therefore also suffices in the nestedutility model, and the proposition holds (see the Appendix in AGM for details of the proof for non-nested utility).

\section{S1.1.2 Within-firm sales distribution}

We revisit optimal sales per product and their relationship to exporter scope and the product's rank in a firm's sales distribution. The relationship lends itself to estimation in micro data. Using the productivity thresholds for firm entry (S.4) and product entry (S.6) in optimal sales (S.2) and 
simplifying yields

$$
\begin{aligned}
(\mathrm{S} .8) p_{s d g}(\phi) x_{s d g}(\phi) & =\sigma Z_{s d}\left(G_{s d}\right) H\left(G_{s d}\right)^{\varepsilon-\sigma}\left(\frac{\phi}{\phi_{s d}^{* G}}\right)^{\sigma-1} h(g)^{-(\varepsilon-1)} \\
& =\sigma \frac{f_{s d}\left(G_{s d}\right) H\left(G_{s d}\right)^{\varepsilon-1}}{1-\left[1-h\left(G_{s d}\right)^{-(\varepsilon-1)} / H\left(G_{s d}\right)^{-(\varepsilon-1)}\right]^{\frac{\sigma-1}{\varepsilon-1}}}\left(\frac{\phi}{\phi_{s d}^{*, G}}\right)^{\sigma-1} h(g)^{-(\varepsilon-1)} .
\end{aligned}
$$

Note that $H(G)^{\varepsilon-\sigma}$ strictly falls in $G$ if $\varepsilon>\sigma$. Under Case C1, the term $Z_{s d}\left(G_{s d}\right) H\left(G_{s d}\right)^{\varepsilon-\sigma}$ must strictly increase in $G$, however, because individual product sales strictly drop as the product index $g$ increases and $h(g)^{-(\varepsilon-1)}$ falls. So, if $Z_{s d}\left(G_{s d}\right) H\left(G_{s d}\right)^{\varepsilon-\sigma}$ did not strictly increase in $G$, average product sales would not strictly increase, contrary to Proposition S.2.

Compared to AGM, the relationship (S.8) is not $\log$-linear if $\varepsilon \neq \sigma$ and requires a non-linear estimator, similar to the general case in continuous product space (Arkolakis and Muendler 2011). One possibility is a Simulated Method of Moments estimator, extending the one in AGM.

\section{S1.2 Aggregation}

To derive clear predictions for equilibrium we specify a Pareto distribution of firm productivity following Helpman, Melitz and Yeaple (2004) and Chaney (2008). A firm's productivity $\phi$ is drawn from a Pareto distribution with a source-country dependent location parameter $b_{s}$ and a shape parameter $\theta$ over the support $\left[b_{s},+\infty\right)$ for all destinations $s$. The cumulative distribution function of $\phi$ is $\operatorname{Pr}=1-\left(b_{s}\right)^{\theta} / \phi^{\theta}$ and the probability density function is $\theta\left(b_{s}\right)^{\theta} / \phi^{\theta+1}$, where more advanced countries are thought to have a higher location parameter $b_{s}$. Therefore the measure of firms selling to country $d$, that is the measure of firms with productivity above the threshold $\phi_{s d}^{*}$, is

$$
M_{s d}=J_{s} \frac{b_{s}^{\theta}}{\left(\phi_{s d}^{*}\right)^{\theta}} .
$$

As a result, the probability density function of the conditional productivity distribution for entrants is given by

$$
\mu_{s d}(\phi)=\left\{\begin{array}{cl}
\theta\left(\phi_{s d}^{*}\right)^{\theta} / \phi^{\theta+1} & \text { if } \phi \geq \phi_{s d}^{*} \\
0 & \text { otherwise. }
\end{array}\right.
$$

We define the resulting Pareto shape parameter of the total sales distribution as $\tilde{\theta} \equiv \theta /(\sigma-1)$.

With these distributional assumptions we can compute a number of aggregate statistics from the model. We denote aggregate bilateral sales of firms from $s$ to country $d$ as $T_{s d}$. The corresponding average sales are defined as $\bar{T}_{s d}$, so that $T_{s d}=M_{s d} \bar{T}_{s d}$ and

$$
\bar{T}_{s d} \equiv \int_{\phi_{s d}^{*}} t_{s d}(\phi) \mu_{s d}(\phi) \mathrm{d} \phi .
$$


Similarly, we define average local entry costs as

$$
\bar{F}_{s d} \equiv \int_{\phi_{s d}^{*}} F_{s d}\left(G_{s d}(\phi)\right) \mu_{s d}(\phi) \mathrm{d} \phi
$$

To compute $\bar{T}_{s d}$, we impose two additional assumptions mirroring Assumptions 2 and 3 in AGM.

Assumption S.2 Parameters are such that $\theta>\sigma-1$.

Assumption S.3 Parameters are such that the mean market-access cost

$$
\tilde{F}_{s d} \equiv \sum_{G=1}^{\infty} f_{s d}(G)^{1-\tilde{\theta}}\left[H(G)^{1-\sigma}-H(G-1)^{1-\sigma}\right]^{\tilde{\theta}}
$$

is strictly positive and finite.

Then we can make the following statement.

Proposition S.3 Suppose Assumptions S.1, S.2 and S.3 hold. Then average sales $\bar{T}_{\text {sd }}$ per firm are a constant multiple of average local entry costs $\bar{F}_{\text {sd }}$

$$
\bar{T}_{s d}=\frac{\tilde{\theta} \sigma}{\tilde{\theta}-1} \bar{F}_{s d}=f_{s d}(1)^{\tilde{\theta}} \tilde{F}_{s d} .
$$

Proof. See Appendix S-C to this Online Supplement.

As a result, bilateral expenditure trade shares can be expressed as

$$
\lambda_{s d}=\frac{M_{s d} \bar{T}_{s d}}{\sum_{k} M_{k d} \bar{T}_{k d}}=\frac{J_{s}\left(b_{s}\right)^{\theta}\left(w_{s} \tau_{s d}\right)^{-\theta} f_{s d}(1)^{-\tilde{\theta}} \bar{F}_{s d}}{\sum_{k} J_{k}\left(b_{k}\right)^{\theta}\left(w_{k} \tau_{k d}\right)^{-\theta} f_{k d}(1)^{-\tilde{\theta}} \bar{F}_{k d}},
$$

an expression that depends on the values of $\varepsilon$ and $\sigma$ only insofar as these parameters affect $\bar{F}_{s d}$ through $H(G)$.

We can also compute mean exporter scope at a destination:

$$
\begin{aligned}
\bar{G}_{s d} & =\int_{\phi_{s d}^{*}} G_{s d}(\phi) \mu_{s d}(\phi) \mathrm{d} \phi \\
& =\left(\phi_{s d}^{*}\right)^{\theta} \theta\left[\int_{\phi_{s d}^{*}}^{\phi_{s d}^{*, 2}} \phi^{-\theta-1} \mathrm{~d} \phi+\int_{\phi_{s d}^{*, 2}}^{\phi_{s d}^{*, 3}} 2 \phi^{-\theta-1} \mathrm{~d} \phi+\ldots\right] \\
& =\frac{\left(\phi_{s d}^{*, 2}\right)^{-\theta}-\left(\phi_{s d}^{*}\right)^{-\theta}}{\left(\phi_{s d}^{*}\right)^{-\theta}}+\frac{\left(\phi_{s d}^{*, 3}\right)^{-\theta}-\left(\phi_{s d}^{*, 2}\right)^{-\theta}}{\left(\phi_{s d}^{*}\right)^{-\theta}}+\ldots
\end{aligned}
$$

Completing the integration, rearranging terms and using equation (S.6), we obtain

$$
\bar{G}_{s d}=f_{s d}(1)^{\tilde{\theta}} \sum_{g=1}^{\infty} Z_{s d}(g)^{-\tilde{\theta}}
$$


For the average number of products to be well defined and finite we require one more assumption:

Assumption S.4 Parameters are such that $\sum_{g=1}^{\infty} Z_{s d}(g)^{-\tilde{\theta}}$ is strictly positive and finite.

In Appendix S-C to this Online Supplement we show that the firms' fixed cost expense is a constant share of their total sales (where we denote means using a bar), as summarized in Proposition S.3:

$$
\frac{\bar{F}_{s d}}{\bar{T}_{s d}}=\frac{\tilde{\theta}-1}{\tilde{\theta} \sigma} .
$$

We derive aggregate welfare in Appendix S-D to this Online Supplement and demonstrate in Appendix S-E to this Supplement that wage income and profit income can be expressed as a constant share of total output $y_{s}$ per capita:

$$
\pi_{s}=\eta y_{s}, \quad w_{s}=(1-\eta) y_{s}
$$

where $\eta \equiv 1 /(\tilde{\theta} \sigma)$. Since aggregates of the model do not depend on $\varepsilon$, the equilibrium definition is the same as in AGM.

\section{S1.3 Summary}

We have characterized an extension of the AGM model, in which the elasticity of substitution between a firm's individual products does not equal the elasticity of substitution across product lines of different firms. The extended model retains the main qualitative implications of the baseline AGM model, in which the two elasticities are the same. Future work using the structure of the generalized model to obtain estimates of the two elasticities may lead to a better understanding of the substitution effects within and across firms.

\section{S2 Combination of Market Access and Market Penetration Cost Definitions}

We turn to a generalization of AGM to nest both market-access costs (as in AGM) and market penetration costs (as in Costas Arkolakis 2010) as special cases.

\section{S2.1 Restatement of AGM market-access costs}

We retain from AGM the specification that a firm draws not only a productivity parameter $\phi$ but also a destination specific market-access $\operatorname{cost}$ shock $c_{d}$ with well defined moments (and possibly a non-unitary mean). Suppose any two firms from source country $s$ happen to draw identical productivity $\phi$ and happen to draw an identical market-access cost parameter $c_{d} \in(0, \infty)$; those two firms face an identical optimization problem in every destination $d$ at the time of their product access decision. The pair of shocks $\left(\phi, c_{d}\right)$ therefore completely characterizes a firm's market access decision. 
To accommodate market penetration costs as in Arkolakis (2010), we extend the marketaccess cost definition (from AGM) and postulate that a firm's incremental market-access cost also depends on its optimal choice of market penetration: a firm from country $s$ decides the fraction $n_{s d}$ of the $L_{d}$ consumers who the firms wants to reach with its product composite (product line or mix) shipped to destination $d$. Consistent with the treatment of a firm in Arkolakis (2010) as the seller of a single product line (brand), we adopt the convention that a firm picks a common penetration rate for all its $g=1, \ldots, G_{s d}$ products shipped to a destination $\left(n_{s d g}=n_{s d}\right.$ for all g). ${ }^{48}$

As in AGM, a firm $\left(\phi, c_{d}\right)$ faces a product-destination specific incremental market-access cost $c_{d} \bar{f}_{s d}\left(g ; n_{s d}\right)$, where $c_{d} \in(0, \infty)$ is a stochastic firm-specific market-access cost shock. A firm that adopts an exporter scope of $G_{s d}$ at destination $d$ therefore incurs a total market-access cost of

$$
F_{s d}\left(G_{s d}, c_{d} ; n_{s d}\right)=\sum_{g=1}^{G_{s d}} c_{d} \bar{f}_{s d}\left(g ; n_{s d}\right)
$$

For any positive market penetration choice $n_{s d}>0$, the firm's market-access cost is zero at zero scope and strictly positive otherwise:

$$
\bar{f}_{s d}\left(0 ; n_{s d}\right)=0 \quad \text { and } \quad \bar{f}_{s d}\left(g ; n_{s d}\right)>0 \text { for all } g=1,2, \ldots, G_{s d}
$$

where $\bar{f}_{s d}\left(g ; n_{s d}\right)$ is a continuous function in $[1,+\infty) \times[0,+\infty)$.

Arkolakis (2010) uses specific functional forms for market penetration costs, derived from primitives on consumer demand and product marketing. We discuss the generalized market access and market penetration cost definition also in terms of those specific functional forms. Extending (6) in AGM, we specify

$$
\begin{aligned}
& \bar{f}_{s d}\left(g ; n_{s d}\right)=f_{s d}\left(n_{s d}\right) \cdot g^{\delta_{s d}} \quad \text { for } \delta_{s d} \in(-\infty,+\infty) \quad \text { and } \\
& h(g)=g^{\alpha} \quad \text { for } \rho \in[0,+\infty) .
\end{aligned}
$$

The market-access cost parameter $f_{s d}\left(n_{s d}\right)$ is zero at zero penetration and strictly positive otherwise:

$$
f_{s d}(0)=0 \quad \text { and } \quad f_{s d}\left(n_{s d}\right)>0 \quad \text { for all } n_{s d}>0
$$

where $f_{s d}\left(n_{s d}\right)$ is a continuous function in $[0,+\infty)$.

Recall from AGM that a firm also faces a multiplicative i.i.d. shock $\xi_{s d g}$ to its $g$-th product's appeal at a destination $d$ (with mean $\mathbb{E}\left[\xi_{s d g}(\omega)\right]=1$, positive support and known realization at the time of consumer choice). Under CES consumer demand, it is irrelevant whether the firm sets optimal price before or after the firm observes the product's appeal realization (see footnote 14 in AGM); price is a proportional markup over the firm-product's marginal production cost irrespective of the size of demand.

However, consistent with AGM and the deterministic setup of Arkolakis (2010), the firm has

\footnotetext{
${ }^{48} \mathrm{~A}$ further generalization that allows for firm-product specific optimal choices of $n_{s d g}$ would result in interesting novel relations between core competency in production and market penetration choices: a firm's efficiency schedule $\phi_{g} \equiv \phi / h(g)$ would interact with product-specific market penetration costs in the product adoption decisions. We leave this generalization for future work.
} 
to take both the product entry (exporter scope $G_{s d}$ ) and the market penetration decision (consumer fraction $n_{s d}$ ) prior to observing any product appeal shock. It follows that, for a firm with an optimal and strictly positive market penetration at a destination $d\left(n_{s d}>0\right)$, the first-order conditions for a firm $\left(\phi, c_{d}\right)$ and therefore its optimal exporter scope $G_{s d}$ and individual product sales are identical to those presented in AGM-with only two differences in interpretation: ${ }^{49}$ we replace the product-invariant part of incremental market-access costs with $f_{s d} \equiv f_{s d}\left(n_{s d}\right)$ and we replace the revenue shifter (equation (7) in AGM) with $D_{s d}=D_{s d}\left(n_{s d}\right)$ using

$$
D_{s d}\left(n_{s d}\right) \equiv n_{s d} \cdot \bar{D}_{s d} \quad \text { for } \bar{D}_{s d} \equiv\left(\frac{P_{d}}{\tilde{\sigma} \tau_{s d} w_{s}}\right)^{\sigma-1} \frac{T_{d}}{\sigma}
$$

under a given (optimal) market penetration rate $n_{s d} \in(0,1]$. Our original AGM model is the special case with $n_{s d}=1$.

\section{S2.2 Generalization of market penetration costs from Arkolakis (2010)}

We now show that a specific functional form for $f_{s d}\left(n_{s d}\right)$ accommodates Arkolakis (2010) market penetration costs as a special case and preserves a firm's relevant optimality conditions from Arkolakis (2010). The wage bill required to reach $n_{s d}$ consumers in a market of size $L_{d}$ is $F_{s d}\left(\cdot, \cdot ; n_{s d}\right)$, where $L_{d}$ is a parameter for the firm and $n_{s d}$ is a decision variable. ${ }^{50}$ For a firm with given optimal exporter scope $G_{s d}$ and market-access cost draw $c_{d}$, define the firm's market penetration cost function $F_{s d}\left(\cdot, \cdot ; n_{s d}\right)$ to be equal to its total market-access cost from (S.14) with

$$
F_{s d}\left(\cdot, \cdot ; n_{s d}\right) \equiv \sum_{g=1}^{G_{s d}} c_{d} \bar{f}_{s d}\left(g ; n_{s d}\right)=\frac{\left(L_{d}\right)^{\rho}}{\psi_{s d}(\cdot, \cdot)} \frac{1-\left(1-n_{s d}\right)^{1-\beta}}{1-\beta} \quad \text { for } \beta \in(0,1) \cup(1,+\infty),
$$

where

$$
\psi_{s d}\left(G_{s d}, c_{d}\right) \equiv \frac{\bar{\psi}}{\left(w_{s}\right)^{\gamma}\left(w_{d}\right)^{1-\gamma}} \frac{1}{c_{d} \cdot \sum_{g=1}^{G_{s d}} g^{\delta_{s d}}}
$$

and $\bar{\psi}$ is a positive scalar (similar to the original $\psi$ from Costas Arkolakis 2010). Importantly, the generalization of the market penetration cost from Arkolakis $(2010)$ to $F_{s d}\left(\cdot, \cdot ; n_{s d}\right)$ in equation (S.17) preserves the four relevant properties of the market penetration cost function: (i) the market penetration cost vanishes at zero penetration since $F_{s d}(\cdot, \cdot ; 0)=0$, (ii) it strictly increases in $n$ since $\partial F_{s d}(\cdot, \cdot ; n) / \partial n>0$ for $n \in[0,1]$, (iii) it is convex in $n$ since $\partial^{2} F_{s d}(\cdot, \cdot ; n) /(\partial n)^{2}>0$ for $n \in[0,1]$, and (iv) it is unbounded since $\lim _{n \rightarrow \infty} F_{s d}(\cdot, \cdot ; n)=+\infty$.

Equivalently, for consistency with $\mathrm{AGM}$ and $c_{d} \bar{f}_{s d}\left(g ; n_{s d}\right)=c_{d} f_{s d}\left(n_{s d}\right) \cdot g^{\delta_{s d}}$ by equa-

\footnotetext{
${ }^{49}$ In AGM, $f_{s d}$ is sometimes also stated as $f_{s d}(1)$ for the first product.

${ }^{50}$ Arkolakis (2010) includes market size $L_{d}$ as an argument in the market penetration cost function and formally states a functional form for $F_{s d}\left(\cdot, \cdot ; n_{s d}\right) \equiv f\left(n_{s d} ; L_{d}\right)$ in equation (2). Arkolakis (2010) treats $f\left(n_{s d} ; L_{d}\right)$ as the labor requirement needed to reach $n_{s d} L_{d}$ consumers and uses a factor of proportionality $\psi$ to standardize the requirement given the composite wage payment $\left(w_{s}\right)^{\gamma}\left(w_{d}\right)^{1-\gamma}$. For comparability to AGM, we think of $F_{s d}\left(\cdot, \cdot ; n_{s d}\right)$ in wage bill equivalents and standardize with an accordingly scaled factor of proportionality $\psi_{s d}$.
} 
tion (S.15), we define

$$
f_{s d}\left(n_{s d}\right) \equiv \frac{\left(w_{s}\right)^{\gamma}\left(w_{d}\right)^{1-\gamma}\left(L_{d}\right)^{\rho}}{\bar{\psi}} \frac{1-\left(1-n_{s d}\right)^{1-\beta}}{1-\beta} \text { for } \beta \in(0,1) \cup(1,+\infty) .
$$

These mutually consistent but alternative fixed cost definitions allow us to now switch perspective between a firm's optimality conditions for the market penetration rate $n_{s d}$ (given the optimal exporter scope $G_{s d}$ and the market-access cost draw $c_{d}$ ) on the one hand side, and a firm's optimality conditions for exporter scope $G_{s d}$ (given the optimal market penetration rate $n_{s d}$ and the market-access cost draw $c_{d}$ ) on the other hand side. Both the optimal exporter scope $G_{s d}$ and the market penetration rate $n_{s d}$ decisions need to be made prior to observing the products' appeal shocks $\left(\xi_{s d g}\right)$, so a firm takes the two decisions simultaneously.

We already pointed out above that the optimality conditions on exporter scope $G_{s d}$ are the same as those in AGM, merely replacing $f_{s d} \equiv f_{s d}\left(n_{s d}\right)$ and $D_{s d} \equiv D_{s d}\left(n_{s d}\right)$ for given optimal $n_{s d}$. We now turn to showing that the new optimality conditions for the market penetration rate $n_{s d}$, given optimal exporter scope $G_{s d}$ and the market-access cost draw $c_{d}$, are a straightforward restatement of the related optimality conditions from Arkolakis (2010), simply generalizing the cost scalar to $\psi_{s d}\left(G_{s d}, c_{d}\right)$. The original Arkolakis (2010) model is the special case with $G_{s d}=c_{d}=1$. The original Melitz (2003) model is a special case with both $G_{s d}=c_{d}=1$ and $\beta=0$.

\section{S2.3 Optimal market penetration costs given optimal exporter scope}

Given the simultaneous choice of exporter scope and the market penetration rate, we can solve without loss of generality for the market penetration rate $n_{s d}$ presuming that exporter scope $G_{s d}$ is optimal. Suppose, conditional on destination market access, a type $\left(\phi, c_{d}\right)$ firm is setting optimal individual product prices (facing a fraction $n_{s d}$ of consumer demand under monopolistic competition) and optimal exporter scope (given market penetration $n_{s d}$ ). The resulting firstorder conditions from the profit maximizing equation imply identical markups over marginal $\operatorname{cost} \tilde{\sigma} \equiv \sigma /(\sigma-1)>1$ for each firm-product under $\sigma>1$. $^{51}$ Given optimal exporter scope $G_{s d}\left(\phi, c_{d}\right)$, and using the optimal pricing decision in the firm's profit function, we obtain the firm's expected profits (prior to product appeal shock realizations) at destination $d$ :

$$
\pi_{s d}\left(\phi, c_{d}\right)=\max _{n_{s d}} D_{s d}\left(n_{s d}\right) \phi^{\sigma-1} \bar{H}\left(G_{s d}\right)^{-(\sigma-1)}-F_{s d}\left(G_{s d}, c_{d} ; n_{s d}\right),
$$

${ }^{51}$ A firm selling an optimal number of products $G_{s d}$ to destination market $d$ has an expected profit of

$$
\pi_{s d}\left(\phi, c_{d}\right)=\max _{G_{s d}} \sum_{g=1}^{G_{s d}} \mathbb{E}\left[\max _{\left\{p_{s d g}\right\}_{g=1}^{G_{s d}}}\left(p_{s d g}-\tau_{s d} \frac{w_{s}}{\phi / h(g)}\right)\left(\frac{p_{s d g}}{P_{d}}\right)^{-\sigma} \xi_{s d g} \frac{T_{d}}{P_{d}}\right]-F_{s d}\left(G_{s d}, c_{d} ; n_{s d}\right) .
$$

The firm's first-order conditions with respect to every individual price $p_{s d g}$ imply an optimal product price

$$
p_{s d g}(\phi)=\tilde{\sigma} \tau_{s d} w_{s} h(g) / \phi
$$

with an identical markup over marginal cost $\tilde{\sigma} \equiv \sigma /(\sigma-1)>1$ for $\sigma>1$. Product price does not depend on the appeal shock realization because the shock enters profits multiplicatively, so it is irrelevant whether a firm is setting price before or after the appeal shock is observed. 
with $F_{s d}\left(G_{s d}, c_{d} ; n_{s d}\right)$ given by (S.17), the penetration dependent revenue shifter given by

$$
D_{s d}\left(n_{s d}\right) \equiv n_{s d} \cdot \bar{D}_{s d} \quad \text { for } \bar{D}_{s d} \equiv\left(\frac{P_{d}}{\tilde{\sigma} \tau_{s d} w_{s}}\right)^{\sigma-1} \frac{T_{d}}{\sigma}
$$

and the average product efficiency index in destination $d$ for a firm with exporter scope $G_{s d}$ given by $\bar{H}\left(G_{s d}\right)^{-(\sigma-1)} \equiv \sum_{g=1}^{G_{s d}} h(g)^{-(\sigma-1)}$.

The first-order condition for maximizing profit $\pi_{s d}\left(\phi, c_{d}\right)$ with respect to the market penetration rate $n_{s d}$ is equivalent to

$$
\frac{\bar{D}_{s d}}{L_{d}} \phi^{\sigma-1} \bar{H}\left(G_{s d}\right)^{-(\sigma-1)}=\frac{1}{\psi_{s d}\left(G_{s d}, c_{d}\right)\left(L_{d}\right)^{1-\rho}} \frac{1}{\left(1-n_{s d}\right)^{\beta}},
$$

given $\beta \in(0,1) \cup(1,+\infty)$ for a type $\left(\phi, c_{d}\right)$ firm with optimal exporter scope $G_{s d}\left(\phi, c_{d}\right)$. Similar to the first-order condition in Arkolakis (2010, equation (8)), the left-hand side of the condition shows the marginal revenue of a firm's product line (net of labor production cost) per consumer and the right-hand side the marginal cost per consumer of bringing the product line to destination $d$.

The zero-consumer threshold of minimal productivity for a firm to start penetrating a market can be found by setting $n_{s d}=0$ in (S.19) and solving out for productivity. The zero-consumer threshold for productivity is

$$
\phi_{s d}^{*, n=0}\left(c_{d}\right)^{\sigma-1} \equiv \frac{\left(L_{d}\right)^{\rho-1}}{\psi_{s d}\left(G_{s d}, c_{d}\right)} \frac{\bar{H}\left(G_{s d}\right)^{\sigma-1}}{\bar{D}_{s d} / L_{d}} .
$$

A firm compares the marginal per-consumer revenue from reaching an infinitesimally small mass of consumers (the left-hand side of (S.19)) to the marginal per-consumer cost of reaching that infinitesimally small mass (the right-hand side of (S.19)). Given elastic CES demand, more productive firms extract higher marginal per-consumer revenue, so they choose higher rates of market penetration. Similar to Arkolakis (2010, Proposition 1), for $\beta>0$, a type $\left(\phi, c_{d}\right)$ firm will choose to stay out of destination $d$ and set $n_{s d}\left(\phi, c_{d}\right)=0$ if $\phi<\phi_{s d}^{*, n=0}\left(c_{d}\right)$. Conversely, two firms of types $\left(\phi_{1}, c_{d}\right)$ and $\left(\phi_{2}, c_{d}\right)$ will enter and set $n_{s d}\left(\phi_{2}, c_{d}\right)>n_{s d}\left(\phi_{1}, c_{d}\right) \geq 0$ if $\phi_{2}>\phi_{1} \geq \phi_{s d}^{*, n=0}\left(c_{d}\right)$.

Inverting the first-order condition (S.19) to solve for the optimal $n_{s d}\left(\phi, c_{d}\right)$, and using (S.20), yields the optimal market penetration rate for a firm's product line

$$
n_{s d}\left(\phi, c_{d}\right)=1-\left(\frac{\phi_{s d}^{*, n=0}\left(c_{d}\right)}{\phi}\right)^{(\sigma-1) / \beta} \quad \text { if } \phi \geq \phi_{s d}^{*, n=0}\left(c_{d}\right)
$$

\section{S2.4 Equilibrium properties}

In the combined model with both AGM market-access costs and Arkolakis (2010) market penetration costs, the optimal exporter scope choice implies that the productivity threshold $\phi_{s d}^{*, 1}\left(c_{d}\right)$ for exporting at all from $s$ to $d$ is $\phi_{s d}^{*, 1}\left(c_{d}\right)$, while the zero-consumer threshold is $\phi_{s d}^{*, n=0}$. Both 
need to be satisfied, so the effective entry threshold is $\phi_{s d}^{*}\left(c_{d}\right)=\max \left[\phi_{s d}^{*, 1}\left(c_{d}\right), \phi_{s d}^{*, n=0}\right] .^{52}$

Note that $\psi_{s d}\left(G_{s d}, c_{d}\right)$ strictly monotonically decreases in $c_{d}$ by (S.17), so the zero-consumer threshold $\phi_{s d}^{*, n=0}\left(c_{d}\right)$ strictly monotonically increases in $c_{d}$ by (S.20). ${ }^{53}$ Similarly, by AGM's equation (10) the productivity threshold for exporting at all $\left(G_{s d} \geq 1\right)$ strictly increases in $c_{d}$. We conclude that, also in the combined model with both AGM market-access costs and Arkolakis (2010) market penetration costs, a higher market-access cost draw $c_{d}$ strictly raises the effective entry threshold $\phi_{s d}^{*}\left(c_{d}\right)$.

However, the effect of a higher market-access cost draw $c_{d}$ on realized total market-access $\operatorname{cost} F_{s d}\left(G_{s d}, c_{d} ; n_{s d}\right)$ is ambiguous by (S.17). The reason is that $\psi_{s d}\left(G_{s d}, c_{d}\right)$ strictly monotonically decreases in $c_{d}$ with a unitary elasticity, thus raising $F_{s d}$ with a unitary elasticity, while $n_{s d}\left(\phi, c_{d}\right)$ strictly decreases in $c_{d}$ with a non-unitary elasticity by (S.21), thus lowering $F_{s d}$ with a non-unitary elasticity. The net effect of a $c_{d}$ shock on a firm's realized $F_{s d}\left(G_{s d}, c_{d} ; n_{s d}\right)$ is therefore ambiguous.

\section{S2.5 Implications for estimation}

A firm's optimal market penetration rate $n_{s d}\left(\phi, c_{d}\right)$ for its product line shifts the product-invariant part of incremental market-access costs $c_{d} f_{s d}\left(n_{s d}\right)$. Our estimator flexibly allows for a firmdestination specific market-access cost shock $c_{d}$, which also shifts the product-invariant part of incremental market-access costs $c_{d} f_{s d}\left(n_{s d}\right)$. Our estimator therefore subsumes within the stochastic market-access cost parameter $c_{d}$ any firm-destination specific variation in the market penetration rate, and fully accounts for the possibility that firms optimally set their market penetration rate $n_{s d}$.

Similarly, our estimator flexibly allows for a non-unitary firm-destination specific average product appeal shock $\bar{\xi}_{s d}=\sum_{g=1}^{G_{s d}} \xi_{s d g} / G_{s d}$. Our estimator therefore subsumes within the average product appeal shock $\bar{\xi}_{s d}$. any firm-destination specific variation in the revenue shifter $D_{s d}\left(n_{s d}\right)=n_{s d} \bar{D}_{s d}$, and fully accounts for the possibility that firms optimally set their market

${ }^{52}$ By AGM's equation (10), the productivity threshold for exporting at all $\left(G_{s d}=1\right)$ is implicitly given by

$$
\begin{aligned}
\phi_{s d}^{*, 1}\left(c_{d}\right)^{\sigma-1} & \equiv \frac{c_{d} f_{s d}\left(n_{s d}\left(\phi_{s d}^{*, 1}, c_{d}\right)\right)}{D_{s d}\left(n_{s d}\left(\phi_{s d}^{*, 1}, c_{d}\right)\right)} \\
& =\frac{\left(L_{d}\right)^{\rho}}{\psi_{s d}\left(1, c_{d}\right) \bar{D}_{s d}} \frac{1-\left(\frac{\phi_{s d}^{*, n=0}\left(c_{d}\right)}{\phi_{s d}^{*, 1}\left(c_{d}\right)}\right)^{(\sigma-1)(1-\beta) / \beta}}{1-\beta} \frac{1}{1-\left(\frac{\phi_{s d}^{*, n=0}\left(c_{d}\right)}{\phi_{s d}^{*, 1}\left(c_{d}\right)}\right)^{(\sigma-1) / \beta}},
\end{aligned}
$$

where the latter equality follows from (S.17), (S.18) and (S.21) under the condition that $\phi_{s d}^{*, 1}\left(c_{d}\right) \geq \phi_{s d}^{*, n=0}\left(c_{d}\right)$. Restating (S.20), the zero-consumer threshold for productivity is

$$
\phi_{s d}^{*, n=0}\left(c_{d}\right)^{\sigma-1} \equiv \frac{\left(L_{d}\right)^{\rho}}{\psi_{s d}\left(1, c_{d}\right) \bar{D}_{s d}} \bar{H}(1)^{\sigma-1}
$$

for a firm's first product $\left(G_{s d}=1\right)$, where $\bar{H}(1)=1$. Using the latter condition in (S.22), it follows that $\phi_{s d}^{*, 1}\left(c_{d}\right) \geq$ $\phi_{s d}^{*, n=0}\left(c_{d}\right)$ need not hold for $\beta<1$ or $\beta>1$.

${ }^{53}$ The optimal market penetration rate $n_{s d}\left(\phi, c_{d}\right)$ therefore strictly decreases in $c_{d}$ by (S.21) for $\sigma>1$ and $\beta>0$. 
penetration rate $n_{s d}$.

In summary, our existing estimation framework in AGM flexibly allows for the consequences of market penetration costs as in Arkolakis (2010).

\section{S3 Reduced Form Evidence on Non-Tariff Measures}

In this section we provide additional evidence on the relationship between exporter behavior and the NTM proxies from UNCTAD's TRAINS data and their extension by Kee, Nicita and Olarreaga (2009). In Section II.A we constructed a single indicator variable for the presence of at least one core non-tariff barrier and used it throughout the main text (the variable $N T M_{j d}$ which takes the value 1 if country $d$ imposes at least one core NTMs in an HS 6-digit product, and zero otherwise). For additional evidence in this supplement, we also explore four separate indicator variables for the presence of each of the four core non-tariff barriers considered in Kee, Nicita and Olarreaga (2009) and Niu et al. (2018).

We specify regressions that reflect Facts 1-3 from Section II.B. As NTM proxies we reuse the firm-destination aggregate $N T M_{\omega d} \equiv \sum_{j \in \mathbb{J}_{\omega d}=\left\{j: y_{\omega d j}>0\right\}} N T M_{j d} /\left|\mathbb{J}_{\omega d}\right|$ and the individual NTM proxies for each of the four core non-tariff barriers. To control for tariffs, we use the mean of the $\log$ of one plus the HS 6-digit tariff rate $\ln \left(1+\tau_{\omega d}\right)$ for an exporter as in Section II.B.

Table S.1 reports results from regressing the logarithm of the revenues of the best selling product for a firm to a destination on the log exporter scope, discerning separate effects for LAC destinations and the prevalence of NTMs at a destination, while conditioning on tariff rates. Specification (1) controls for firm fixed effects, specification (2) controls for industry-destination fixed effects, specification (3) controls for both types of fixed effects, and specification (4) parses out separate effects for different categories of NTMs. In general, more prevalent NTMs at a destination act on exporter scope in a similar way as does the remoteness of non-LAC destinations. A comparison of the specification in column (4), which breaks down the non-tariff measure into individual NTM categories, to preceding specifications in columns (1) through (3) suggests that the main NTM types behind the NTM effect of wide-scope exporters in log sales are price based non-tariff barriers. Wide-scope exporters exhibit higher total export sales in destinations with restrictive price based NTMs.

Table S.2 revisits Fact 2 with regressions of log exporter scope on indicators for LAC as well as the NTMs that a firm faces, conditional on average tariff rates. Specification (1) controls for firm fixed effects, specification (2) for industry-destination fixed effects, specification (3) for both types of fixed effects, and specification (4) parses out separate effects for different categories of NTMs. Exporter scope is lower for exporters to non-LAC destinations and for exporters to destinations with many NTMs. Quantity based and technical non-tariff measures are the most relevant for a firm's exporter scope, resulting in narrower product scope for exporters to destinations that are subject to more restrictive quantity based and technical NTMs.

Table S.3 turns to Fact 3 and regresses average exporter scale on exporter scope and interactions with both LAC destinations and NTMs proxies. Specification (1) controls for firm fixed effects, specification (2) for industry-destination fixed effects, specification (3) for both types of fixed effects, and specification (4) parses out separate effects for different categories of NTMs. In general, the scope-scale association is weakly positive and increases for exports 
Table S.1: Fact 1.1. Firm-product Sales Distributions by Exporter Scope

\begin{tabular}{|c|c|c|c|c|}
\hline & $\begin{array}{c}(1) \\
\log y_{\omega d 1}\end{array}$ & $\begin{array}{c}(2) \\
\log y_{\omega d 1}\end{array}$ & $\begin{array}{c}(3) \\
\log y_{\omega d 1}\end{array}$ & $\begin{array}{c}\text { (4) } \\
\log y_{\omega d 1}\end{array}$ \\
\hline $\log G_{\omega d}$ & $\begin{array}{c}1.272^{* * *} \\
(.0397)\end{array}$ & $\begin{array}{l}.986^{* * *} \\
(.0397)\end{array}$ & $\begin{array}{c}1.160^{* * *} \\
(.0385)\end{array}$ & $\begin{array}{c}1.158^{* * *} \\
(.0382)\end{array}$ \\
\hline LAC & $\begin{array}{l}-.105^{* *} \\
(.0406)\end{array}$ & & & \\
\hline $\log G_{\omega d} \times \mathrm{LAC}$ & $\begin{array}{c}-.230^{* * *} \\
(.0413)\end{array}$ & $\begin{array}{c}-.217^{* * *} \\
(.0395)\end{array}$ & $\begin{array}{c}-.277^{* * *} \\
(.0373)\end{array}$ & $\begin{array}{c}-.269^{* * *} \\
(.0389)\end{array}$ \\
\hline $\mathrm{NTM}_{\omega d}$ & $\begin{array}{c}.0464 \\
(.0367)\end{array}$ & $\begin{array}{l}.00760 \\
(.0462)\end{array}$ & $\begin{array}{l}.0704 \\
(.0502)\end{array}$ & \\
\hline $\log G_{\omega d} \times \mathrm{NTM}_{\omega d}$ & $\begin{array}{l}.125^{* *} \\
(.0418)\end{array}$ & $\begin{array}{l}.124^{* *} \\
(.0460)\end{array}$ & $\begin{array}{l}.121^{* *} \\
(.0423)\end{array}$ & \\
\hline Mean Ln Tariff & $\begin{array}{l}-.163^{* * *} \\
(.00950)\end{array}$ & $\begin{array}{l}-.108^{* *} \\
(.0345)\end{array}$ & $\begin{array}{c}-.166^{* * *} \\
(.0354)\end{array}$ & $\begin{array}{c}-.166^{* * *} \\
(.0354)\end{array}$ \\
\hline NTM - Price Based & & & & $\begin{array}{l}-.0336 \\
(.0629)\end{array}$ \\
\hline NTM - Quantity Based & & & & $\begin{array}{l}-.371 \\
(.219)\end{array}$ \\
\hline NTM - Competition Based & & & & $\begin{array}{l}.0353 \\
(.381)\end{array}$ \\
\hline NTM - Technical Measures & & & & $\begin{array}{l}.138^{*} \\
(.0588)\end{array}$ \\
\hline $\log G_{\omega d} \times$ NTM - Price Based & & & & $\begin{array}{l}.157^{* *} \\
(.0479)\end{array}$ \\
\hline $\log G_{\omega d} \times$ NTM - Quantity Based & & & & $\begin{array}{l}.134 \\
(.172)\end{array}$ \\
\hline $\log G_{\omega d} \times$ NTM - Competition Based & & & & $\begin{array}{l}-.514 \\
(.456)\end{array}$ \\
\hline $\log G_{\omega d} \times$ NTM - Technical Measures & & & & $\begin{array}{l}.0270 \\
(.0507)\end{array}$ \\
\hline Fixed Effects & Firm & Ind.-dest. & Ind.-dest., Firm & Ind.-dest., Firm \\
\hline Observations & 32,486 & 34,450 & 30,167 & 30,167 \\
\hline$R^{2}$ & .539 & .416 & .685 & .685 \\
\hline
\end{tabular}

Source: SECEX 2000, manufacturing firms and their manufactured products, UNCTAD TRAINS database, WTO WITS tariff database.

Notes: Standard errors clustered at the firm level (: $p<.05,: p<.01,: p<.001)$. The dependent variable is the log sales of a firm's bestselling product to a given destination. Sample sizes change across specifications since singleton observations are dropped from regressions with multiple fixed effects. 
Table S.2: Fact 2. Exporter Scope Distribution

\begin{tabular}{|c|c|c|c|c|}
\hline & $\begin{array}{c}(1) \\
\log G_{\omega d}\end{array}$ & $\begin{array}{c}(2) \\
\log G_{\omega d}\end{array}$ & $\begin{array}{c}\text { (3) } \\
\log G_{\omega d}\end{array}$ & $\begin{array}{c}(4) \\
\log G_{\omega d}\end{array}$ \\
\hline LAC & $\begin{array}{l}.450^{* * *} \\
(.0198)\end{array}$ & & & $\begin{array}{l}.459^{* * *} \\
(.0202)\end{array}$ \\
\hline $\mathrm{NTM}_{\omega d}$ & $\begin{array}{c}-.0495^{* * *} \\
(.0124)\end{array}$ & $\begin{array}{c}-.0626^{* *} \\
(.0192)\end{array}$ & $\begin{array}{l}-.0329 \\
(.0191)\end{array}$ & \\
\hline Mean Ln Tariff & $\begin{array}{c}-.0943^{* * *} \\
(.00453)\end{array}$ & $\begin{array}{c}.0548^{* * *} \\
(.0123)\end{array}$ & $\begin{array}{l}.0122 \\
(.0131)\end{array}$ & $\begin{array}{r}-.0925^{* * *} \\
(.00460)\end{array}$ \\
\hline NTM - Price Based & & & & $\begin{array}{l}-.00417 \\
(.0148)\end{array}$ \\
\hline NTM - Quantity Based & & & & $\begin{array}{c}-.177^{* * *} \\
(.0452)\end{array}$ \\
\hline NTM - Competition Based & & & & $\begin{array}{l}-.0998 \\
(.0632)\end{array}$ \\
\hline NTM - Technical Measures & & & & $\begin{array}{c}-.0571^{* * *} \\
(.0150)\end{array}$ \\
\hline Fixed Effects & Firm & Ind.-dest. & Ind.-dest., Firm & Firm \\
\hline Observations & 36,647 & 34,450 & 30,167 & 36,647 \\
\hline$R^{2}$ & .596 & .296 & .700 & .597 \\
\hline
\end{tabular}

Source: SECEX 2000, manufacturing firms and their manufactured products, UNCTAD TRAINS database, WTO WITS tariff database.

Notes: Standard errors clustered at the firm level (: $p<.05,: p<.01,: p<.001)$. The dependent variable is the $\log$ exporter scope (the log of the number of products sold by a firm to a given destination). Sample sizes change across specifications since singleton observations are dropped from regressions with multiple fixed effects. 
Table S.3: Fact 3. Exporter Scope and Exporter Scale

\begin{tabular}{|c|c|c|c|c|}
\hline & $\begin{array}{c}(1) \\
\ln t_{\omega d} / G_{\omega d}\end{array}$ & $\begin{array}{c}(2) \\
\ln t_{\omega d} / G_{\omega d}\end{array}$ & $\begin{array}{c}(3) \\
\ln t_{\omega d} / G_{\omega d}\end{array}$ & $\begin{array}{c}(4) \\
\ln t_{\omega d} / G_{\omega d}\end{array}$ \\
\hline $\log G_{\omega d}$ & $\begin{array}{l}.505^{* * *} \\
(.0383)\end{array}$ & $\begin{array}{l}.231^{* * *} \\
(.0384)\end{array}$ & $\begin{array}{l}.397^{* * *} \\
(.0378)\end{array}$ & $\begin{array}{l}.399^{* * *} \\
(.0375)\end{array}$ \\
\hline LAC & $\begin{array}{l}-.0874^{*} \\
(.0396)\end{array}$ & & & \\
\hline $\log G_{\omega d} \times \mathrm{LAC}$ & $\begin{array}{c}-.226^{* * *} \\
(.0379)\end{array}$ & $\begin{array}{c}-.208^{* * *} \\
(.0375)\end{array}$ & $\begin{array}{c}-.261^{* * *} \\
(.0358)\end{array}$ & $\begin{array}{c}-.254^{* * *} \\
(.0373)\end{array}$ \\
\hline $\mathrm{NTM}_{\omega d}$ & $\begin{array}{c}.0334 \\
(.0364)\end{array}$ & $\begin{array}{l}-.00657 \\
(.0456)\end{array}$ & $\begin{array}{l}.0640 \\
(.0495)\end{array}$ & \\
\hline $\log G_{\omega d} \times \mathrm{NTM}_{\omega d}$ & $\begin{array}{l}.160^{* * *} \\
(.0389)\end{array}$ & $\begin{array}{l}.188^{* * *} \\
(.0439)\end{array}$ & $\begin{array}{l}.162^{* * *} \\
(.0405)\end{array}$ & \\
\hline Mean Ln Tariff & $\begin{array}{l}-.163^{* * *} \\
(.00927)\end{array}$ & $\begin{array}{l}-.107^{* *} \\
(.0341)\end{array}$ & $\begin{array}{c}-.159^{* * *} \\
(.0347)\end{array}$ & $\begin{array}{c}-.159^{* * *} \\
(.0347)\end{array}$ \\
\hline NTM - Price Based & & & & $\begin{array}{l}-.0415 \\
(.0620)\end{array}$ \\
\hline NTM - Quantity Based & & & & $\begin{array}{l}-.419 \\
(.220)\end{array}$ \\
\hline NTM - Competition Based & & & & $\begin{array}{l}-.0171 \\
(.380)\end{array}$ \\
\hline NTM - Technical Measures & & & & $\begin{array}{l}.143^{*} \\
(.0581)\end{array}$ \\
\hline $\log G_{\omega d} \times$ NTM - Price Based & & & & $\begin{array}{l}.187^{* * *} \\
(.0458)\end{array}$ \\
\hline $\log G_{\omega d} \times$ NTM - Quantity Based & & & & $\begin{array}{l}.281 \\
(.171)\end{array}$ \\
\hline $\log G_{\omega d} \times$ NTM - Competition Based & & & & $\begin{array}{l}-.462 \\
(.450)\end{array}$ \\
\hline $\log G_{\omega d} \times$ NTM - Technical Measures & & & & $\begin{array}{c}.0419 \\
(.0484)\end{array}$ \\
\hline $\begin{array}{l}\text { Fixed Effects } \\
\text { Observations } \\
R^{2}\end{array}$ & $\begin{array}{c}\text { Firm } \\
32,488 \\
.512\end{array}$ & $\begin{array}{c}\text { Ind.-dest. } \\
34,452 \\
.378\end{array}$ & $\begin{array}{c}\text { Ind.-dest., Firm } \\
30,169 \\
.666\end{array}$ & $\begin{array}{c}\text { Ind.-dest., Firm } \\
30,169 \\
.667\end{array}$ \\
\hline
\end{tabular}

Source: SECEX 2000, manufacturing firms and their manufactured products, UNCTAD TRAINS database, WTO WITS tariff database.

Notes: Standard errors clustered at the firm level (: $p<.05,: p<.01,: p<.001)$. The dependent variable is the $\log$ exporter scale (the log of the average sales of a firm's products to a given destination). Sample sizes change across specifications since singleton observations are dropped from regressions with multiple fixed effects. 
to non-LAC destinations and destinations with more NTMs. Price based non-tariff measures, when interacted with exporter scope, are the only relevant category of non-tariff measures for a firm's average export sales. Wide-scope exporters exhibit higher average sales in destinations with restrictive price based NTMs.

When it comes to the breakdown of non-tariff measures by type, a comparison between Tables S.1 through S.3 suggests that quantity based and technical non-tariff barriers are associated with a narrower exporter scope at the destinations that are subject to more such NTM restrictions. However, it is the price based non-tariff barriers that are associated with higher total sales and higher average export sales per product at relatively wide-scope exporters, suggesting that the exporters that enter a destination with wide exporter scope do so with higher sales to cover the price based non-tariff measures.

\section{S4 Export Products and Export Destinations}

Tables S.1 and S.2 show Brazil's top ten export destinations by number of exporters and the top ten exported HS 6-digit product codes by total value in 2000. In Table S.1, Argentina is the most common export destination and the United States receives most Brazilian exports in value. In Table S.2, medium-sized aircraft is the leading export product in value, followed by wood pulp and soybean material for fodders.

Table S.1: Top Brazilian Export Destinations

\begin{tabular}{lrr}
\hline Destination & \# Exporters & Export Value (USD) \\
\hline Argentina & 4,590 & $5,472,333,618$ \\
Uruguay & 3,251 & $504,642,201$ \\
USA & 3,083 & $9,772,577,557$ \\
Chile & 2,342 & $1,145,161,210$ \\
Paraguay & 2,319 & $561,065,104$ \\
Bolivia & 1,799 & $282,543,791$ \\
Mexico & 1,336 & $1,554,452,204$ \\
Venezuela & 1,333 & $658,281,591$ \\
Germany & 1,217 & $1,364,610,059$ \\
Peru & 1,191 & $329,896,577$ \\
\hline
\end{tabular}

Source: SECEX 2000, manufacturing firms and their manufactured products.

\section{S5 Monte Carlo Simulations}

To document identification under our simulated method of moments estimator, we run Monte Carlo tests with generated data. We create 333,000 Brazilian firms under the initial parameters $\Theta$, where

$$
\Theta=\left\{\delta_{1}, \delta_{2}, \tilde{\alpha}, \tilde{\theta}, \sigma_{\xi}, \sigma_{c}\right\}=\{-1.20,-.90,1.73,1.84,1.89, .53\}
$$


Table S.2: Top Brazilian Exported Items

\begin{tabular}{llr}
\hline HS Code & Description & Value (USD) \\
\hline 880230 & Airplanes between 2 and 15 tons & $2,618,856,983$ \\
470329 & Bleached non-coniferous chemical wood pulp & $1,523,403,942$ \\
230400 & Soybean oil-cake and other solid residues & $1,245,752,048$ \\
870323 & Passenger vehicles between 1,500 and 3,000 cc & $1,197,222,859$ \\
852520 & Transmission apparatus incorporating reception apparatus & $926,618,451$ \\
640399 & Footwear, with outer soles & $854,950,667$ \\
720712 & Semifinished products of iron or nonalloy steel & $802,801,270$ \\
760110 & Unwrought aluminum, not alloyed & $765,195,563$ \\
200911 & Orange juice, frozen & $561,103,666$ \\
170111 & Raw solid cane sugar & $520,544,094$ \\
\hline
\end{tabular}

Source: SECEX 2000, manufacturing firms and their manufactured products.

reflects the baseline estimates from Table 3 in the main text. The generated data have approximately 10,000 exporters. We then apply our simulated method of moments routine to the generated data and find the optimum, recovering an estimate of the parameter vector $\hat{\Theta}$. We repeat the data generation and estimation procedure 30 times and report in Table S.1 the mean and standard deviation of the elements of $\hat{\Theta}$.

The Monte Carlo results in Table S.1 document that our procedure accurately pinpoints all parameters of interest. In particular, the parameters $\left(\hat{\tilde{\alpha}}, \hat{\sigma}_{\xi}, \hat{\sigma}_{c}\right)$ are precisely estimated, with point estimates close to the initial parameters behind the generated data and with standard errors less than 2 percent of the true value. Similarly, $\hat{\delta}$ and $\hat{\tilde{\theta}}$ are estimated close to their true values, their standard errors are under 4 percent of their true values. The proximity of our parameter estimates to the initial parameters underlying the data generation, and their precision, substantiate the hypothesis that our simulated method of moments estimator identifies the AGM model's parameters of interest.

Table S.1: Monte Carlo Results

\begin{tabular}{lccccccc}
\hline$\Theta$ & $\delta_{1}$ & $\delta_{2}$ & $\tilde{\alpha}$ & $\tilde{\theta}$ & $\sigma_{\xi}$ & $\sigma_{c}$ & $\delta_{1}-\delta_{2}$ \\
\hline Parameter of generated data & -1.17 & -.90 & 1.73 & 1.84 & 1.89 & .53 & -.27 \\
$\begin{array}{l}\text { Estimate (mean) } \\
\text { (s.e.) }\end{array}$ & -1.20 & -.92 & 1.71 & 1.90 & 1.88 & .51 & -.28 \\
\hline
\end{tabular}


Table S.1: Estimation Results

\begin{tabular}{lrrrrrrr}
\hline & $\delta_{\mathrm{LAC}}$ & $\delta_{\mathrm{ROW}}$ & $\tilde{\alpha}$ & $\tilde{\theta}$ & $\sigma_{\xi}$ & $\sigma_{c}$ & $\delta_{\mathrm{LAC}}-\delta_{\mathrm{ROW}}$ \\
\hline Baseline & -1.17 & -.87 & 1.77 & 1.73 & 1.82 & .58 & -.30 \\
& $(.05)$ & $(.07)$ & $(.05)$ & $(.09)$ & $(.04)$ & $(.02)$ & $(.06)$ \\
No product appeal & -1.41 & -1.18 & 2.42 & 1.00 & & .99 & -.23 \\
$\quad$ shocks $\left(\sigma_{\xi}=0\right)$ & $(.03)$ & $(.05)$ & $(.03)$ & $(.001)$ & & $(.01)$ & $(.04)$ \\
No market access & -1.20 & -.91 & 1.78 & 1.77 & 2.00 & & -.28 \\
$\quad$ cost shocks $\left(\sigma_{c}=0\right)$ & $(.05)$ & $(.08)$ & $(.03)$ & $(.11)$ & $(.03)$ & & $(.05)$ \\
Imposed single products & & & & 3.82 & 1.26 & 0.30 & \\
$\quad\left(\delta_{c}=\alpha=\infty\right)$ & & & & $(0.55)$ & $(.03)$ & $(.04)$ & \\
\hline
\end{tabular}

Source: SECEX 2000, manufacturing firms and their manufactured products.

Note: Products at the HS 6-digit level. Standard errors from 100 bootstraps in parentheses. Estimates of $\delta_{\text {LAC }}$ measure the scope elasticity of market-access costs for Brazilian firms shipping to other LAC destinations, $\delta_{\mathrm{ROW}}$ for Brazilian firms shipping to destinations outside LAC. The upper three rows restate Table 3, the final row shows the limiting case of our model close to the Eaton, Kortum and Kramarz (2011) model with single-product firms.

\section{S6 Limit Cases}

In the main text, we deviate from the baseline estimation model in two ways: we remove product appeal shocks by setting their variance to the limit $\left(\sigma_{\xi}=0\right)$, and we remove market access cost shocks by setting their variance to the limit $\left(\sigma_{c}=0\right)$. In this supplement, we strip the multiproduct nature out of our model entirely by setting the scope elasticity of market access cost $\delta$ and the scope elasticity of marginal cost $\alpha$ both to infinity. The resulting modification needed for estimation is to exclude moments from the SMM estimator that relate to the multi-product aspects of the data. We remove these moments to create an approximation of the Eaton, Kortum and Kramarz (2011) model within our framework. The accordingly reduced model allows us to identify the parameters $\tilde{\theta}, \sigma_{\xi}$ and $\sigma_{c}$. We report the findings on the final row of Table S.1. The upper three rows of Table S.1 repeat for comparison the results from the baseline and the limit cases $\left(\sigma_{\xi}=0, \sigma_{c}=0\right)$ considered in Table 3 in the text.

When we force the model to make all firms single-product firms $\left(\delta_{c}=\alpha=\infty\right)$, the estimate of the Pareto shape parameter $\tilde{\theta}$ does not drop to the limit of one, as it did when we removed product appeal shocks (with $\sigma_{\xi}=0$ ) but retained multi-product firms. To the contrary, when we force firms to be single-product exporters, the Pareto shape parameter increases substantively. Important implications follow from this result and related findings in the other limits.

First, the imposed single-product version of our model results in a non-problematic $\tilde{\theta}$ estimate away from the lower bound of one. Second, taken together with the opposite finding for multi-product firms in the absence of product appeal shocks, we infer that a deterministic multi-product model makes the SMM estimator strive for possibly much other variationraising cross-firm dispersion to its limit at the lower bound of $\tilde{\theta}=1$ and raising cross-destination dispersion within firms by pushing $\sigma_{c}$ above the baseline level (of 0.58) and far above the level in the imposed single-product version (0.30). Third, our $\tilde{\theta}$ estimates take plausible values when compared with the Eaton, Kortum and Kramarz (2011) benchmark: we find that $\tilde{\theta}$ is 1.73 in the 
baseline product-level model, while Eaton, Kortum and Kramarz (2011) obtain $\tilde{\theta}$ around 2.46 using French data for single-product firms; we find $\tilde{\theta}=3.82$ (with a wide standard error of 0.55 ) using Brazilian data after forcing the firms in the model to be single-product firms. The estimate of $\tilde{\theta}=3.82$ in the single-product limit of our model is higher than in EKK but plausible, especially in light of the fact that the productivity dispersion tends to be wider in low-income economies than in advanced countries (e.g. Hsieh and Klenow 2009). These insights lend support to our choices of heterogeneity: product appeal shocks are a crucial source of variation when turning to firm-product-destination data in estimation.

There are crucial differences between our model and the Eaton, Kortum and Kramarz (2011) model. Most importantly, the product appeal shock $\xi$ in our model varies by product within firm, not just by firm as in Eaton, Kortum and Kramarz (2011). The models also differ in timing. In our model firms realize the entry cost shock $\xi$ only after entering a market and after choosing the number of products to export. This is different from the Eaton, Kortum and Kramarz (2011) setup, where the market access shocks are jointly observed. Moreover, the Eaton, Kortum and Kramarz (2011) model features two additional parameters that we do not estimate. One additional parameter regulates the correlation between the shocks, which we can omit because our model has different timing. The other additional parameter in the Eaton, Kortum and Kramarz (2011) model is the Arkolakis (2010) market penetration sensitivity parameter. We discuss in Supplement S2 above how we accommodate market penetration cost through our stochastic setup rather than through a deterministic functional form.

\section{S7 Sensitivity Analysis}

To assess the robustness of our baseline estimates in AGM, we perform a number of modifications to our main specification. Overall, we find that our baseline results are remarkably robust to sample restrictions and alternative variable definitions.

\section{S7.1 Adjusted sales}

Our baseline estimates imply a large and statistically significant difference between $\delta_{\text {LAC }}$ and

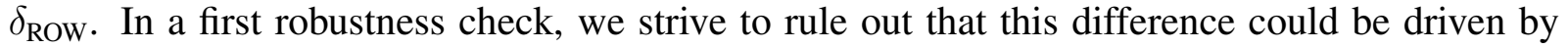
different typical sales across sets of products that Brazilian firms ship to LAC and non-LAC countries. We therefore correct sales and control for the mean sales of product groups at the HS 2-digit level. Concretely, we take the upward or downward deviation of a firm's HS 6-digit product sales to a destination $\ln y_{\omega d}^{p}$ from the worldwide product-group sales mean of Brazilian exporters:

$$
\tilde{y}_{\omega d g}=\exp \left\{\ln y_{\omega d g}-\frac{1}{M} \sum_{\omega} \frac{1}{N} \sum_{d} \sum_{g \in \mathrm{HS} 2} \ln y_{\omega d g}\right\} .
$$

This adjustment does not reduce the sample size. We report the results in the row 1. Adjusted sales of Table S.1. The estimates are broadly consistent with the baseline, but the estimated scope elasticities of market-access costs $\delta$ and of product efficiency $\tilde{\alpha}$ are lower in absolute magnitude, and so is the estimated Pareto shape parameter $\tilde{\theta}$. These estimates imply that both 
the within-firm product distribution is more concentrated in the top product and the betweenfirm sales distribution has more firms in the upper tail with extremely high sales. An intuitive explanation is that demeaning sales by the average exporter's typical sale in a product group exacerbates sales deviations of specific products, thus making distributions appear more extreme. However, signs of our estimates stay the same and broad magnitudes remain qualitatively similar to the baseline estimates.

\section{S7.2 Advanced manufacturing}

A related robustness concern is that estimation could be driven by different feasible exporter scopes across product groups that Brazilian firms ship to LAC and non-LAC destination. For example, more differentiated industries, or more technology driven industries, might allow for the export of more varieties, or the HS classification system might simply provide more individual HS 6-digit products within more refined HS 2-digit product groups. In a second robustness exercise we therefore restrict the sample to firms that are active in relatively advanced manufacturing industries. We present results from our definition of advanced manufacturing as three top-level CNAE sectors "Manufacture of machinery and equipment", "Manufacture of electrical and optical equipment" and "Manufacture of transport equipment" (codes DK, DL and DM).

Under this sectoral restriction, a markedly reduced sample size of only 2,539 Brazilian manufacturing exporters remains. Despite the considerable drop in sample size, however, results in the row labeled 2. Advanced manufacturing in Table S.1 are broadly consistent with the baseline. In advanced manufacturing industries, the difference in scope elasticities of market-access costs $\delta$ is slightly larger between LAC and non-LAC countries than it is in the baseline (but the difference in not statistically significant). Market-access costs in advanced manufacturing industries drop off similarly fast with scope in LAC and non-LAC countries as in the average industry. For our counterfactual exercise, the slightly wider difference of market-access cost elasticities between LAC and non-LAC countries implies somewhat more pronounced benefits of harmonizing market-access costs across the world. Except for the higher variance of product appeal shocks in advanced manufacturing than in the average industry, parameter estimates are generally similar to the baseline, and specially the scope elasticity of product efficiency $\tilde{\alpha}$ is not statistically significantly different in advanced industries compared to the average industry. Overall, every sign remains the same and estimates that are statistically different from the baseline remain comparable in their qualitative economic implications.

\section{S7.3 Eight-digit NCM product categories}

To make our results closely comparable to evidence from other countries, in our main text we define a product as a Harmonized System (HS) 6-digit code, which is internationally comparable by requirement of the World Customs Organization (WCO) across its 200 member countries. To query the potential sensitivity of our results to a refined product classification, we use the Mercosur 8-digit level (Nomenclatura Comum do Mercosul NCM8), which roughly corresponds to the 8-digit HS level by the World Customs Organization. As the row 3. NCM 8-digit manufacturing in Table $\mathrm{S} .1$ shows, our results are hardly sensitive at all to the change in level of disaggregation. No single estimate is statistically different from our baseline estimates. 
Table S.1: Robustness for Select Subsamples

\begin{tabular}{lccccccc}
\hline & $\delta_{\text {LAC }}$ & $\delta_{\text {ROW }}$ & $\tilde{\alpha}$ & $\tilde{\theta}$ & $\sigma_{\xi}$ & $\sigma_{c}$ & $\delta_{\text {LAC }}-\delta_{\text {ROW }}$ \\
\hline Baseline & -1.16 & -.86 & 1.76 & 1.72 & 1.82 & .58 & -.30 \\
& $(.04)$ & $(.06)$ & $(.04)$ & $(.08)$ & $(.04)$ & $(.02)$ & $(.06)$ \\
1. Adjusted & -1.00 & -.76 & 1.60 & 1.67 & 1.88 & .62 & -.24 \\
$\quad$ sales & $(.05)$ & $(.06)$ & $(.05)$ & $(.06)$ & $(.03)$ & $(.02)$ & $(.04)$ \\
2. Advanced & -1.14 & -.78 & 1.63 & 1.77 & 2.19 & .56 & -.36 \\
$\quad$ manufacturing & $(.13)$ & $(.13)$ & $(.17)$ & $(.23)$ & $(.09)$ & $(.08)$ & $(.16)$ \\
3. NCM 8-digit & -1.14 & -.88 & 1.73 & 1.71 & 1.79 & .58 & -.26 \\
$\quad$ manufacturing & $(.04)$ & $(.06)$ & $(.05)$ & $(.08)$ & $(.03)$ & $(.02)$ & $(.05)$ \\
4. Dropping ARG, USA & -1.20 & -.95 & 1.74 & 2.01 & 1.78 & .56 & -.35 \\
$\quad$ all manufacturing) & $(.06)$ & $(.08)$ & $(.05)$ & $(.15)$ & $(.03)$ & $(.04)$ & $(.06)$ \\
5. Exporter share & -1.28 & -1.02 & 1.86 & 1.80 & 1.79 & .56 & -.27 \\
$\quad$ 10 percent & $(.08)$ & $(.11)$ & $(.07)$ & $(.11)$ & $(.04)$ & $(.03)$ & $(.04)$ \\
\hline
\end{tabular}

Source: SECEX 2000, manufacturing firms and their manufactured products.

Note: Products at the HS 6-digit level. Estimates of $\delta_{\text {LAC }}$ indicates the scope elasticity for incremental product access costs for Brazilian firms shipping to other LAC destinations. Similarly $\delta_{\text {ROW }}$ perform the same role for exports to non-LAC destinations. See text for full description of various specifications.

\section{S7.4 Sensitivity to destinations Argentina and United States}

Two destination markets dominate Brazilian manufacturing exports: Argentina (the top destination in terms of exporter counts) and the United States (the top destination in terms of export value). To assure ourselves that the estimates are not driven by potential outlier behavior of export flows to those two destinations, we remove them from the sample. As Table S.1 in the row labeled 4. Dropping ARG, USA shows, only the estimate of the firm size distribution's shape parameter $\tilde{\theta}$ becomes statistically significantly different from the baseline estimate. All other estimates are statistically indistinguishable from the baseline estimates. When we omit Argentina and the United States, the higher estimate for the Pareto tail index $\tilde{\theta}$ implies a lower probability mass in the upper tail of firms with extremely high sales. Even though Argentina and the United States attract a large number of export entrants from Brazil, these markets also exhibit a stronger concentration of exports among just a few top-selling firms than the average Brazilian export destination.

\section{S7.5 Exporter share}

An arguably important moment for our simulated method of moments is the share of formally established Brazilian manufacturing firms that export. Among the universe of Brazilian firms with at least one employee, only three percent of firms are exporters in 2000. This share is similar to that observed in other countries, for which data on the universe of firms with at least one employee is available. However, censuses and surveys in most developing and some in- 
Table S.2: Alternative Regional Aggregates

\begin{tabular}{llc}
\hline$\delta_{1}$ & $\delta_{2}$ & $\delta_{1}-\delta_{2}$ \\
\hline Baseline & Baseline & -.30 \\
Latin America and Caribbean (LAC) & Rest of World & $(.06)$ \\
1. Mercosur & Rest of LAC (Non-Mercosur) & -.03 \\
& & $(.03)$ \\
2. Mercosur & Rest of World (Non-Mercosur) & -.20 \\
& & $(.04)$ \\
\hline
\end{tabular}

Source: SECEX 2000, manufacturing firms and their manufactured products.

Note: Products at the HS 6-digit level.

dustrialized countries truncate their target population of firms from below with thresholds up to 20 employees. To query sensitivity of our estimates to the share of exporters, we hypothetically consider an alternative share of 10 percent of Brazilian firms exporting. This exercise serves two purposes. First, comparisons of our findings to future results in other countries may depend on using a hypothetically truncated target population of firms from below. Second, we can check how our results might depend on a hypothetically more export oriented manufacturing sector such as, for instance, the U.S. manufacturing sector.

Table S.1 reports the results in the row 5. Exporter share 10 percent. Compared to the baseline, the scope elasticities of market-access costs $\delta$ and of product efficiency $\tilde{\alpha}$ increase in absolute magnitude. Intuitively, the estimator tries to "explain" the hypothetically higher share of exporters with relatively faster declines in market-access costs as exporter scope increases but to offset those access cost reductions with relatively steeper declines in product efficiency away from core competency, so as to keep matching the overall pattern of exporter scopes across destinations. The other three parameter estimates remain similar to the baseline estimates. This final robustness exercise therefore clarifies how the firm entry margin influences identification: if firm entry with the first product were hypothetically more prevalent, then for a given common market-access cost component $f_{s d}(1)$ the access cost schedule would need to decline faster with scope, leading to wider exporter scopes everywhere, unless production efficiency also declines faster with scope.

\section{S7.6 Sensitivity to Mercosur}

In a final set of robustness exercises, we alternate the pairings of regional aggregates. In the baseline, we split the world into LAC (Latin American and the Caribbean) and the Rest of the World (non-LAC). In a first alteration, we drop destination countries outside of LAC from our sample and split LAC into Mercosur destinations in 2000 (Argentina, Paraguay, Uruguay) and non-Mercosur destinations. In the row labelled 1. Mercosur-Rest of LAC, Table S.2 reports the results for the difference in the scope elasticities of market-access costs between the two sub-regions within LAC, and the difference is negative as in the baseline but small (and not statistically different from zero). This finding justifies our treatment of LAC in the baseline as 
a relatively homogeneous region for Brazilian exporters. In a second alteration of the regional split, we discern between Mercosur destinations in 2000 and the Rest of the World, where the Rest of the World includes LAC countries outside Mercosur as well as non-LAC destinations. Expectedly, given the earlier results in the baseline and in the first alteration, the difference is negative but not quite as pronounced in magnitude as the difference between LAC and the Rest of the World. We therefore conclude that LAC countries outside Mercosur are more similar to Mercosur than to the Rest of the World and consider our baseline split of destinations into LAC and non-LAC an adequate country grouping.

\section{S8 Counterfactual Exercises with Log-normal Productivity}

Counterfactual exercises in international trade traditionally use the "hat" algebra of Dekle, Eaton and Kortum (2007a) to show welfare changes in the presence of Pareto distributed firm productivity. We generalize this methodology to allow for any arbitrary productivity distribution, including the log-normal distribution used in Fernandes et al. (2018). We find results that are

predicated on recovering the minimum productivity cutoff for a domestic firm: $z_{i i}^{*}$, which serves as a useful normalization and allows for the recovery of nearly all other required parameters. While our data do not allow us to recover this object, we find in simulations that counterfactual welfare results are sensitive to the choice of $z_{i i}^{*}$ under log-normal firm productivities, but are stable under Pareto firm productivities. The stability of simulation results for the Pareto distribution stems from the "memoryless" property of the ratio of weighted firm productivities that holds only under the Pareto distribution. 


\section{Appendix to the Online Supplement}

\section{S-A Optimal Product Prices}

We characterize the first-order conditions for the firm's optimal pricing rules at every destination $d$. There are $G_{s d}(\phi)$ first-order conditions with respect to $p_{s d g}$. For any $G_{s d}(\phi)$, taking the first derivative of profits $\pi_{s d}(\phi)$ from (S.1) with respect to $p_{s d g}$ yields

$$
\begin{aligned}
\left(\mathrm{S}-\frac{\partial \pi_{s d}(\phi)}{\partial p_{s d g}}\right)=P_{d}^{\sigma-1} T_{d} \cdot P_{s d}(\phi ; & \left.G_{s d}\right)^{\varepsilon-\sigma} p_{s d g}^{-\varepsilon}\left\{1-\varepsilon\left(1-\frac{w_{s}}{\phi / h(g)} \tau_{s d} p_{s d g}^{-1}\right)\right. \\
& \left.+(\varepsilon-\sigma) P_{s d}\left(\phi ; G_{s d}\right)^{\varepsilon-1} \sum_{k=1}^{G_{s d}(\phi)}\left(p_{s d k}-\frac{w_{s}}{\phi / h(k)} \tau_{s d}\right) p_{s d k}^{-\varepsilon}\right\} .
\end{aligned}
$$

The first-order conditions require that (S-A.1) is equal to zero for all products $g=1, \ldots, G_{s d}(\phi)$. Using the first-order conditions for any two products $g$ and $g^{\prime}$ and reformulating we find

$$
p_{s d g} / p_{s d g^{\prime}}=h(g) / h\left(g^{\prime}\right) \text {. }
$$

So the firm must optimally charge an identical markup over the marginal costs for all products. Define this optimal markup as $\bar{m}$. To solve out for $\bar{m}$ in terms of primitives, use $p_{s d g}=$ $\bar{m} w_{s} \tau_{s d} /[\phi / h(g)]$ in the first-order condition above and simplify:

$$
1-\varepsilon \frac{1}{\bar{m}}+(\varepsilon-\sigma) P_{s d}\left(\phi ; G_{s d}\right)^{\varepsilon-1} \frac{\bar{m}-1}{\bar{m}} \sum_{k=1}^{G_{s d}(\phi)} p_{s d k}^{-(\varepsilon-1)}=0 .
$$

Note that $\sum_{k=1}^{G_{s d}(\phi)} p_{s d k}^{-(\varepsilon-1)}=P_{s d}\left(\phi ; G_{s d}\right)^{-(\varepsilon-1)}$. Solving the first-order condition for $\bar{m}$, we find the optimal markup over each product $g$ 's marginal cost

$$
\bar{m}=\tilde{\sigma} \equiv \sigma /(\sigma-1) .
$$

A firm with productivity $\phi$ optimally charges a price

$$
p_{s d g}(\phi)=\tilde{\sigma} w_{s} \tau_{s d} /[\phi / h(g)]
$$

for its products $g=1, \ldots, G_{s d}(\phi)$.

\section{S-B Second-order Conditions}

We now turn to the second-order conditions for price choice. To find the entries along the diagonal of the Hessian matrix, take the first derivative of condition (S-A.1) with respect to the 
own price $p_{s d g}$ and then replace $w_{s} \tau_{s d} /[\phi / h(g)]=p_{s d g}(\phi) / \tilde{\sigma}$ by the first-order condition to find

$$
\frac{\partial^{2} \pi_{s d}(\phi)}{\left(\partial p_{s d g}\right)^{2}}=P_{d}^{\sigma-1} T_{d} \cdot P_{s d}\left(\phi ; G_{s d}\right)^{\varepsilon-\sigma} p_{s d g}^{-\varepsilon}\left\{-\frac{\varepsilon}{\tilde{\sigma}} p_{s d g}^{-1}\right.
$$

$$
\begin{gathered}
+(\varepsilon-\sigma) P_{s d}\left(\phi ; G_{s d}\right)^{\varepsilon-1}[-(\varepsilon-1)+\varepsilon / \tilde{\sigma}] p_{s d g}^{-\varepsilon} \\
\left.+(\varepsilon-\sigma)(\varepsilon-1) P_{s d}\left(\phi ; G_{s d}\right)^{2(\varepsilon-1)} p_{s d g}^{-\varepsilon} \cdot \sum_{k=1}^{G_{s d}}(1-1 / \tilde{\sigma}) p_{s d k}^{-(\varepsilon-1)}\right\} \\
=P_{s d}\left(\phi ; G_{s d}\right)^{\varepsilon-\sigma} P_{d}^{\sigma-1} T_{d} \cdot\left\{-\varepsilon p_{s d g}^{-\varepsilon-1}+(\varepsilon-\sigma) P_{s d}\left(\phi ; G_{s d}\right)^{\varepsilon-1} p_{s d g}^{-2 \varepsilon}\right\} / \tilde{\sigma} .
\end{gathered}
$$

This term is strictly negative if and only if

$$
(\varepsilon-\sigma) P_{s d}\left(\phi ; G_{s d}\right)^{\varepsilon-1} p_{s d g}^{-(\varepsilon-1)}<\varepsilon .
$$

If $\varepsilon \leq \sigma$, this last condition is satisfied because the left-hand side is weakly negative and $\varepsilon>0$. If $\varepsilon>\sigma$, then we can rewrite the condition as $p_{s d g}^{-(\varepsilon-1)} /\left[\sum_{k=1}^{G_{s d}} p_{s d g}^{-(\varepsilon-1)}\right]<1<\varepsilon /(\varepsilon-\sigma)$ so that the condition is satisfied. The diagonal entries of the Hessian matrix are therefore strictly negative for any demand elasticity configuration across nests.

To derive the entries off the diagonal of the Hessian matrix, we take the derivative of condition (S-A.1) for product $g$ with respect to any other price $p_{s d g^{\prime}}$ and then replace $w_{s} \tau_{s d} /\left[\phi / h\left(g^{\prime}\right)\right]=$ $p_{s d g^{\prime}}(\phi) / \tilde{\sigma}$ by the first-order condition to find

$$
\begin{gathered}
\frac{\partial^{2} \pi_{s d}(\phi)}{\partial p_{s d g} \partial p_{s d g^{\prime}}}=P_{d}^{\sigma-1} T_{d} \cdot P_{s d}\left(\phi ; G_{s d}\right)^{\varepsilon-\sigma} p_{s d g}^{-\varepsilon}\left\{(\varepsilon-\sigma) P_{s d}\left(\phi ; G_{s d}\right)^{\varepsilon-1}[-(\varepsilon-1)+\varepsilon / \tilde{\sigma}] p_{s d g^{\prime}}^{-\varepsilon}\right. \\
\left.+(\varepsilon-\sigma)(\varepsilon-1) P_{s d}\left(\phi ; G_{s d}\right)^{2(\varepsilon-1)} p_{s d g^{\prime}}^{-\varepsilon} \sum_{k=1}^{G_{s d}}(1-1 / \tilde{\sigma}) p_{s d k}^{-(\varepsilon-1)}\right\} \\
\text { (S-B.4) }=P_{d}^{\sigma-1} T_{d} \cdot(\varepsilon-\sigma) P_{s d}\left(\phi ; G_{s d}\right)^{\varepsilon-\sigma+\varepsilon-1} p_{s d g}^{-\varepsilon} p_{s d g^{\prime}}^{-\varepsilon} / \tilde{\sigma} .
\end{gathered}
$$

This term is strictly positive if and only if $\varepsilon>\sigma$.

Having derived the entries of the Hessian matrix, it remains to establish the conditions under which the Hessian is negative definite. We discern two cases. First the case of $\varepsilon \leq \sigma$ and then the case $\varepsilon>\sigma$.

\section{S-B.1 Negative definiteness of Hessian if $\varepsilon \leq \sigma$}

By (S-B.3) and (S-B.4), the Hessian matrix can be written as

$$
\mathbf{H}=P_{s d}\left(\phi ; G_{s d}\right)^{\varepsilon-\sigma} P_{d}^{\sigma-1} T_{d}\left[\mathbf{H}_{A}+(\varepsilon-\sigma) P_{s d}\left(\phi ; G_{s d}\right)^{\varepsilon-1} \mathbf{H}_{B}\right],
$$


where

$$
\mathbf{H}_{A} \equiv\left(\begin{array}{cccc}
-\varepsilon p_{s d 1}^{-\varepsilon-1} & & & \\
0 & -\varepsilon p_{s d 2}^{-\varepsilon-1} & & \\
0 & 0 & -\varepsilon p_{s d 3}^{-\varepsilon-1} & \\
\ldots & & & \ldots
\end{array}\right) \text { and } \mathbf{H}_{B} \equiv\left(\begin{array}{cccc}
p_{s d 1}^{-\varepsilon} p_{s d 1}^{-\varepsilon} & & & \\
p_{s d 2}^{-\varepsilon} p_{s d 1}^{-\varepsilon} & p_{s d 2}^{-\varepsilon} p_{s d 2}^{-\varepsilon} & & \\
p_{s d 3}^{-\varepsilon} p_{s d 1}^{-\varepsilon} & p_{s d 3}^{-\varepsilon} p_{s d 2}^{-\varepsilon} & p_{s d 3}^{-\varepsilon} p_{s d 3}^{-\varepsilon} & \\
\ldots & & & \\
\ldots & & &
\end{array}\right)
$$

The Hessian matrix $\mathbf{H}$ is negative definite if and only if the negative Hessian

$$
-\mathbf{H}=P_{s d}\left(\phi ; G_{s d}\right)^{\varepsilon-\sigma} P_{d}^{\sigma-1} T_{d}\left[-\mathbf{H}_{A}+(\sigma-\varepsilon) P_{s d}\left(\phi ; G_{s d}\right)^{\varepsilon-1} \mathbf{H}_{B}\right]
$$

is positive definite. Note that the sum of one positive definite matrix and any number of positive semidefinite matrices is positive definite. Hence if $-\mathbf{H}_{A}$ and $\mathbf{H}_{B}$ are positive semidefinite and at least one of the two matrices is positive definite (given $\varepsilon \leq \sigma$ ), then the Hessian is negative definite.

A necessary and sufficient condition for a matrix to be positive definite is that the leading principal minors of the matrix are positive. The leading principal minors of $-\mathbf{H}_{A}$ are positive, so $-\mathbf{H}_{A}$ is positive definite. For $\mathbf{H}_{B}$, the first leading principal minor is positive, and all remaining principal minors are equal to zero. So $\mathbf{H}_{B}$ is positive semidefinite. Therefore the Hessian matrix $\mathbf{H}$ is negative definite.

\section{S-B.2 Negative definiteness of Hessian if $\varepsilon>\sigma$}

Another necessary and sufficient condition for the Hessian matrix $\mathbf{H}$ to be negative definite is that the leading principal minors alternate sign, with the first principal minor being negative. The first diagonal entry is strictly negative as is any diagonal entry by (S-B.3). An application of the leading principal minor test in our case requires a recursive computation of the determinants of $G_{s d}(\phi)$ submatrices (a solution of polynomials with order up to $G_{s d}(\phi)$ ). We choose to check for negative definiteness of the Hessian in two separate ways when $\varepsilon>\sigma$. First, we derive a sufficient (but not necessary) condition for negative definiteness of the Hessian and query its empirical validity. Second, we present a necessary (but not sufficient) condition for negative definiteness of the Hessian for any pair of two products.

Sufficiency. A sufficient condition for the Hessian to be negative definite is due to McKenzie (1960): a symmetric diagonally dominant matrix with strictly negative diagonal entries is negative definite. A matrix is diagonally dominant if, in every row, the absolute value of the diagonal entry strictly exceeds the sum of the absolute values of all off-diagonal entries. By our derivations above, all diagonal entries of the Hessian are strictly negative.

For $\varepsilon>\sigma$, the condition for the Hessian to be diagonally dominant is

$$
\sum_{k \neq g}^{G_{s d}}(\varepsilon-\sigma) P_{s d}\left(\phi ; G_{s d}\right)^{\varepsilon-1} p_{s d k}^{-\varepsilon} p_{s d g}^{-\varepsilon}<\varepsilon p_{s d g}^{-\varepsilon-1}-(\varepsilon-\sigma) P_{s d}\left(\phi ; G_{s d}\right)^{\varepsilon-1} p_{s d g}^{-2 \varepsilon}
$$

for all of a firm $\phi$ 's products (rows of its Hessian), where we cancelled the strictly positive terms 
$P_{d}^{\sigma-1} T_{d} P_{s d}\left(\phi ; G_{s d}\right)^{\varepsilon-\sigma} / \tilde{\sigma}$ from the inequality.

Using the optimal price (S-A.2) of product $g$ from the first-order condition and rearranging terms yields the following condition

$$
\frac{\sum_{k=1}^{G_{s d}} h(k)^{-\varepsilon}}{\sum_{k=1}^{G_{s d}} h(k)^{-(\varepsilon-1)}}<\frac{\varepsilon}{\varepsilon-\sigma} h(g)^{-1}
$$

for the Hessian to be a diagonally dominant matrix at the optimum.

By convention and without loss of generality $h(1)=1$ for a firm with productivity $\phi$. So the product efficiency schedule $h(g)$ strictly exceeds unity for the second product and subsequent products. As a result, the left-hand side of the inequality is bounded above for an exporter with a scope of at least two products at a destination:

$$
\frac{\sum_{k=1}^{G_{s d}} h(k)^{-\varepsilon}}{\sum_{k=1}^{G_{s d}} h(k)^{-(\varepsilon-1)}}<\frac{\sum_{k=1}^{G_{s d}} h(k)^{-(\varepsilon-1)}}{\sum_{k=1}^{G_{s d}} h(k)^{-(\varepsilon-1)}}=1 .
$$

A sufficient (but not necessary) condition for the Hessian to be negative definite is therefore

$$
1 \leq h(g)<\frac{\varepsilon}{\varepsilon-\sigma}
$$

for all of the firm's products. However, the Hessian can still be negative definite even if this condition fails. Clearly, the Hessian becomes negative definite the closer is $\varepsilon$ to $\sigma$ because then the off-diagonal entries approach zero and the Hessian is trivially diagonally dominant. Moreover, the Hessian can be negative definite even if it is not a diagonally dominant matrix.

To query the empirical validity of the sufficient condition $h(g)<\varepsilon /(\varepsilon-\sigma)$, consider evidence on products and brands in Broda and Weinstein (2006). Their preferred estimates for $\varepsilon$ and $\sigma$ within and across domestic U.S. brand modules are 11.5 and 7.5. Estimates in AGM suggest that $\alpha(\varepsilon-1)$ is around 1.84 under the specification that $h(g)=g^{\alpha}$. These parameters imply that the condition $h(g)<\varepsilon /(\varepsilon-\sigma)$ is satisfied for Hessians with up to 414 products. In the AGM data, no firm-country observations involve 415 or more products in a market (with a median of one product and a mean of 3.52). Even if additional products individually violate the sufficient condition, Hessians with more products may still be negative definite.

Necessity. Consider any two products $g$ and $g^{\prime}$. Negative definiteness of the Hessian must be independent of the ordering of products, so these two products can be assigned the first and second row in the Hessian without loss of generality. As stated before, a necessary and sufficient condition for the Hessian to be negative definite is that the leading principal minors of the Hessian alternate sign, with the first principal minor being negative. A necessary condition for the Hessian to be negative definite is therefore that the principal minors of any two products (first and second in the Hessian) alternate sign, with the first principal minor negative and the second positive.

The first principle minor is strictly negative because all diagonal entries are strictly negative 
by (S-B.3). The second principal minor is strictly positive if and only if the determinant satisfies (S-B.6)

$2 \varepsilon^{2} P_{s d}\left(\phi ; G_{s d}\right)^{-(\varepsilon-1)}-\varepsilon(\varepsilon-\sigma)\left(p_{s d g}^{-(\varepsilon-1)}+p_{s d g^{\prime}}^{-(\varepsilon-1)}\right)-(\varepsilon-\sigma)^{2}\left(p_{s d g} p_{s d g^{\prime}}\right)^{-(\varepsilon-1)} P_{s d}\left(\phi ; G_{s d}\right)^{\varepsilon-1}>0$,

where we cancelled the strictly positive terms $P_{d}^{2(\sigma-1)} T_{d} P_{s d}\left(\phi ; G_{s d}\right)^{2(\varepsilon-\sigma)} / \tilde{\sigma}^{2}$ from the inequality and multiplied both sides by $p_{s d g}^{\varepsilon-1} p_{s d g^{\prime}}^{\varepsilon-1} P_{s d}\left(\phi ; G_{s d}\right)^{-(\varepsilon-1)}$.

To build intuition, consider the dual-product case with $G_{s d}(\phi)=2$. Then condition (S-B.6) simplifies to

$$
\frac{h(g)^{-(\varepsilon-1)}}{\sum_{k=1}^{G_{s d}} h(k)^{-(\varepsilon-1)}} \cdot \frac{h\left(g^{\prime}\right)^{-(\varepsilon-1)}}{\sum_{k=1}^{G_{s d}} h(k)^{-(\varepsilon-1)}}<\frac{\varepsilon}{\varepsilon-\sigma} \frac{\varepsilon+\sigma}{\varepsilon-\sigma} .
$$

For $\varepsilon>\sigma$, both terms in the product on the right-hand side strictly exceed unity while the terms in the product on the left-hand side are strictly less than one, and the condition is satisfied.

In the multi-product case with $G_{s d}(\phi)>2$, replace $p_{s d g}^{-(\varepsilon-1)}+p_{s d g^{\prime}}^{-(\varepsilon-1)}=P_{s d}\left(\phi ; G_{s d}\right)^{-(\varepsilon-1)}-$ $\sum_{k \neq g, g^{\prime}} p_{s d k}^{-(\varepsilon-1)}$ in condition (S-B.6) and simplify to find

$$
\frac{h(g)^{-(\varepsilon-1)}}{\sum_{k=1}^{G_{s d}} h(k)^{-(\varepsilon-1)}} \cdot \frac{h\left(g^{\prime}\right)^{-(\varepsilon-1)}}{\sum_{k=1}^{G_{s d}} h(k)^{-(\varepsilon-1)}}<\frac{\varepsilon}{\varepsilon-\sigma} \frac{\varepsilon+\sigma}{\varepsilon-\sigma}+\frac{\varepsilon}{\varepsilon-\sigma} \frac{\sum_{k \neq g, g^{\prime}} h(k)^{-(\varepsilon-1)}}{\sum_{k=1}^{G_{s d}} h(k)^{-(\varepsilon-1)}} .
$$

For $\varepsilon>\sigma$, the necessary condition on any two products of a multi-product firm is trivially satisfied by the above derivations because the additional additive term on the right-hand side is strictly positive.

In summary, parameters of our model are such that, for any two products of a multi-product firm, the second-order condition is satisfied.

\section{S-C Proof of Proposition S.3}

Average sales from $s$ to $d$ are

$$
\bar{T}_{s d}=\int_{\phi_{s d}^{*}} y_{s d}\left(G_{s d}\right) \frac{\theta\left(\phi_{s d}^{*}\right)^{\theta}}{\phi^{\theta+1}} \mathrm{~d} \phi=\sigma f_{s d}(1) \theta \int_{\phi_{s d}^{*}} \frac{\phi^{\sigma-2-\theta} /\left(\phi_{s d}^{*}\right)^{\sigma-1-\theta}}{H\left(G_{s d}(\phi)\right)^{\sigma-1}} \mathrm{~d} \phi .
$$

The proof of the proposition follows from the following Lemma.

Lemma 2 Suppose Assumptions S.1, S.2 and S.3 hold. Then

$$
\int_{\phi_{s d}^{*}} \frac{\phi^{\sigma-2-\theta} /\left(\phi_{s d}^{*}\right)^{\sigma-1-\theta}}{H\left(G_{s d}(\phi)\right)^{\sigma-1}} d \phi=\frac{f_{s d}(1)^{\tilde{\theta}-1}}{\theta-(\sigma-1)} \tilde{F}_{s d}
$$

where

$$
\tilde{F}_{s d} \equiv \sum_{v=1}^{\infty} \frac{\left[f_{s d}(v)\right]^{1-\tilde{\theta}}}{\left[H(v)^{1-\sigma}-H(v-1)^{1-\sigma}\right]^{-\tilde{\theta}}}
$$


Proof. Note that

$$
\begin{aligned}
\int_{\phi_{s d}^{*}} \frac{\phi^{\sigma-2-\theta} /\left(\phi_{s d}^{*}\right)^{\sigma-1-\theta}}{H\left(G_{s d}(\phi)\right)^{\sigma-1} \mathrm{~d} \phi=} & H(1)^{1-\sigma} \int_{\phi_{s d}^{*}}^{\phi_{s d}^{*, 2}} \phi^{\sigma-2-\theta} \mathrm{d} \phi+H(2)^{1-\sigma} \int_{\phi_{s d}^{*, 2}}^{\phi_{s d}^{*, 3}} \phi^{\sigma-2-\theta} \mathrm{d} \phi+\ldots \\
= & H(1)^{1-\sigma}\left[\frac{\left(\phi_{s d}^{*, 2}\right)^{\sigma-1-\theta}-\left(\phi_{s d}^{*}\right)^{\sigma-1-\theta}}{\left.[\theta-(\sigma-1)]\left(\phi_{s d}^{*}\right)^{\sigma-1-\theta}\right]}\right. \\
& +H(2)^{1-\sigma}\left[\frac{\left(\phi_{s d}^{*, 3}\right)^{\sigma-1-\theta}-\left(\phi_{s d}^{*, 2}\right)^{\sigma-1-\theta}}{[\theta-(\sigma-1)]\left(\phi_{s d}^{*}\right)^{\sigma-1-\theta}}\right]+\ldots
\end{aligned}
$$

Also note that, using equations (S.4) and (S.6), the ratio

$$
\left[\left(\phi_{s d}^{*, 2}\right)^{\sigma-1-\theta}-\left(\phi_{s d}^{*}\right)^{\sigma-1-\theta}\right] /\left(\phi_{s d}^{*}\right)^{\sigma-1-\theta}
$$

can be rewritten as

$$
\begin{aligned}
& \frac{\left(\phi_{s d}^{*, G}\right)^{\sigma-1-\theta}-\left(\phi_{s d}^{*, G-1}\right)^{\sigma-1-\theta}}{\left(\phi_{s d}^{*}\right)^{\sigma-1-\theta}}= \\
& =\frac{\left[\frac{\left(\phi_{s d}^{*}\right)^{\sigma-1}}{H(g)^{1-\sigma}-H(g-1)^{1-\sigma}} \frac{f_{s d}(g)}{f_{s d}(1)}\right]^{\frac{\sigma-1-\theta}{\sigma-1}}-\left[\frac{\left(\phi_{s d}^{*}\right)^{\sigma-1}}{H(g-1)^{1-\sigma}-H(g-2)^{1-\sigma}} \frac{f_{s d}(g-1)}{f_{s d}(1)}\right]^{\frac{\sigma-1-\theta}{\sigma-1}}}{\left[\left(\phi_{s d}^{*}\right)^{\sigma-1}\right]^{\frac{\sigma-1-\theta}{\sigma-1}}} \\
& =f_{s d}(1)^{\tilde{\theta}-1}\left\{\frac{f_{s d}(g)^{1-\tilde{\theta}}}{\left[H(g)^{1-\sigma}-H(g-1)^{1-\sigma}\right]^{1-\tilde{\theta}}}-\frac{f_{s d}(g-1)^{1-\tilde{\theta}}}{\left[H(g-1)^{1-\sigma}-H(g-2)^{1-\sigma}\right]^{1-\tilde{\theta}}}\right\} .
\end{aligned}
$$

We define $e^{54}$

$$
\begin{aligned}
\tilde{F}_{s d} & \equiv \sum_{v=1} H(v)^{1-\sigma}\left[\frac{\left[f_{s d}(v+1)\right]^{1-\tilde{\theta}}}{\left[H(v+1)^{1-\sigma}-H(v)^{1-\sigma}\right]^{1-\tilde{\theta}}}-\frac{\left[f_{s d}(v)\right]^{1-\tilde{\theta}}}{\left[H(v)^{1-\sigma}-H(v-1)^{1-\sigma}\right]^{1-\tilde{\theta}}}\right] \\
& =\sum_{v=1}\left[\left[H(v)^{1-\sigma}-H(v-1)^{1-\sigma}\right] \frac{\left[f_{s d}(v)\right]^{1-\tilde{\theta}}}{\left[H(v)^{1-\sigma}-H(v-1)^{1-\sigma}\right]^{1-\tilde{\theta}}}\right] \\
& =\sum_{v=1} \frac{\left[f_{s d}(v)\right]^{1-\tilde{\theta}}}{\left[H(v)^{1-\sigma}-H(v-1)^{1-\sigma}\right]^{-\tilde{\theta}}} .
\end{aligned}
$$

\footnotetext{
${ }^{54}$ In the special case with $\varepsilon=\sigma$, we can rearrange the terms and find
}

$$
\tilde{F}_{s d}=\sum_{v=1}^{\infty} \frac{\left[f_{s d}(v)\right]^{1-\tilde{\theta}}}{\left[h(v)^{\sigma-1}\right]^{-\tilde{\theta}}}=\sum_{v=1}^{\infty} \frac{\left[f_{s d}(v)\right]^{1-\tilde{\theta}}}{h(v)^{-\theta}} .
$$


With this definition we obtain

$$
\int_{\phi_{s d}^{*}} \frac{\phi^{\sigma-2-\theta} /\left(\phi_{s d}^{*}\right)^{\sigma-1-\theta}}{H\left(G_{s d}(\phi)\right)^{\sigma-1}} \mathrm{~d} \phi=\frac{f_{s d}(1)^{\tilde{\theta}-1}}{\theta-(\sigma-1)} \tilde{F}_{s d} .
$$

\section{S-D Welfare}

We have that

$$
\begin{aligned}
P_{d}^{1-\sigma} & =\sum_{s} \int_{\phi_{s d}^{*}}\left[P_{s d}(\phi)\right]^{1-\sigma} \mu(\phi) \mathrm{d} \phi \\
& =\sum_{s} \int_{\phi_{s d}^{*}} M_{s d}\left[\sum_{v=1}^{G_{s d}(\phi)}\left(\tilde{\sigma} \frac{w_{s}}{\phi / h(g)} \tau_{s d}\right)^{1-\varepsilon}\right]^{\frac{1-\sigma}{1-\varepsilon}} \frac{\theta\left(\phi_{s d}^{*}\right)^{\theta}}{\phi^{\theta+1}} \mathrm{~d} \phi \\
& =\sum_{s}\left(\tilde{\sigma} w_{s} \tau_{s d}\right)^{1-\sigma} b_{s}^{\theta} \theta\left[H(1)^{1-\sigma}\left(\frac{\left(\phi_{s d}^{*, 2}\right)^{\sigma-1-\theta}-\left(\phi_{s d}^{*, 1}\right)^{\sigma-1-\theta}}{\theta-(\sigma-1)}\right)+\ldots\right] \\
& =\sum_{s}\left(\tilde{\sigma} w_{s} \tau_{s d}\right)^{-\theta} b_{s}^{\theta} \theta\left(\frac{f_{s d}(1)}{\frac{1}{\sigma} T_{d}}\right)^{1-\tilde{\theta}}\left[H(1)^{1-\sigma}\left(\frac{\left(\phi_{s d}^{*, 2}\right)^{\sigma-1-\theta}-\left(\phi_{s d}^{*, 1}\right)^{\sigma-1-\theta}}{\left(\phi_{s d}^{*, 1}\right)^{\sigma-1-\theta}}\right)+\ldots\right],
\end{aligned}
$$

where we use the definition of $\phi_{s d}^{*, 1}$ for the last step. The final term in parentheses equals $\tilde{F}_{s d}$ so

$$
P_{d}^{-\theta}=\frac{\theta(\tilde{\sigma})^{-\theta}}{\left(\frac{1}{\sigma}\right)^{1-\theta /(\sigma-1)} T_{d}^{1-\tilde{\theta}}} \sum_{s} b_{s}^{\theta}\left(w_{s} \tau_{s d}\right)^{-\theta} \tilde{F}_{s d} .
$$

Using this relationship in equation (S.12), we obtain

$$
\left(\frac{T_{d}}{P_{d}}\right)^{\theta}=\left(\frac{T_{d}}{w_{d}}\right)^{\theta} \frac{\theta(\tilde{\sigma})^{-\theta}}{(\sigma)^{\tilde{\theta}-1}} \frac{b_{d}^{\theta}}{\lambda_{d d}^{-\theta}} \frac{\tilde{F}_{d d}(1)}{T_{d}^{1-\tilde{\theta}}} .
$$

If trade is balanced then $T_{d}=Y_{d}$, where $T_{d}$ is consumption expenditure and $Y_{d}$ is output. By the definition of $\tilde{F}_{d d}(1)$, this variable is homogeneous of degree $1-\tilde{\theta}$ in wages, and the wage bill share in output $w_{d} L_{d} / Y_{d}$ is constant in all equilibria (see proof below). We therefore arrive at the same welfare expression as in Arkolakis, Costinot and Rodríguez-Clare (2012): the share of domestic sales in consumption expenditure $\lambda_{d d}$ and the coefficient of the Pareto distribution are sufficient statistics to characterize aggregate welfare in the case of balanced trade.

The final step is to verify that the wage $w_{d}$ is a constant fraction of per-capita output $y_{d}$ so that the first ratio on the right-hand side is constant. We demonstrate this next. 


\section{S-E Constant Wage Share in Output per Capita}

We show that the ratio $w_{d} / y_{d}$ is a constant number. We first look at the share of fixed costs in bilateral sales. Average fixed costs incurred by firms from $s$ selling to $d$ are

$$
\begin{aligned}
\bar{F}_{s d} & =\int_{\phi_{s d}^{*}}^{\phi_{s d}^{*, 2}} F_{s d}(1) \theta \frac{\left(\phi_{s d}^{*}\right)^{\theta}}{\phi^{\theta+1}} \mathrm{~d} \phi+\int_{\phi_{s d}^{*, 2}}^{\phi_{s d}^{*, 3}} F_{s d}(2) \theta \frac{\left(\phi_{s d}^{*}\right)^{\theta}}{\phi^{\theta}} \mathrm{d} \phi+ \\
& =-F_{s d}(1)\left(\phi_{s d}^{*}\right)^{\theta}\left[\left(\phi_{s d}^{*, 2}\right)^{-\theta}-\left(\phi_{s d}^{*}\right)^{-\theta}\right]-F_{s d}(2)\left(\phi_{s d}^{*}\right)^{\theta}\left[\left(\phi_{s d}^{*, 3}\right)^{-\theta}-\left(\phi_{s d}^{*, 2}\right)^{-\theta}\right]-\ldots
\end{aligned}
$$

Using the definition $F_{s d}\left(G_{s d}\right) \equiv \sum_{g=1}^{G_{s d}} f_{s d}(g)$ and collecting terms with respect to $\phi_{s d}^{*, G}$ we can write the above expression as

$$
\bar{F}_{s d}=f_{s d}(1)+\left(\phi_{s d}^{*, 2}\right)^{-\theta}\left(\phi_{s d}^{*}\right)^{\theta} f_{s d}(2)+\left(\phi_{s d}^{*, 3}\right)^{-\theta}\left(\phi_{s d}^{*}\right)^{\theta} f_{s d}(3)+\ldots
$$

Using the definition of $\phi_{s d}^{*, G}$ from equation (S.6) to replace terms in the above equation, we obtain

$$
\left(\phi_{s d}^{*, G}\right)^{\sigma-1}=\frac{\left(\phi_{s d}^{*}\right)^{\sigma-1}}{H\left(G_{s d}\right)^{-(\sigma-1)}-H\left(G_{s d}-1\right)^{-(\sigma-1)}} \frac{f_{s d}\left(G_{s d}\right)}{f_{s d}(1)} .
$$

Therefore

$$
\begin{aligned}
\bar{F}_{s d} & =f_{s d}(1)+\left(\frac{f_{s d}(2)^{1 /(\sigma-1)}\left[H(2)^{-(\sigma-1)}-H(1)^{-(\sigma-1)}\right]^{-1 /(\sigma-1)}}{f_{s d}(1)^{1 /(\sigma-1)}\left[H(1)^{-(\sigma-1)}\right]^{-1 /(\sigma-1)}}\right)^{-\theta} f_{s d}(2)+\ldots \\
& =\left[f_{s d}(1)+f_{s d}(1)^{\tilde{\theta}}\left(f_{s d}(2)^{1 /(\sigma-1)}\left[H(2)^{-(\sigma-1)}-H(1)^{-(\sigma-1)}\right]^{-1 /(\sigma-1)}\right)^{-\theta} f_{s d}(2)+\ldots\right] \\
& =\left[f_{s d}(1)\right]^{\tilde{\theta}}\left[f_{s d}(1)^{1-\tilde{\theta}}+\frac{f_{s d}(2)^{1-\tilde{\theta}}}{\left[H(2)^{-(\sigma-1)}-H(1)^{-(\sigma-1)}\right]^{-\tilde{\theta}}}+\frac{f_{s d}(3)^{1-\tilde{\theta}}}{\left[H(3)^{-(\sigma-1)}-H(2)^{-(\sigma-1)}\right]^{-\tilde{\theta}}} \cdots\right] \\
& =\left[f_{s d}(1)\right]^{\tilde{\theta}} \tilde{F}_{s d}
\end{aligned}
$$

and hence

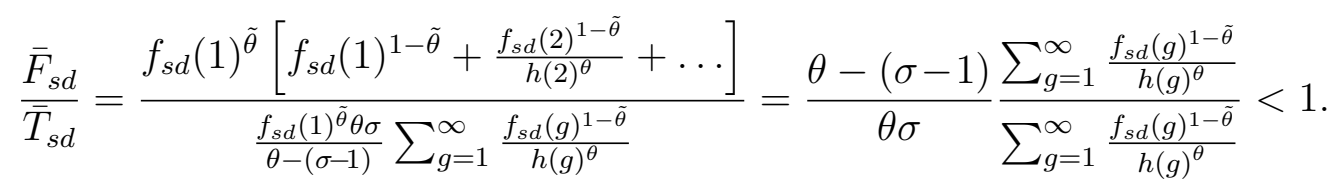

Finally, the share of profits generated by the corresponding bilateral sales is the share of variable profits in total sales $(1 / \sigma)$ minus the average fixed costs paid, as derived above. So

$$
\frac{\bar{\pi}_{s d}}{\overline{\bar{T}}_{s d}}=\frac{1}{\sigma}-\frac{\theta-(\sigma-1)}{\theta \sigma}=\frac{\sigma-1}{\theta \sigma}=\frac{1}{\tilde{\theta} \sigma} \equiv \eta .
$$

This finding implies that the wage is a constant fraction of per capita income. The reason is that total profits for country $s$ are $\pi_{s} L_{s}=\sum_{k} \lambda_{s k} T_{k} /(\tilde{\theta} \sigma)$, where $\sum_{k} \lambda_{s k} T_{k}$ is the country's 
total income because total manufacturing sales of a country $s$ equal its total sales across all destinations. So profit income and wage income can be expressed as constant shares of total income:

$$
\pi_{s} L_{s}=\frac{1}{\tilde{\theta} \sigma} Y_{s} \quad \text { and } \quad w_{s} L_{s}=\frac{\tilde{\theta} \sigma-1}{\tilde{\theta} \sigma} Y_{s}
$$

